\title{
Insecticidal properties of the physic nut tree \\ Jatropha curcas L. (Euphorbiaceae) and potential use in pest management
}

\author{
Dissertation \\ to obtain the Ph.D. degree \\ in the International Ph.D. Program for Agricultural Sciences in Goettingen (IPAG) \\ at the Faculty of Agricultural Sciences, \\ Georg-August-University Göttingen, Germany \\ presented by \\ Farouk Bourogâa \\ born in Paris (France)
}

Göttingen, February 2018 
1. Name of supervisor: Prof. Dr. Stefan Vidal

2. Name of co-supervisor: Prof. Dr. Klaus Becker

Date of dissertation: February 2018 


\section{AKNOWLEDGEMENTS}

First of all, I would like to express my special gratitude to the German Academic Exchange Service DAAD (Deutscher Akademischer Austauschdienst) for funding my PhD and offering me the opportunity to develop my knowledge at the University of Göttingen (Germany). Also, the cultural and scientific events organized by DAAD were significantly valuable for me during my PhD.

I am greatly pleased to express my deepest gratitude to Prof. Dr. Stefan Vidal for his excellent supervision and support along the way. His guidance, constructive criticism and valuable suggestions were very helpful to complete this PhD. I am grateful to him for the approval of the research topic, helping in developing the research axes and improving the experimental protocols. His devoted time to review and improve my writing skills was highly appreciated.

I wish to express my special and deep thanks to Prof. Dr. Klaus Becker for providing us with the extracts of Jatropha curcas during the PhD. The great interest which he devoted to our results as a co-supervisor, helped to follow our research plan and address various investigation topics. I also gratefully thank Dr. Bernd Ulber for the precious advices he gave me during my PhD seminars. I am also thankful to him for his valuable suggestions as an examiner.

I express my deep gratitude to the friendly group of my lab-follows (PhDs, Postdocs and scientists). The rich conversations and the exchange of knowledge, which we had during our meetings, contributed to the establishment of a multidisciplinary research environment in the laboratory. I must also thank the technician staff for their assistance and friendly attitude. Their availability, cooperation and flexibility made it easy and fluent the set-up of bioassays.

Finally, I am delighted to thank all my family for the big support that they provided me to accomplish my study. The patience they displayed throughout the years of my PhD offered valuable help to proceed in my works. Their encouragement and the regular interest on the progress of my $\mathrm{PhD}$, from the initial planning stage until completion, was a motivation to go ahead and invest much effort to finalize my thesis.

Farouk Bourogâa February 2018 


\section{Table of Contents}

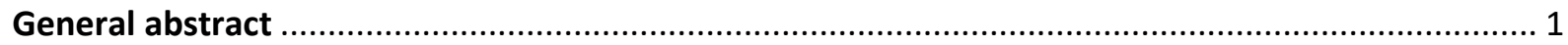

Chapter 1

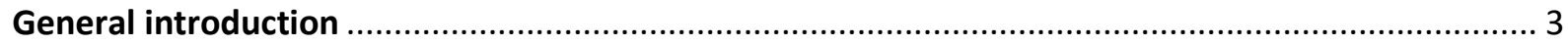

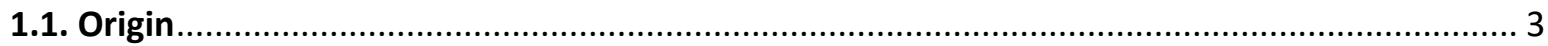

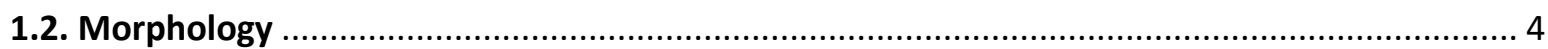

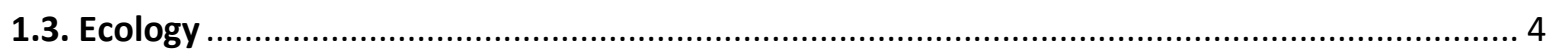

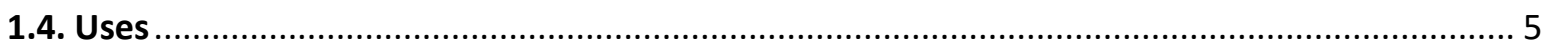

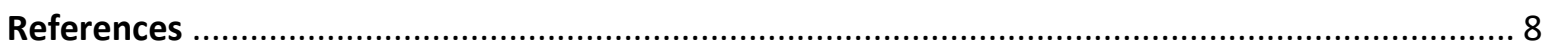

Chapter 2

Assessment of the insecticidal effect of different compounds from the physic nut tree Jatropha curcas on the grain aphid Sitobion avenae and the black bean aphid Aphis fabae (Hemiptera:

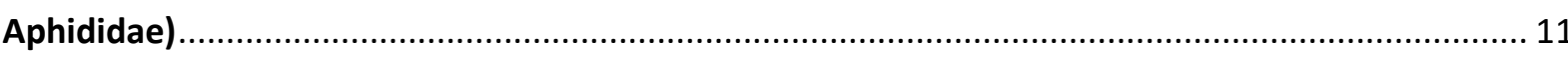

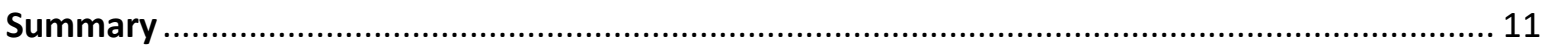

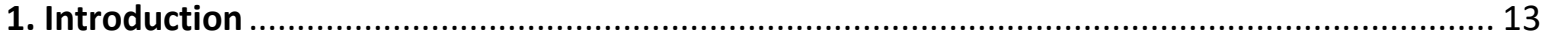

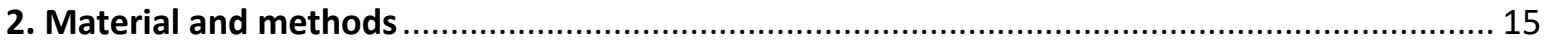

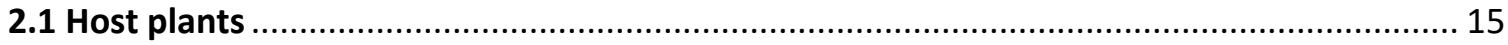

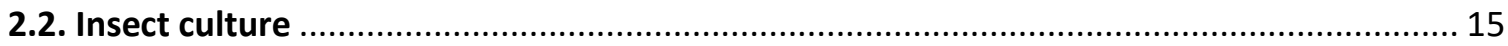

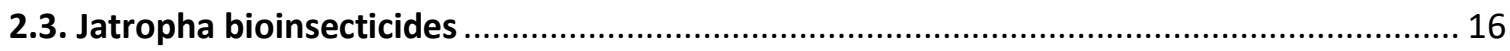

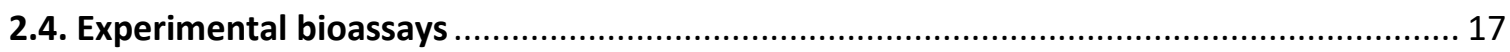

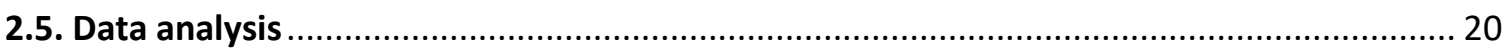

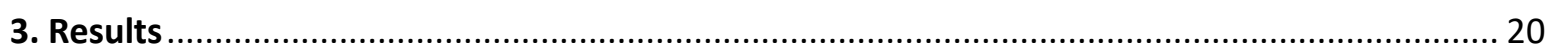

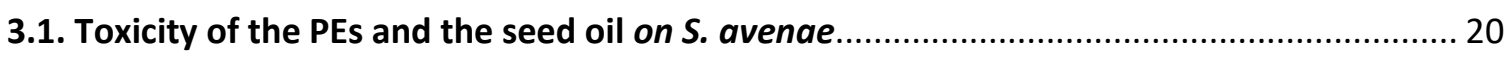

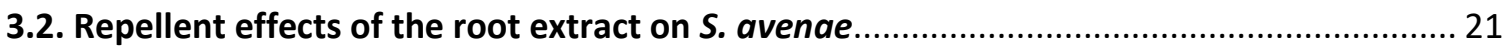

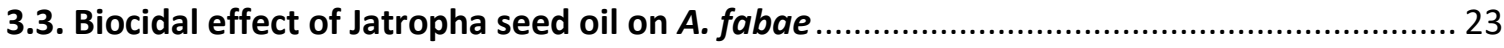

3.4. Effect of systemic application of the seed oil on A. fabae .............................................. 23

3.5. Effect of seed oil on the reproductive performance of $A$. fabae ….................................. 24

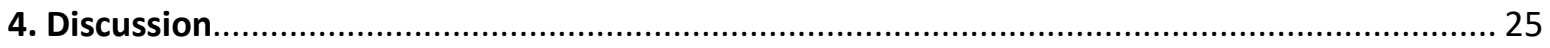

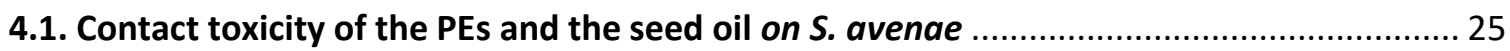

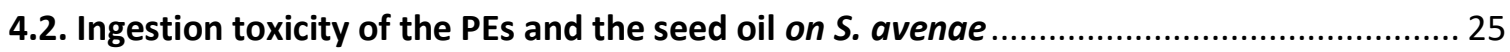

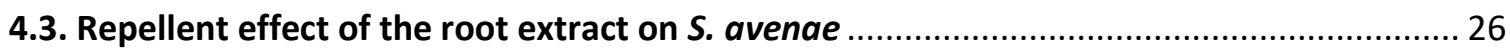

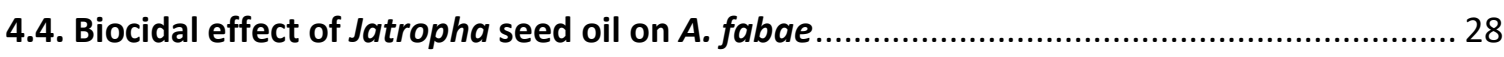

4.5. Effect of the systemic application of the seed oil on A. fabae.......................................... 29

4.6. Effect of the seed oil on the reproductive performance of $A$. fabae ................................ 29

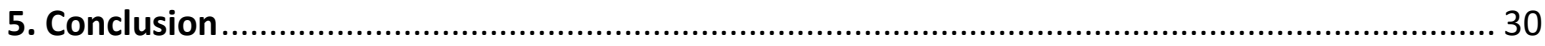


Study of the killing and antifeedant effects of some botanical extracts from the physic nut tree Jatropha curcas on the Diamondback moth (DBM) Plutella xylostella (Lepidoptera: Plutellidae) ... 40

Summary 40

1. Introduction .42

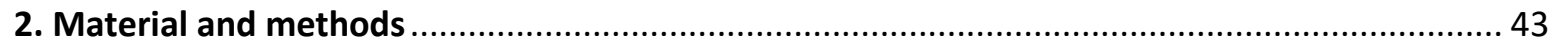

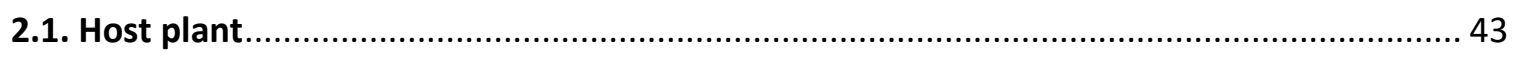

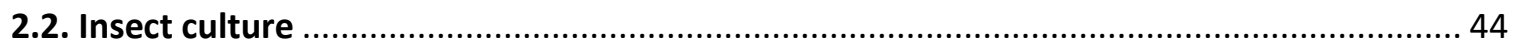

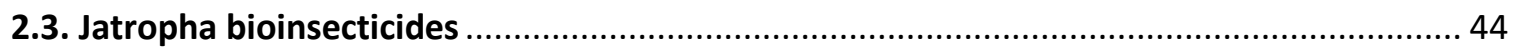

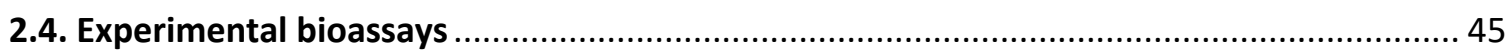

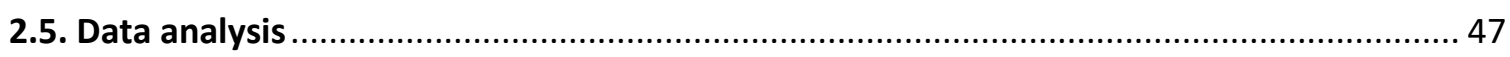

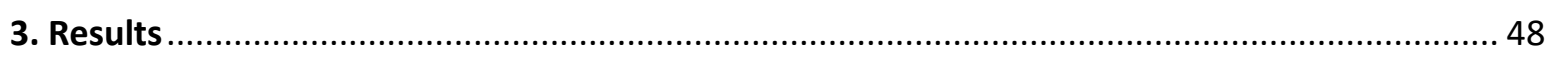

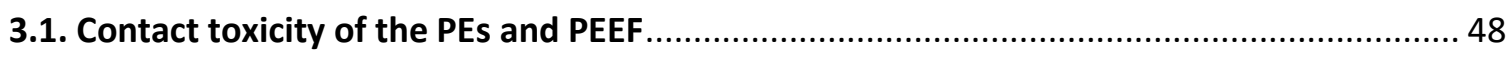

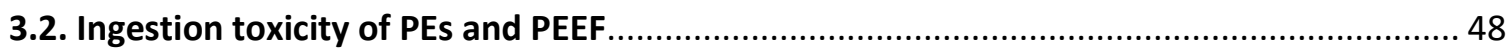

3.3. Effect of the PEEF on the feeding behavior of the $1^{\text {st, }} 2^{\text {nd }}$ and $3^{\text {rd }}$ instar larvae.................... 49

3.4. Anti-feedant effect of the PEEF, the stem bark extract and the leaf extract ..................... 50

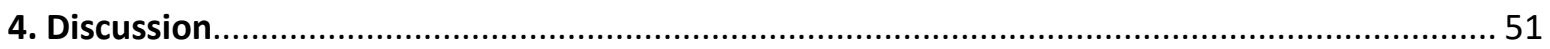

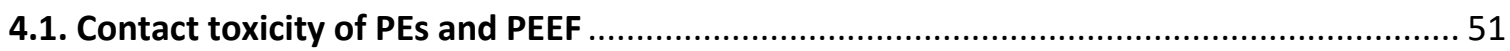

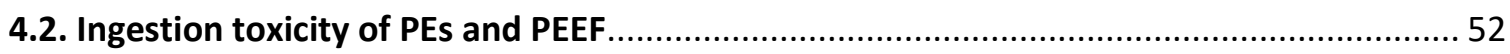

4.3. Effect of the PEEF on the feeding behavior of the $1^{\text {st, }} 2^{\text {nd }}$ and $3^{\text {rd }}$ instar larvae.................... 52

4.4. Anti-feedant effect of the PEEF, the stem bark extract and the leaf extract ...................... 54

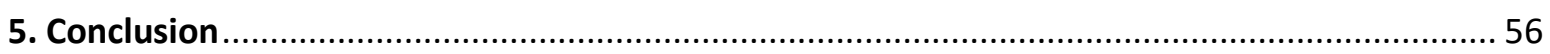

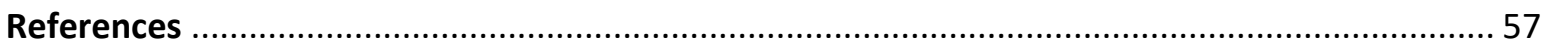

Chapter 4

Efficacy of some botanical extracts from the physic nut tree Jatropha curcas in the control of the

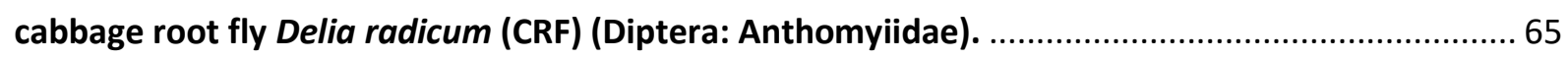

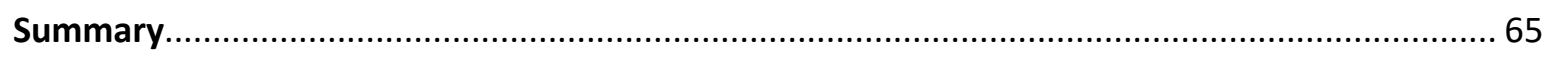

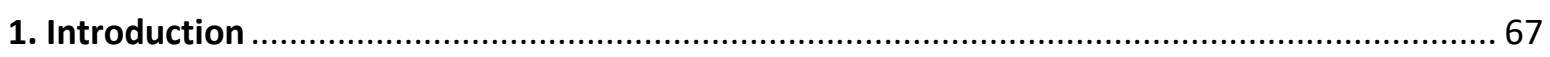

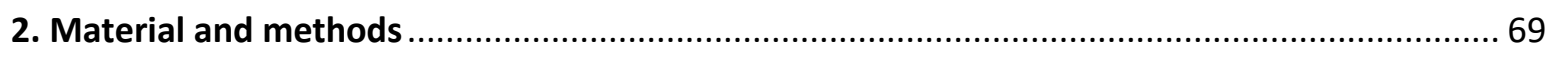

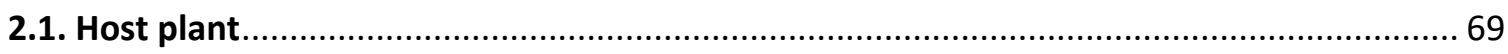

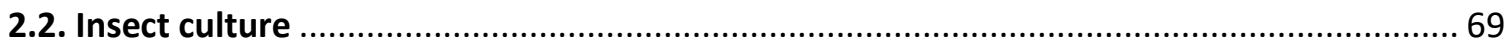

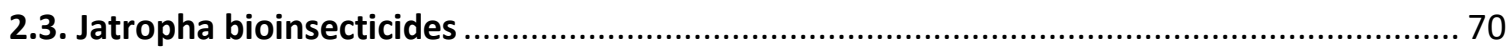

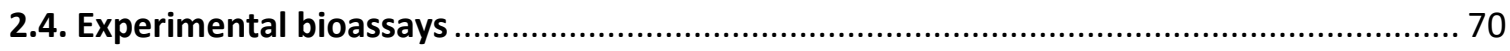

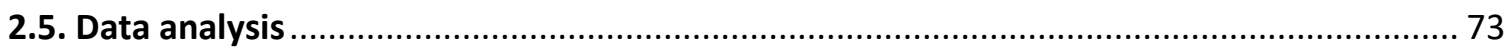


3. Results.

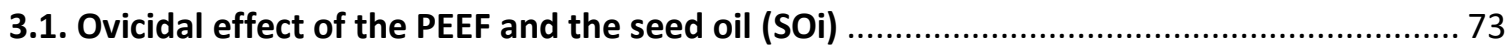

3.2. Larvicidal effect of the PEEF and the seed oil (SOi) ................................................ 74

3.3. Insecticidal effect of PEEF on D. radicum under greenhouse conditions ....................... 75

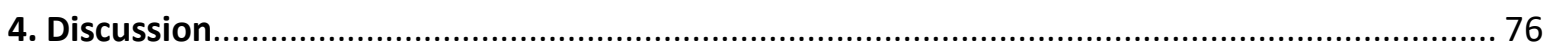

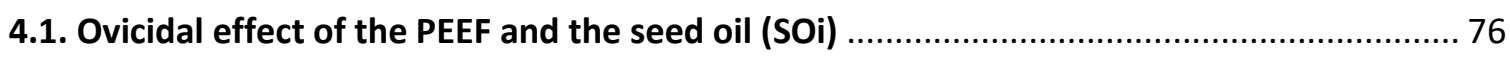

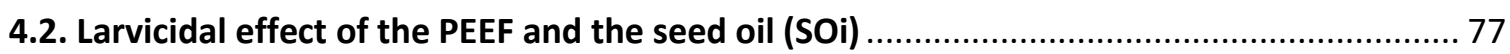

4.3. Insecticidal effect of PEEF under greenhouse conditions on $D$. radicum ........................ 77

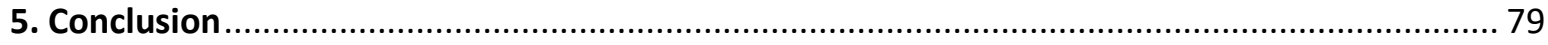

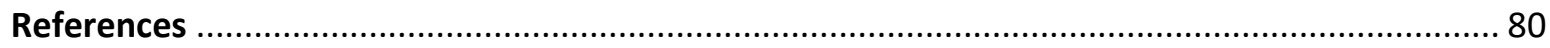

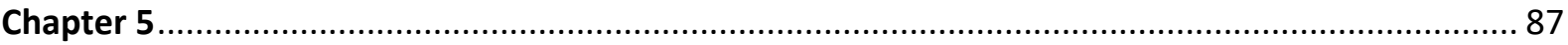

Potential use of some biocompounds extracted from the physic nut tree Jatropha curcas in the control of the cotton bollworm Helicoverpa armigera (Lepidoptera: Noctuidae) .........................8 87

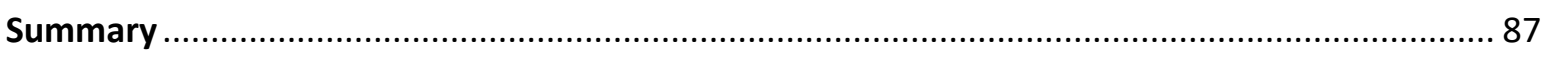

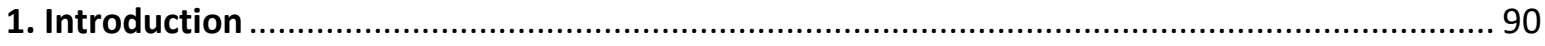

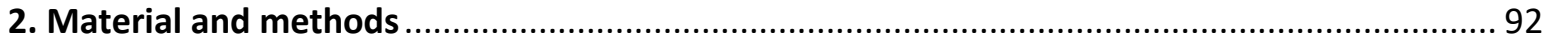

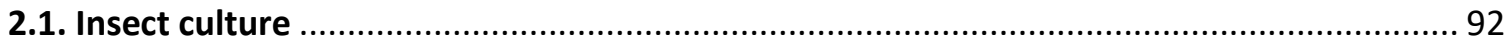

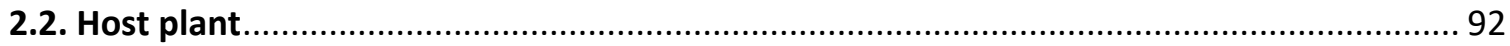

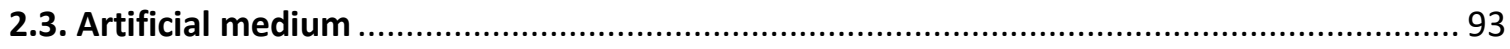

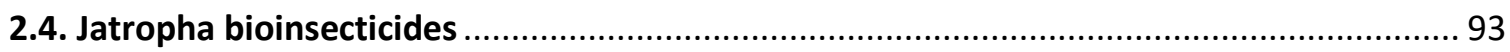

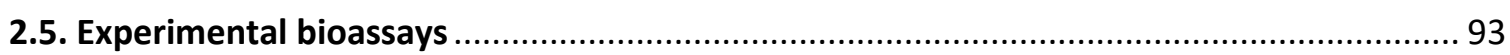

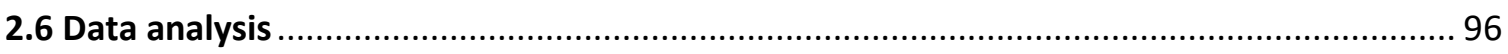

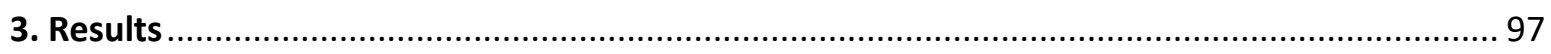

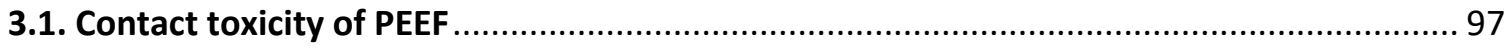

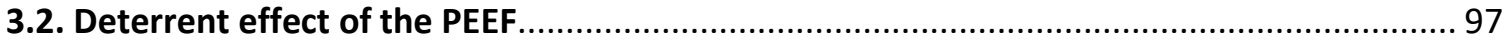

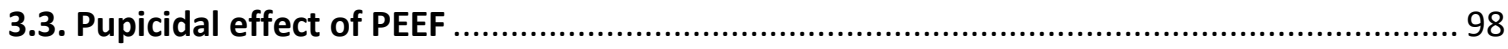

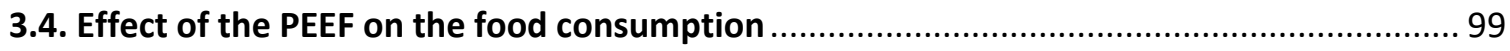

3.5. Comparative study of the insecticidal effect of the seed oil and the PEEF .................... 99

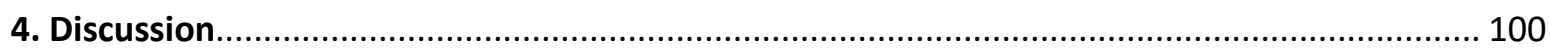

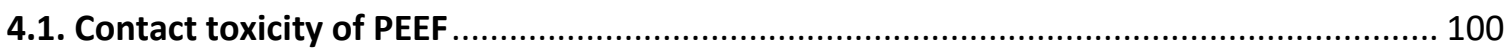

4.2. Deterrent effect of the PEEF...................................................................... 101

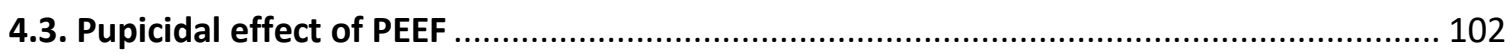

4.4. Effect of the PEEF on the food consumption ................................................... 103

4.5. Comparative study of the insecticidal effect of the seed oil and the PEEF ................. 104

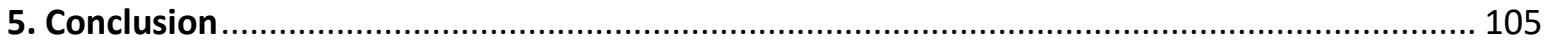


References .

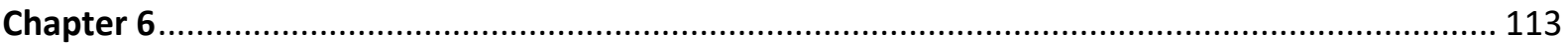

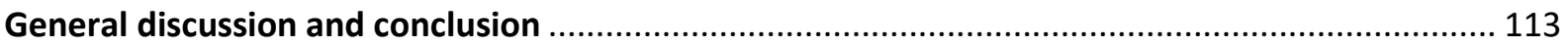

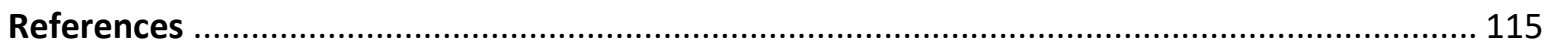




\section{$\underline{\text { General abstract }}$}

The physic nut tree Jatropha curcas possesses pesticidal properties and is considered a rich source of toxic phytochemicals. Our study focused on the toxic properties of J. curcas, in particular the seed oil (SOi), the Phorbol Esters Fraction (PEs) and the Phorbol Esters Enriched Fraction (PEEF), on different pests. The root, the leaf and the stem bark extracts were tested for their antifeedant and repellent effects. Our study concerned 3 insects' orders: Hemiptera, Lepidoptera and Diptera. It focused on different insect species: The grain aphid Sitobion avenae (Hemiptera: Aphididae), the black bean aphid Aphis fabae (Hemiptera: Aphididae), the Diamondback moth Plutella xylostella (Lepidoptera: Plutellidae), the cabbage root fly Delia radicum (Diptera: Anthomyiidae) and the cotton bollworm Helicoverpa armigera (Lepidoptera: Noctuidae).

This study showed that the extracts of $J$. curcas exhibited a wide spectrum of aphicidal activities. The Phorbol esters fraction and the seed oil exhibited a high killing effect on aphids by topical and spray application too. The seed oil had an age-dependent toxicity on the black bean aphid $A$. fabae. The young nymphs were highly susceptible to the seed oil. Our work proved also the presence of a repellent effect of the extract of the primary (Tukey's HSD; $p<0.001$ ) and secondary roots (Tukey's HSD; $p<0.001$ ) on S. avenae in Petri dishes after 12 hours of application on wheat leaflets. In in vitro conditions, the secondary root extract showed a clear protective effect and provided a long lasting protection for the wheat plants (Tukey's HSD; $p<0.001$ ). Our findings showed also a reproduction inhibitory effect of the seed oil on $A$. fabae. The females released on control plants gave birth to a progeny significantly larger than on plants treated with $1 \%$ of seed oil (Tukey's HSD; $p<0.001)$.

J. curcas was also investigated for its toxicity on the diamondback moth P. xylostella. Jatropha extracts induced a moderate contact toxicity on the $2^{\text {nd }}$ instar larvae of $P$. xylostella. A significant difference was found between the mortality caused by the Phorbol Esters Enriched Fraction (PEEF) and the control treatment (Tukey's HSD; $p<0.01$ ). The ingestion of $2 \%$ of these Jatropha compounds induced the mortality of $20 \%$ and $38 \%$ of the larvae respectively, for PEs and PEEF. The ingestion of PEEF induced also a deterrent effect. It affected the larval feeding behavior of $P$. xylostella. In fact, the choice test showed that the $1^{\text {st }}$ and the $2^{\text {nd }}$ instar larvae preferred to feed on the control leaf discs and avoided PEEF 
treated leaf discs. Jatropha based extracts caused also an antifeedant effect. Larvae fed for 3 days on leaf discs dipped in $0.75 \%$ PEEF had a lower weight. The leaf extract affected also the larval growth (Tukey's HSD; $p<0.001$ ), while no effect of the stem bark extract was observed (Tukey's HSD; $\mathrm{p}=0.83$ ).

The ovicidal tests carried on the eggs of $D$. radicum showed a high toxicity of PEEF and seed oil. The number of eggs that failed to hatch after exposure to $1.25 \%$ and $2 \%$ of PEEF was significantly higher than the control (Tukey's HSD; $p<0.001$ ). Moreover, a clear ovicidal effect was observed after exposure to $1.25 \%$ and $2 \%$ of SOi compared to the control (Tukey's HSD; $\mathrm{p}$ 0.001). On another hand, a high toxic effect was observed after feeding, during the larval stage, on turnip pieces treated with $2 \%$ of PEEF (Tukey's HSD; $p<0.001$ ). The ingestion of $0.5 \%$ of PEEF did not affect the pupation success. Feeding on $2 \%$ of the seed oil during the larval stage reduced significantly the pupation success (Tukey's HSD; $p>0.05$ ). Under greenhouse conditions, we observed that drenching the soil with a concentration of $2 \%$ of PEEF reduced significantly the number of pupae in comparison with the control (Tukey's HSD; $p<0.001$ ) on cabbage plants. The roots of cabbage plants treated with $2 \%$ of PEEF were less damaged by the feeding activity of larvae (Tukey's HSD; $p<0.001$ ).

The topical application of the PEEF on the cuticle of the $2^{\text {nd }}$ and $4^{\text {th }}$ instar larvae of $H$. armigera caused a non-significant mortality. The survivorship of the $2^{\text {nd }}$ instar larvae was not significantly different between treatments (Chi-square test, $\chi 2=10.97$, d.f. $=2, p>0.05$ ). On another hand, the feeding choice test assessed on early $1^{\text {st }}$ instar larvae of $H$. armigera showed a clear deterrent effect of PEEF when mixed with the artificial diet. In this case, a significant difference was observed between treatments $24 \mathrm{~h}$ after release of larvae in Petri dishes $\left(F_{2,42}=165.2, p<0.001\right)$. At $2 \%$ concentration of PEEF mixed with the artificial medium, the larval presence on the control artificial medium was significant, whereas few released larvae were recorded on the PEEF treated diet (Tukey's HSD; $p<0.001$ ).

Keywords: Jatropha curcas, Phorbol esters, mortality, antifeedant, Hemiptera, Lepidoptera, Diptera. 


\section{Chapter 1}

\section{General introduction}

Botanical insecticides have been long used as environmentally friendly alternatives to synthetic chemicals for pest management. They are renewable, degradable in the environment and relatively safe to natural enemies, non-target organisms and human beings. Plants produce a range of chemical substances to prevent attack by herbivores. Several extracts of plants have been evaluated for their activity against agriculturally important insects and being evaluated further for use in plant protection (Koul et al., 2009). Such chemicals are secondary plant metabolites and include alkaloids, flavonoid and terpenoids.

Many phytocompounds showed a variety of toxic activity against pests and have been long considered as effective as synthetic chemicals for pest management (Isman et al., 2005). These plant-based compounds affect arthropod pests, vectors and other infectious agents, but only few of botanicals are concretely used in agriculture (Isman et al., 2000). Inspite of their biological effectiveness, the long regulatory procedure and the availability of many competing products delay their agricultural success. Few plant extracts have been developed for commercial use but many plants were screened for their toxic aspects (Isman et al., 2006).

The genus Jatropha, rich with phytochemicals and investigated for its toxic properties, is native to tropical America and widely distributed in the tropical and subtropical areas of South America, Central America, Asia, Australia and Africa (Gübitz et al., 1999). It belongs to the tribe Jatropheae, orders Malpighiale in the Euphorbiaceae family and contains more than 170 known species (Wurdack, 2008). The most widespread specie around the world is Jatropha curcas (Ratnadass et al., 2012).

\subsection{Origin}

Although the center of origin and the center of domestication are still open questions (Dias et al., 2012), this shrub is thought to be native to tropical America then widely distributed to the rest of the tropical and subtropical areas of South America, Central America, Asia, Australia and Africa (Gübitz et al., 1999). Some records from antic civilizations in the Gulf of Mexico mentioned the use of J. curcas and its products. Also, the phenological, 
biochemical and molecular studies defend this region as the center origin of this plant: many related taxa are found in this area, the rich genetic diversity and the unique phytochemical profile of the Mexican successions help to support this hypothesis (Basha et al., 2009; Wilbur, 1954). In South America, J. curcas is found to be only associated with man settlement. In these regions, there are no records of the physic nut tree as a wild plant in forests or savannas which excludes the South American origin of this plant (Martin et al., 1984).

\subsection{Morphology}

J. curcas is a perennial, deciduous, monoecious shrub that grows to a height of about $5 \mathrm{~m}$. It has smooth bark, sturdy branches, and thick leaves. The leaves are large, shiny and glabrous, with exiguous and pilose stipules. The inflorescence is monoecious, but the individual flowers are unisexual. This plant exudes soapy and sticky latex that becomes brownish when dry. The fruit of J. curcas is a green subsphaeroidal capsule that becomes brown when ripe. The seeds are elliptical, black and rich in oil that can be converted into biodiesel of high quality (Ye et al., 2009).

Jatropha has a succulent stem with a large water storage but low wood density. This stem water seems to play a major role in regulating the leaf water potential, serving as a buffer against low soil water potential (Maes et al., 2009). The root system of this plant is composed of up to 4 lateral roots and a taproot, which can reach $5 \mathrm{~m}$ in depth (Foidl et al., 1996; Heller, 1996; Dias et al., 2007). This root system is well-developed especially in loose soil, with long and prominent taproots and lateral roots well distributed near to the soil surface.

\subsection{Ecology}

J. curcas is a highly climate-adapted shrub. It is present within various bioclimatic regimes from arid to rainy climate, tolerates high temperature extremes but does not prosper at low temperatures and high altitudes. It can grow on a wide range of soils provided they are well drained and aerated (Kumar et al., 2008). It can be grown well on degraded soils having low fertility and moisture and also on stony, shallow and even on calcareous soils. It also develops well in sandy and gravelly soils but in heavy texture, the root development is hindered. 
J. curcas is often described as a plant with low nutrient requirements. However for an economic and commercial use, this crop requires adequate fertilization (nitrogen and phosphorus) and sufficient irrigation (Brittaine et al., 2010). When planted as a hedge in a poor nutrient soil, the mycorrhiza associated with the root system assimilates the microelements from the rhizosphere to sustain the growth and the development of the plant and to compensate the lack of fertilization (Achten et al., 2008).

\subsection{Uses}

J. curcas has been considered as a "miracle tree" (Ratnadass et al., 2012) for its multipurpose use. It has been reported as a medicinal plant in many regions of the world and used for the treatment of a wide spectrum of infections. In Latin America India and also Africa, various parts of J. curcas are still used in ethno-medicine (Gübitz et al., 1999).

Jatropha species are known for their purgative effect. The seed oil and the water extract of leaves help to cure digestive system troubles i.e. diarrhea, vomiting, retching and stomachache (Sabandar et al., 2012). In Africa, the seeds are used as an anthelmintic and the leaves as a haemostatic (Watt et al., 1962). The skin application of the leaf extract relieves rheumatism and inflammation symptoms. In case of pneumonia, the root decoction is drunk to clear the respiratory tracts and cure also the vermifuge (Chhabra et al., 1991). The latex and stem bark are believed to be efficacious against skin infections (Heller, 1996). The oral administration of the stem bark extract is thought to enhance the excretory function of human organism (Kirtikar et al., 1980; Horsten et al., 1996; Goel et al., 2007)

J. curcas was developed not so far as an energy resource crop and considered as a promising alternative for biofuel production (Foidl et al., 1996). The seeds are rich with nonedible oil and can be converted to a high quality biodiesel. Its production is processed through the trans-esterification of the plant oil with the addition of methanol (or other alcohols) and a catalyst to end up with combustible product (Lu et al., 2009). This way of use of $J$. curcas could contribute to the replacement of the fossil diesel as a major source of fuel with a significant reduction of the environmental impacts and creating socio-economic benefits for farmers (Devappa et al., 2010).

Beside its medicinal and energy use, various extracts of J. curcas (leaves, roots, bark...) produce a wide range of biological properties such as molluscicidal, acaricidal and insecticidal activities (Ratnadass et al., 2012). These extracts have shown a toxic effect on different insect orders (Lepidoptera, Coleoptera, Diptera and Hemiptera) and offer 
protection for field and stored crops. Phorbol esters and curcin are respectively the major toxic phytochemicals of the physic nut tree (Devappa et al., 2011) which makes the plant non-edible by wild animals. In many tropical and subtropical countries, Jatropha cuttings are planted as a hedge to delimit and protect fields from wandering animals: Livestock doesn't feed on the mature leaves and even goats will die of starvation without browsing on Jatropha (Henning, 2004)

In term of soil conservation, the cultivation of J. curcas has shown to play a major role in reducing the soil erosion by the rainwater: the robust taproot fixes the plant to the ground and protects the land from sliding while the dense biomass of the lateral roots near the surface preserves the cohesion of the soil particles and protects it from water erosion (Brittaine et al., 2010). This soil conservation mechanism helps also to retain the rain water and enhances its infiltration in the soil (Achten et al., 2008). Jatropha has also proven to be effective against wind erosion in open fields: the shape of the branches, the foliage density and the hedge biomass prevent wind erosion by breaking wind velocity and fixing the soil particles by the superficial roots (Henning, 2004).

The major interest of our study was focused on the toxic properties of the physic nut tree J. curcas, in particular the insecticidal potential that the extracts from this plant could exhibit on pests. The main compounds tested for their toxicity were the seed oil, the Phorbol Esters Fraction (PEs) and the Phorbol Esters Enriched Fraction (PEEF). The leaf, the root and the stem bark extract were also screened for their pesticidal potential. The killing, the antifeedant, the anti-reproduction and the deterrent effects of these compounds were investigated on agriculturally important pests.

Our study involved 3 insects' orders including sap-sucking, leaf-chewing and rootfeeding pests belonging to Hemiptera, Diptera and Lepidoptera orders. The research focused on 5 different insect species: The grain aphid Sitobion avenae (Hemiptera: Aphididae), the black bean aphid Aphis fabae (Hemiptera: Aphididae), the cotton bollworm Helicoverpa armigera (Lepidoptera: Noctuidae), the Diamondback moth Plutella xylostella (Lepidoptera: Plutellidae) and the cabbage root fly Delia radicum (Diptera: Anthomyiidae).

The following questions were addressed in this study:

- Which compounds of J. curcas show an aphicidal effect? Is this effect concentration dependent? 
- Does the root extract of J. curcas can be used as an insecticide? Does it provide an efficient protection against S. avenae?

-Does the seed oil effective on A. fabae? Does it affect the reproduction performance of this aphid when spayed on faba bean plants?

- Are phorbol esters-based compounds (PEs and PEEF) effective on P. xylostella? Which mode of application can induce the highest mortality?

- Does the PEEF affect the feeding behavior of the first instars larvae of $P$. xylostella and $H$. armigera?

- Are the extracts of J. curcas effective on D. radicum?

- Do the leaf and the stem bark extracts show an insecticidal effect on P. xylostella?

- Does the PEEF induce a pupicidal effect on $H$. armigera? Does it depend on the larval instar? 


\section{References}

Achten WMJ, Verchot L, Franken YJ, Mathijs E, Singh VP, Aerts R, Muys B. 2008. Jatropha bio-diesel production and use. Biomass and Bioenergy, 32:1063-1084.

Basha SD, Franis G, Makkar HPS, Becker K, Sujatha. M. 2009. A comparative study of biochemical traits and molecular markers for assessment of genetic relationships between Jatropha curcas L. germplasm from different countries. Plant Science, 176: 812-823.

Brittaine R., Lutaladiao N. 2010. Jatropha: A Smallholder Bioenergy Crop: The Potential for Pro-Poor Development. Bulletin: Integrated Crop Management. Food and agriculture organization of the United Nations. ISBN: 9789251064382. Rome (Italy)

Chhabra, S.C., Mahunnah, L.A., Mshiu, E.N., 1991. Plants used in traditional medicine in eastern Tanzania $V$ Angiosperms (Euphorbiaceae to Menispermaceae). Journal Ethnopharmacology, 33:143-157.

Devappa R.K., Makkar H.P.S., Becker K. 2010. Jatropha toxicity: a review. Journal of Toxicology and Environmental Health, 13: 476-507.

Devappa R.K., Makkar H.P.S, Becker K. 2011. Jatropha Diterpenes: a Review. Journal of the American Oil Chemists' Society, 88: 301-322.

Dias L.A.S., Leme L., Laviola B., Pallini A., 2007. Cultivo de Pinhão Manso (Jatropha curcas L.) para Produção de Óleo Combustível. UFV, Viçosa. 40

Dias L.A.S., Missio R.F., Dias D.C.F.S. 2012. Antiquity, botany, origin and domestication of Jatropha curcas (Euphorbiaceae), a plant species with potential for biodiesel production. Genetics and Molecular Research, 11: 2719-2728.

Foidl N, Foidl G, Sanchez M., Mittelbach M., Hackel S., 1996. Jatropha curcas L. as a source for the production of biofuel in Nicaragua. Bioresource Technology, 58: 77-82.

Goel G., Makkar H., Francis G., Becker K. 2007. Phorbol Esters: structure, biological activity, and toxicity in animals. International Journal of Toxicology, 26:279-88.

Gübitz G.M., Mittelbach, M., Trabi, M. 1999. Exploitation of the tropical oil seed plant Jatropha curcas L. Bioresource Technology, 67: 73-82.

Heller J. 1996. Physic Nut Jatropha curcas L. Promoting the conservation and use of underutilized and neglected Crops. Institute of Plant Genetics and Crop Plant Research (IPGRI), Gatersleben / International Plant Genetic Resources Institute: Rome, Italy, p. 66

Henning, R. K. 2004b. Jatropha curcas L. in Africa: an evaluation. Assessment of the impact of the dissemination of "the Jatropha System" on the ecology of the rural area and the social and economic situation of the rural population (target group) in selected countries in Africa. Weissenberg, Germany. 
Horsten S.F.A.J., Van den Berg, A.J.J., Kettenes-van den Bosch, J.J., Leeflang, B.R., Labadie, R.P., 1996. Cyclogossine A: a novel cyclic heptapeptide isolated from the latex of Jatropha gossypiifolia. Planta Medica, 62: 46-50.

Isman M.B. 2000. Plant essential oils for pest and disease management. Crop Protection, 19, 603-608.

Isman M.B. 2005. Problems and opportunities for the commercialization of botanical insecticides. In C. Regnault-Roger, B.J.R. Philogène and C. Vincent (eds.), Biopesticides of Plant Origin, Lavoisier, Paris, 1:283-291.

Isman M. 2006. Botanical insecticides, deterrents and repellents in modern agriculture and increasingly regulated world. Annual review of entomology, 51: 45-66.

Kirtikar K.R., Basu B.D. 1980. Indian Medicinal Plants, vol. III. M/S Bishen Singh Mahendra Pal Singh, Dehradun, India.

Koul O., Walia S. 2009. Comparing impacts of plant extracts and pure allelochemicals and implications for pest control, 49: 1-30.

Kumar A, Sharma S. 2008. An evaluation of multipurpose oil seed crop for industrial uses (Jatropha curcas L.): A review. Industrial crops and Products, 28: 1-10.

Lu H., Liu Y., Zhou H., Yang Y., Chen M., Liang B. 2009. Production of biodiesel from Jatropha curcas L. oil. Computers and Chemical Engineering, 33: 1091-1096.

Maes W.H, Achten W.M.J, Reubens B., Raes D., Samson R., Muys B., 2009. Plant-water relationships and growth strategies of Jatropha curcas L. seedlings under different levels of drought stress. Journal of Arid Environments, 73: 877-884.

Martin G and Mayeux A (1984). Reflections on oil crops as sources of energy. II. The physic nut (Jatropha curcas L.) a possible source of fuel. Oléagineux 39: 283-287.

Ratnadass A., Wink M. 2012. The Phorbol Ester Fraction from Jatropha curcas seed oil: Potential and limits for crop protection against insect pests. International Journal of Molecular sciences. 13: 16157-16171.

Sabandar C., Norizan A., Faridahanim Mohd J, Sahidin I. 2013. Medicinal property, phytochemistry and pharmacology of several Jatropha species (Euphorbiaceae): A review. Phytochemistry, 85: 7-29.

Watt J.M., Breyer-Brandwijk M.G., 1962. The Medicinal and Poisonous Plants of Southern and Eastern Africa, E\&S Livingstone, Edinburgh

Wilbur RL. 1954. A synopsis of Jatropha, subsection Eucurcas, with the description of two new species from Mexico. Journal Elisha Mitchell Science Society, 70: 92-101 
Wurdack KJ. 2008. Molecular evolution and phylogenetics of Euphorbiaceae: Beyond the model organisms. Plant and Animal Genomes XVI Conference San Diego, CA. http://www.intl-pag.org/16/abstracts/PAG16_W21_155.html.

Ye M., Li C., Francis G., Makkar H .P.S. 2009. Current situation and prospects of Jatropha curcas as a multipurpose tree in China Agroforest System, 76: 487-497. 


\section{Chapter 2}

\section{Assessment of the insecticidal effect of different compounds from the physic nut tree Jatropha curcas on the grain aphid Sitobion avenae and the black bean aphid Aphis fabae (Hemiptera: Aphididae)}

\section{Summary}

The genus Jatropha is reported as a rich source of phytochemicals. The assessment of the efficacy of Jatropha extracts in pest control has been conducted on field and stored crops. The reported effects were ranging from repellency to feeding deterrence and mortality. In our study, we assessed the aphicidal properties of the seed oil of Jatropha curcas (SOi) and the Phorbol Esters (PEs) on the grain aphid Sitobion avenae and the black bean aphid Aphis fabae.

These extracts were screened for their contact and ingestion toxicity. The thoracic dorsum of young nymphs was treated with $0.5 \mu$ of two different concentrations of the seed oil and the PEs (1\% (V/V) and 2\% (V/V)). In another bioassay, the contact toxicity of these extracts was assessed by spraying directly the aphids. The young nymphs were firstly released on the top of the wheat plants then sprayed 1 hour later with a fine mist spray bottle filled with the bioinsecticides. The ingestion toxicity of Phorbol Esters and the seed oil was tested by spraying the host plants until run-off with $1 \%(\mathrm{~V} / \mathrm{V})$ and $2 \%(\mathrm{~V} / \mathrm{V})$ concentrations of bioinsecticides. Also, the toxic property of the seed oil was tested on different live stages of the black bean aphid $A$. fabae (young nymphs, old nymphs and wingless adults). A dual choice test was set up to test the repellency of the root extracts of $J$. curcas on the aphid S. avenae. The in vitro choice test consisted of releasing in a Petri dish 15 wingless adults at a mid-distance from two wheat leaflets: one treated with $3 \%(\mathrm{~W} / \mathrm{V})$ of root extract and the other simply dipped in bidest water (Control). The second part of the bioassay was conducted on potted wheat plants sprayed with the same concentrations of root extract. Moreover, the systemic effect of the seed oil was tested on the black bean aphid by drenching the soil of the faba bean plants with a concentration of $1 \%(\mathrm{~V} / \mathrm{V})$ and $2 \%$ (V/V) of oil. The anti-reproduction properties of the seed oil were tested on treated bean plants infested with gravid females of $A$. fabae released on the treated on plants.

This study showed that the extracts of J. curcas exhibited a wide spectrum of aphicidal activities. These compounds exhibited a high mortality by topical and spray 
application. The PEs and the seed oil showed a contact and ingestion toxicity on the grain aphid S. avenae. The mortality of aphids due to the topical application of $2 \%$ of PEs was significantly different compared to the control (Tukey's HSD, $\mathrm{p}<0.01$ ). It increased after $8 \mathrm{~h}$ to $81 \%$ and reached $91 \%$ after $24 \mathrm{~h}$. The spray application of $2 \%$ of PEs and $2 \%$ seed oil on infested plants caused the mortality of respectively $77 \%$ and $71 \%$ after $24 \mathrm{~h}$ (Tukey's HSD, $p<0.01)$. The ingestion of PEs and the seed oil had a slow toxic effect on S. avenae. We recorded $57 \%$ and $32 \%$ of dead aphids, respectively after ingestion of $2 \%$ of PEs and $2 \%$ seed oil (Tukey's HSD, p<0.01). This research showed also that the seed oil had an age-dependent toxicity on the black bean aphid $A$. fabae. The young nymphs were highly susceptible to the toxicity of the seed oil. In this case, a significant difference was detected in comparison with the control at $1 \%$ concentration (Tukey's HSD; $p<0.001$ ) and $2 \%$ concentration (Tukey's HSD; $\mathrm{p}<0.001$ ). A significant difference was also observed between concentrations (Tukey's HSD; $p<0.001)$ which shows that the mortality was concentration dependent: at a concentration of $2 \%$, the mortality rate of young nymphs reached $80 \%$ after 5 days whereas $45 \%$ were killed after the spray of $1 \%$ concentration of the seed oil.

Our work showed also, in comparison with the control, a significant repellent effect of the extract of the primary (Tukey's HSD; p<0.001) and secondary roots (Tukey's HSD; $\mathrm{p}<0.001$ ) of J. curcas on S. avenae in Petri dishes after 12 hours of application. In in vitro conditions, the secondary root extract showed a clear protective effect and provided a long lasting protection for the wheat plants (Tukey's HSD; $p<0.001$ ). However, the primary root extract showed at a concentration of $3 \%$ a short repellent effect against aphids when applied in semi-real conditions (Tukey's HSD; $p=0.25$ ). The study showed also no systemic effect on the old nymphs of $A$. fabae after feeding on seed oil-treated plants: only $6.66 \%$ of the aphids were dead (Tukey's HSD; $p>0.05$ ). The results revealed also that the seed oil induced a very low toxicity on the adults of $A$. fabae. Only $5 \%$ of the adults were recorded dead at the end of the experiment (Tukey's HSD; $p>0.05$ ). Our findings showed also a reproduction inhibitory effect of the seed oil. The females released on control plants gave birth to a progeny significantly larger than on plants treated with $1 \%$ of seed oil (Tukey's HSD; $p<0.001)$.

Keywords: Jatropha curcas, Sitobion avenae, Aphis fabae, Phorbol esters, mortality, toxicity, repellent. 


\section{Introduction}

The family of Euphorbiaceae is one of the largest families of angiosperms, composed of over 300 genera and 8,000 species (Webster, 1994). It includes different growth forms with a predominance of trees, shrubs but also succulent plants (Devappa et al., 2011). Jatropha curcas L. commonly referred to as "physic nut", is a member of Euphorbiaceae family (Ratnadass et al., 2012). This plant (a shrub or small tree) is widely distributed in tropical and subtropical areas but could be also present in extreme climates and poor growth conditions (Jing et al., 2004).

J. curcas has many potential uses (Ratnadass et al., 2012). It has been firstly used in ethno-medicine as a traditional medicinal plant (Openshaw, 2000). In fact, the name Jatropha is derived from the Greek word "jatros" (doctor) and "trophe" (food), which indicates its use for medicinal (Sabandar et al., 2013) and veterinary purposes (Heller, 1996). The genus Jatropha is reported as a rich source of phytochemicals that can be valorized in pharmaceutical industries (Devappa et al., 2010a). Based on treatments from leaves, stem, bark and roots extracts, J. curcas has been stated as an efficacious cure plant (Dias et al., 2007) with a variety of biological activities (antitumor, cytotoxic, anti-inflammatory, antiprotozoal, anticoagulant and skin diseases) (Ratnadass et al., 2012). The medicinal and pharmaceutical potential of Jatropha has been thoroughly researched but not fully realized.

J. curcas is also known, since few decades, as an oil seed plant (Lu et al., 2009). The increasing demand for crude oil has increased the interest to this crop and its exploitation as a renewable energy source. J. curcas produces large seeds containing a high amount of oil (28-32\%) (Devappa et al., 2010b), that can be used as fuel substitute for diesel engines after transesterification (Jing et al., 2004). A special interest has been also shown for the exploitation of the seed cake after oil extraction (Ye et al., 2009). Since it is produced in large quantities and has a high energy value, the seed cake can be shaped in small bricks and burned as fuel (Wang, 2006) which increases the sustainability of Jatropha production system.

Among Euphorbiaceae, species of Jatropha are particularly known for their toxic properties (Ratnadass et al., 2012). It is one of the richest sources of bio-compounds such as alkaloids, lignans, cyclic peptides and terpenes (Devappa et al., 2011) involved in the plant defense mechanism. Various biologically active substances isolated from almost all parts of the plant have been reported to have insecticidal, acaricidal or molluscicidal activities 
(Ratnadass et al., 2012). The assessment of the efficacy of Jatropha extracts on pests has been conducted on field and stored crops. The reported effects were ranging from repellency to feeding deterrence and mortality (Silva et al., 2012). The evaluation of their insecticidal effect has concerned mainly 4 insect orders with different mode of feeding (sapsucking, leaf-chewing and stem-boring) and 20 insect families among them the family of Aphididae, investigated in our study.

The grain aphid (Sitobion avenae) is a serious damaging crop pest, especially in the temperate regions of the northern and southern hemispheres (Larsson, 2004). It is one of the most harmful cereal aphids in Western Europe and occurs on all cereal species including rice and maize (Llewellyn et al., 2003). S. avenae clones have a clear preference for the ear and feeds on the rachis and on the base of the spikelets of cereals. As the ear generally remains physiologically active longer than the leaf, $S$. avenae can maintain itself longest in the crop compared to other aphids (Larsson, 2004). The damages on the yield depend on the size and duration of infestation. The typical population development consists of an initial slow build-up, rapid multiplication, slow down, stagnation and rapid decrease (Vereijken, 1979). At the absence of effective control approaches, the intensive take-up of plant nutrients causes the reduction of the number of heads and subsequently yields losses.

Another economically important pest is the black bean aphid (Aphis fabae) which affects a wide range of host plants. It infests beans, peas, and celery but can also attack trees and shrubs. Aphids feed on the plant by sap-sucking and produce a large amount of honeydew. This honeydew covers leaves and represents a suitable substrate for the growth of black sooty molds and other fungi, reducing photosynthesis and subsequent plant growth. This pest has a high multiplication rate which enables rapid exploitation of the host-plant. The clustering aspect of the colonies makes them visible on the buds. The high colonization potential of the different plant parts by $A$. fabae causes a stunted growth, low production and high susceptibly to diseases (Mergel, 2010).

In order to search for new botanical compounds for the control of aphids, our study focused on the insecticidal aspects of different extracts of $J$. curcas on the grain aphid S. avenae and the black bean aphid $A$. fabae. We investigated the following axes of research:

- Do the seed oil of J. curcas and the Phorbol Esters fraction (PEs) affect the survivorship of aphids? Does the contact or ingestion application cause the highest mortality rate? 
- Does the aqueous root extract of J. curcas show protective aspects of wheat plants from S. avenae in in vitro conditions? Is it a long lasting effect under semi-real conditions?

- Could the systemic application of seed oil provide protection for faba bean plants from the colonization by $A$. fabae?

- Does the seed oil inhibit the reproduction performance of $A$. fabae on faba bean plants?

\section{Material and methods}

\subsection{Host plants}

Due to the variety of pest species included in our study, 2 different host plants were used to carry out the toxicity bioassays. Wheat plants (cultivar "Dekan" KWS GmbH, Germany) were used as a host for the grain aphid S. aveane. Plants were grown in $11 \mathrm{~cm}$ diameter plastic pots containing a mixture of 2:1 soil : sand (Fruhstorfer Erde Typ 25, Hawita Gruppe $\mathrm{GmbH}$, Vechta, Germany, peat fine structure with volcanic clay, $\mathrm{pH}$ : 5.7-6.3, Fertilization of 200-300mg $\mathrm{N}$ ) and kept for 10 days in greenhouse conditions $\left(22 \pm 1^{\circ} \mathrm{C}\right.$ temperature, $65 \%$ relative humidity and $16 \mathrm{~L}$ : $8 \mathrm{D}$ photoperiod).

Faba bean Vicia faba (or broad bean) plants (cultivar "Hangdown" Grünkernig Gevo $\mathrm{GmbH}$, Germany) were used for the bioassays on the black bean aphid $A$. fabae. Plants were grown from seeds in soil (Fruhstorfer Erde Typ 25, Hawita Gruppe GmbH, Vechta, Germany, peat fine structure with volcanic clay, pH: 5.7-6.3, Fertilization of 200-300mg N) and sand mixture (3:1 volume) was used as a growth substrate. Plants were grown under controlled conditions in a greenhouse chamber at $24 \pm 3^{\circ} \mathrm{C}$ temperature, $65 \%$ relative humidity and $16 \mathrm{~L}$ : $8 \mathrm{D}$ photoperiod.

\subsection{Insect culture}

The aphids of $S$. avenae were collected from a laboratory rearing established from single asexual female aphids collected in Giessen (Germany) from wheat plants. Aphids were continuously reared on wheat plants grown in $11 \mathrm{~cm}$ diameter plastic pots and covered with aerated plexiglas cylinder $(30 \mathrm{~cm} \times 10 \mathrm{~cm})$. Aphids were transferred every 2 weeks to new wheat plants and maintained in a climatic chamber (WB 750 KFL; Mytron Bio-Und Solartechnik $\mathrm{GmbH}$, Germany) under controlled conditions (20 $\pm 1^{\circ} \mathrm{C}$ temperature, $70 \%$ relative humidity and $16 \mathrm{~L}: 8 \mathrm{D}$ photoperiod) favorable for the parthenogenetic reproduction of the grain aphid. 
The black bean aphid $A$. fabae was obtained from a laboratory colony reared on faba bean grown in culture trays in a wood ventilated rearing cage $(90 \mathrm{~cm} \times 50 \mathrm{~cm} \times 50 \mathrm{~cm})$. Every 2 weeks, aphids were offered a new tray of fresh faba bean seedlings after removing the old tray. The rearing tray was irrigated on alternate days and the insect culture was kept in a climate controlled room ( $18 \pm 2^{\circ} \mathrm{C}, 70 \pm 5 \%$ relative humidity; $16 \mathrm{~L}$ : $8 \mathrm{D}$ photoperiod).

\subsection{Jatropha bioinsecticides}

In this study, different extracts of J. curcas were screened for their insecticidal effect: the seed oil (SOi), the Phorbol Esters (PEs) and the root extract (RE). The oils including SOi and PEs were provided by the company of JatroSolutions GmbH (Stuttgart, Germany) where they have been extracted and purified following the method of Devappa et al. (2010a).

Table 1: Composition of Jatropha seed oil (\% $\mathrm{m} / \mathrm{m})$

\begin{tabular}{|l|c|}
\hline Compounds & Amounts \\
\hline C12:0/ Lauric acid & $<0.1$ \\
\hline C14:0/ Myristic acid & 14.1 \\
\hline C16:0/ Palmitic acid & 0.9 \\
\hline C16:1/ Palmitoleic acid & 6.1 \\
\hline C18:0/ Stearic acid & 42.2 \\
\hline C18:1/ Oleic acid & 34.8 \\
\hline C18:2/ Linoleic acid & 1.2 \\
\hline C18:3/ Linolenic acid & 0.2 \\
\hline C20:0/ Arachidic acid & 0.2 \\
\hline C20:1/ Gadolinium acid & $<0.1$ \\
\hline C22:0/ Behenic acid & $<0.1$ \\
\hline C22:1/ Erucic acid & $040 S 014$ ( \\
\hline
\end{tabular}

(JatroSolutions $\mathrm{GmbH}$, 2014)

The root extract was prepared in the laboratory before the set-up of the experiments. The root material was collected from 4 years old plants of J. curcas, originally from the island of Madagascar but maintained under glasshouse conditions in an environment similar to the area of origin ( $23{ }^{\circ} \mathrm{C}$ temperature and $65 \%$ humidity). After plant harvesting, the roots were washed and cut in small pieces then freeze dried at $-20{ }^{\circ} \mathrm{C}$. After 
one week, primary and secondary roots were separately milled to a fine powder, weighed, filled in hermetic plastic bags and conserved at $-20{ }^{\circ} \mathrm{C}$ for further use.

The aqueous root extract was obtained by soaking the root powder in an Erlenmeyer flask containing bidest water. The solution was kept overnight mixing on a horizontal shaker (120 rpm) (HS 250, IKA Labortechni, Germany) before being heat-treated for 1 hour in a water-bath (Köttermann $\mathrm{GmbH} \& \mathrm{Co} . \mathrm{KG}$, Uetze, Germany) at $65^{\circ} \mathrm{C}$. It was then decanted with a funnel filter paper (grade 595.5, $185 \mathrm{~mm}$ diameter) (Schleicher and Schuell Bioscience $\mathrm{GmbH}$, Dasse, Germany) and placed in cold water to cool down in order preserve the efficacy of the phytochemicals.

\subsection{Experimental bioassays}

\subsubsection{Toxicity of the PEs and the seed oil (SOi) on S. avenae}

The contact toxicity of these compounds was firstly topically tested on 9 days old aphids. The thoracic dorsum of young nymphs was treated with a micropipette with $0.5 \mu$ of different concentrations of the extracts $(1 \%(\mathrm{~V} / \mathrm{V})$ and $2 \%(\mathrm{~V} / \mathrm{V}))$. TWEEN ${ }^{\circledR} 80$ was added as emulsifier to enhance the miscibility of the compounds in water. After application, the treated nymphs were released on 7 days old wheat plants grown in $11 \mathrm{~cm}$ pots. In another bioassay, the contact toxicity of the seed oil and the PEs was assessed by spraying directly the aphids. The young nymphs were firstly released on the top of the wheat plants then sprayed 1 hour later with a fine mist spray bottle $(2.7 \mathrm{oz}, 200 \mathrm{ml})$ containing one of the bioinsecticides.

The ingestion toxicity of the PES and SOi was tested by spraying the host plant until run-off with a fine mist spray flask $(2.7 \mathrm{oz}, 200 \mathrm{ml})$ with different concentrations of bioinsecticides (1\% (V/V), 2\% (V/V)). After drying, 9 days old aphids of $S$. avenae were randomly collected with a fine camel hair brush from the rearing colonies then released on the top of the treated host plants. The plants in all bioassays were covered with an aerated plexiglas cylinder (30 cm length $\times 10 \mathrm{~cm}$ diameter) and kept in a climatic chamber (WB 750 KFL; Mytron Bio-Und Solartechnik GmbH, Germany) at $22 \pm 1{ }^{\circ} \mathrm{C}$ with a 16:8 $\mathrm{h}$ (L:D) photoperiod and $60 \% \mathrm{RH}$. Each treatment had 10 replicates and each replicate included 10 specimens. Aphid's mortality was recorded after $3 \mathrm{~h}, 8 \mathrm{~h}$ and $24 \mathrm{~h}$ after exposure to the extracts of J. curcas. Insects were considered dead when no leg or antennal movements were observed. 


\subsubsection{Repellent effect of the root extract on S. avenae}

A basic dual choice test was set up to test the repellency of the root extracts on the aphid S. avenae. The in vitro choice test consisted of releasing 15 wingless adults at a middistance from a wheat leaflet treated with $3 \%(\mathrm{~W} / \mathrm{V})$ of root extract and a wheat leaflet simply dipped in bidest water. The bioassay was conducted in Petri dishes (140 mm diameter x 20mm height) (Sarstedt, Aktiengesellschaft \& CO Nuembrecht, Germany) lined with a moistened filter paper (125 mm diameter, Cat № 1001 125) (Schleicher and Schuell Bioscience $\mathrm{GmbH}$, Dasse, Germany) at the bottom and sealed with parafilm after the aphid release. The Petri dishes were kept in a climatic chamber (WB 750 KFL; Mytron Bio-Und Solartechnik $\mathrm{GmbH}$, Germany) at $22 \pm 1 \circ \mathrm{C}$ with a $16: 8 \mathrm{~h}$ (L:D) photoperiod and $60 \% \mathrm{RH}$.

The second bioassay is conducted on one week old potted wheat plants. After being sprayed with a fine mist spray flask $(2.7 \mathrm{oz}, 200 \mathrm{ml})$ containing $3 \%$ of root extracts, 2 wheat pots (treated and non-treated) were placed randomly in a plastic cubic cage $(30 \mathrm{~cm} \times 30 \mathrm{~cm}$ $\times 30 \mathrm{~cm}$ ) separated by a distance of $10 \mathrm{~cm}$. The control plants were only sprayed with bidest water. Winged aphids were released at the middle of the cage $45 \mathrm{mn}$ after the plants dried. The cages were kept in a rearing room under controlled conditions $\left(22 \pm 1{ }^{\circ} \mathrm{C}, 16: 8 \mathrm{~h}(\mathrm{~L}: \mathrm{D})\right.$ and $60 \% \mathrm{RH}$ ). Each experiment was replicated 12 times in a completely random design. The number of insects was recorded in the treated and control wheat plants after $3 \mathrm{~h}, 8 \mathrm{~h}$ and $24 \mathrm{~h}$.

\subsubsection{Biocidal effect of the seed oil on $A$. fabae}

The toxic property of the seed oil was tested on different live stages of the black bean aphid $A$. fabae (young nymphs, old nymphs and wingless adults). For that, 10 days old faba bean plants were used in this experiment. After infestation, plants were sprayed with $1 \%$ (V/V) and $2 \%(V / V)$ of a seed oil solution mixed with $0.05 \%(V / V)$ TWEEN $^{\circledR} 80$ as emulsifier. The control plants were only treated with bidest water mixed with emulsifier. There were 10 plants each one infested with 10 aphids. The nymphs and the adults were gently collected from the rearing culture, checked for their viability and used for the plant infestation. Because of their tininess, young nymphs were enclosed in a clip cage $(3.5 \mathrm{~cm}$ diameter $\mathrm{x} 2$ $\mathrm{cm}$ height) on a faba bean leaf which makes them easy to monitor. For the bioassays on old nymphs and adults, aphids were released on the top of the host then the plant was covered with an aerated plexiglas cylinder $(30 \mathrm{~cm}$ length $\times 10 \mathrm{~cm}$ diameter). The experiment was run in a glasshouse chamber $(22 \pm 1 \circ \mathrm{C}, 16: 8 \mathrm{~h}(\mathrm{~L}: \mathrm{D})$ and $60 \% \mathrm{RH})$ and the mortality was assessed 
after 5 days. Aphids were considered dead if they gave no coordinated response after stimulation of the antennae and the cornicles.

\subsubsection{Effect of systemic application of the seed oil on A. fabae}

Faba bean plants were seeded in soil (Fruhstorfer Erde Typ 25, Hawita Gruppe GmbH, Vechta, Germany, peat fine structure with volcanic clay, pH: 5.7-6.3, Fertilization of 200$300 \mathrm{mg} \mathrm{N}$ ) and sand mixture (3:1 volume) as a growth substrate. The seedlings were grown in greenhouse conditions $\left(22 \pm 1{ }^{\circ} \mathrm{C}, 16: 8 \mathrm{~h}(\mathrm{~L}: \mathrm{D})\right.$ and $\left.60 \% \mathrm{RH}\right)$ until two true leaves were fully expanded. At this stage, plants were divided into 3 different groups of 12 plants. The $1^{\text {st }}$ group was twice soil drenched with a solution of SOi $1 \%(V / V)$. The $2^{\text {nd }}$ group was twice soil drenched with a solution of $2 \%$ SOi (V/V). The $3^{\text {rd }}$ group was daily watered with bidest water mixed with TWEEN ${ }^{\circledR} 80$ as emulsifier. Plants in all treatments were regularly watered except in the days of soil application of the bioinsecticide. Plants were infested with 10 aphids (young nymphs or old nymphs or adults) then covered with a ventilated plexiglas cylinder and randomly placed in a climatic chamber (WB 750 KFL; Mytron Bio-Und Solartechnik $\mathrm{GmbH}$, Germany) at $22 \pm 1{ }^{\circ} \mathrm{C}$ with a $16: 8 \mathrm{~h}$ (L:D) photoperiod and $60 \% \mathrm{RH}$. During the running of the bioassay, offsprings were removed from plants. After 5 days, aphid's mortality was recorded. There were 12 plants per treatment infested with 10 aphids.

\subsubsection{Effect of the seed oil on the reproductive performance of $A$. fabae}

In order to obtain age-synchronized nymphs, 50 wingless females were selected from the stock colony and clip caged on clean faba bean plants. After 24 hours, aphid nymphs were softly moved with a fine brush then individually clip caged on a treated host plant. Prior to infestation, plants were sprayed until run-off with different concentrations (1\% $(\mathrm{V} / \mathrm{V}), 2 \%(\mathrm{~V} / \mathrm{V})$ and $3 \%(\mathrm{~V} / \mathrm{V}))$ of seed oil before being infested with nymphs. The control plants were treated with bidest water mixed with $0.05 \%(V / V)$ TWEEN ${ }^{\circledR} 80$ as emulsifier. The clip caged nymphs were daily checked for their survival on the host plants until they reached the adult stage. At this step, the clip cage was removed and gravid females were left to develop, give offsprings and establish new colonies on the treated host plant. There were 12 plants per treatment covered with an aerated plexiglas cylinder $(30 \mathrm{~cm}$ length $\times 10 \mathrm{~cm}$ diameter) and randomly distributed in a climatic chamber (WB $750 \mathrm{KFL}$; Mytron Bio-Und Solartechnik $\mathrm{GmbH}$, Germany) at $22 \pm 1{ }^{\circ} \mathrm{C}$ with a $16: 8 \mathrm{~h}$ (L:D) photoperiod and $60 \% \mathrm{RH}$. After 
5 days, we recorded the total number of aphids, the new formed colonies and the number of aphids per colony.

\subsection{Data analysis}

Statistical processing of results was carried out using the statistical software $R(v$ 3.0.2) ( $R$ Development Core Team, 2008). Prior to analysis, all data were tested for homogeneity of variance and normality. To detect the difference between treatments, we performed One-way analysis of variance (ANOVA). If significant differences between groups were detected, means were compared by performing Tukey's test at $\alpha=0.05$.

The mortality of aphids was analyzed using generalized linear models (GLM) taking into account the binomial distribution of the data (alive or dead). To correct data variation (overdispersion / underdispersion), quasi-binomial distribution error was used in data analyses. Thereafter, Tukey's test at $\alpha=0.05$ was employed to detect differences between means.

Giving that some insects did not make a choice during the dual choice test, the non-choice category was also considered during the data analysis which made counts divided into 3 major groups (Control, treated and no-choice). This non-binary aspect of data deriving from choice bioassays (Control or Treated or No-choice) made it unsuitable to perform a binomial test for data analysis. In this case, we proceeded to generalized linear models (GLM) using Poisson distribution followed by quasi-poisson models analysis. In case of significant differences between groups, data were subjected to a Tukey test at $\alpha=0.05$ to separate the means.

\section{Results}

\subsection{Toxicity of the PEs and the seed oil on S. avenae}

A high contact toxicity of the PEs and the seed oil was observed on the grain aphid S. avenae. With both compounds, aphids died soon after application of these compounds on the cuticle. The experiment indicated that the mortality was concentration-dependent. At $2 \%$ of PEs topically applied, $77 \%$ of aphids were dead after $3 \mathrm{~h}$ of treatment whereas no aphid were dead in the control treatment (Tukey's HSD, $p<0.01$ ). The mortality of aphids due to PEs application increased after $8 \mathrm{~h}$ to reach $81 \%$ and kept increasing to $91 \%$ after $24 \mathrm{~h}$. The seed oil revealed also a high aphicidal effect at $2 \%$ after $3 \mathrm{~h}$ where $71 \%$ of aphids were dead. The mortality rate reached $79 \%$ at $24 \mathrm{~h}$ after the topical application of the seed oil. A 
concentration as low as $1 \%$ caused a mortality of $50 \%$ and $40 \%$, respectively by the PEs and the seed oil within $24 \mathrm{~h}$.

The spray application of $2 \%$ of PEs and seed oil on infested plants caused the mortality of respectively $63 \%$ and $58 \%$ of aphids after $3 \mathrm{~h}$. After $8 \mathrm{~h}, 73 \%$ of aphids were dead due to the PEs and $68 \%$ after spray with the seed oil. At the end of the bioassay, the aphicidal effect of the PEs and the seed oil was highly significant in comparison with the control (Tukey's HSD, $\mathrm{p}<0.01$ ) and reached respectively $77 \%$ and $71 \%$ after $24 \mathrm{~h}$. The spray application of $1 \%$ of PEs showed a moderate effectiveness and reduced the aphid population to $49 \%$ after $24 \mathrm{~h}$. A lower efficacy was recorded after spray of $1 \%$ of the seed oil where only $38 \%$ of aphids were dead within $24 \mathrm{~h}$. No aphids were dead on the plants sprayed with water mixed with TWEEN $^{\circledR}$ 80. The ingestion of PEs and the seed oil had a slow toxic effect on S. avenae few hours next to the release on plants. After $3 \mathrm{~h}$, only $5 \%$ of aphids were dead on plants treated with $2 \%$ of PEs whereas the mortality reached only $2 \%$ on wheat plants sprayed with seed oil. After $8 \mathrm{~h}$, the mortality rate increased and $27 \%$ of aphids were dead after ingestion of $2 \%$ of PEs and $19 \%$ after being exposed to the same concentration of the seed oil. The mortality rate increased steadily after $24 \mathrm{~h}$ where we recorded $57 \%$ and $32 \%$ of dead aphids, respectively after ingestion of PEs and seed oil compared to the control (Tukey's HSD, $\mathrm{p}<0.01$ ). At $1 \%$ concentration, both bioinsecticides showed a low efficacy against $S$. avenae where only $12 \%$ were dead.

\subsection{Repellent effects of the root extract on S. avenae}

In in vitro conditions, the aqueous extract of the primary roots of J. curcas showed a significant repellent effect overtime on the aphid S. avenae (Figure 1a). After 1 h of release, a significant difference was observed between the different treatments $\left(F_{2,33}=50.43, p<0.001\right)$ where $32.22 \%$ of aphids preferred to establish on the control wheat leaflets against $21.11 \%$ found on the treated leaflets (Tukey's HSD; $p<0.001$ ). After $8 \mathrm{~h}$, we observed a slight increase of the number of aphids settled on the treated leaflets where $25 \%$ were recorded, against $37 \%$ on leaflets treated with water. Although more aphids tended to colonize the treated leaflets, a significant difference still be detected after $12 \mathrm{~h}$ between the different treatments $\left(F_{2,33}=186.54, p<0.001\right)$. We recorded $50.55 \%$ aphids on the control leaflets of wheat against $39 \%$ on leaflets treated with the root extract (Tukey's HSD; $p<0.001$ ).

After application, the secondary root extract showed also a clear protective effect in Petri dishes (Figure $1 \mathrm{~b}$ ). After $1 \mathrm{~h}$, a highly significant difference between treatments was 
observed $\left(F_{2,33}=103.59, \mathrm{p}<0.001\right)$ and $52.22 \%$ of aphids avoided the treated wheat leaflets and chose the control ones as a host (Tukey's HSD; $p<0.001$ ). After $8 \mathrm{~h}$, a statistical difference was present between the different treatments $\left(F_{2,33}=112.73, \mathrm{p}<0.001\right)$. At this time of observation, $60 \%$ of aphids were found on the control treatment while we observed a decrease of aphid's presence on the treated ones to $11.11 \%$ (Tukey's HSD; $p<0.001$ ). At the end of the bioassay, $\mathbf{7 7 . 7 8 \%}$ of aphids preferred to establish on the leaflets treated with water against $10.55 \%$ observed on the wheat treated with secondary root extract (Tukey's HSD; $p<0.001)$.

When sprayed on wheat plants, the primary root extract of J. curcas showed a significant protective effect 1 hour after spray $\left(F_{2,33}=7.31, p<0.001\right.$; Figure $\left.1 c\right)$. At this time of observation, $38.88 \%$ of the winged adults were recorded on the control plants against $29 \%$ on the treated plants (Tukey's HSD; $\mathrm{p}<0.001$ ). After $8 \mathrm{~h}$ hours of treatment, most of the adults that did not make a choice during the first hours tended to be equally distributed between the two wheat plants with $48.88 \%$ aphids recorded on the control plants against $40 \%$ on the treated plants. No significant difference was detected between the control wheat plants and the other sprayed with the root extract (Tukey's HSD; $p=0.153$ ). At the end of the experiment, the primary root extract showed no repellent effect against aphids when applied in semi-real conditions (Tukey's HSD; $p=0.256$ ) and we recorded $50.55 \%$ of aphids on the control plants against $41.66 \%$ settled on the treated plants.

The secondary root extract of $J$. curcas provided a good protection of the wheat plants after 1 hour of spray $\left(F_{2,33}=75.24, p<0.001\right.$; Figure $\left.1 d\right)$. At this time, $55 \%$ of the winged aphids chose to settle on the control plants and about $25 \%$ choose to establish on the plants treated with the secondary root extract (Tukey's HSD; $p<0.001$ ). This repellent effect increased after 8 hours where a significant difference was observed between the different treatments $\left(F_{2,33}=94.93, \mathrm{p}<0.001\right)$. We recorded $65 \%$ of aphids established on control wheat plants whereas only $16 \%$ were found on the wheat plants sprayed with the secondary root extract (Tukey's HSD; $\mathrm{p}<0.001$ ). After $12 \mathrm{~h}$ from the beginning of the experiment, we observed more aphids established on the treated plants with about $53.33 \%$ of adults settled on the control and $32 \%$ established on the treated plants. However, a significant difference was still observed between the two treatments (Tukey's HSD; $p<0.001$ ). 


\subsection{Biocidal effect of Jatropha seed oil on A. fabae}

The seed oil had a significant influence on the survival of young nymphs of the black bean aphid $A$. fabae $\left(F_{2,33}=184.71, p<0.001\right)$. A significant difference was detected in comparison with the control at $1 \%$ concentration (Tukey's HSD; $p<0.001$ ) and $2 \%$ concentration (Tukey's HSD; $p<0.001$ ). A significant difference was also observed between concentrations (Tukey's HSD; $p<0.001$ ) which showed that the mortality was concentration dependent: at a concentration of $2 \%$, the mortality rate of young nymphs reached $80 \%$ after 5 days whereas $45 \%$ were killed after the spray of $1 \%$ concentration of the seed oil.

Although a significant difference was observed among treatments $\left(F_{2,33}=95.68\right.$, $\mathrm{p}<0.001$ ), the seed oil of J. curcas showed a moderate toxicity on the old nymphs of $A$. fabae. After 5 days of exposure, the mortality induced by $1 \%$ and $2 \%$ of the seed oil reached respectively $39.16 \%$ and $56.66 \%$. As it was the case of the young nymphs, the mortality of the old nymphs was concentration dependent and a significant difference was detected between the mortality rates induced by the two concentrations (Tukey's HSD; $p<0.001$ ). Because of being handled, $2 \%$ of the old nymphs were dead on the control plants.

The data mortality of the adults induced by the seed oil revealed a significant difference between treatments $\left(F_{2,33}=42.17, \mathrm{p}<0.001\right)$. In comparison with young and old nymphs, a low toxicity of the seed oil of J. curcas was observed on the adults of $A$. fabae. Despite a large significant difference was observed between the mortality rates at $1 \%$ and $2 \%$ (Tukey's HSD; $p<0.001)$, the killing effect of the oil on the adults was limited in comparison with early life stages. For example, $31.66 \%$ of aphids were dead at a concentration of $2 \%$ and only $13.33 \%$ were killed 5 days after spraying $1 \%$ of the oil. On the control plants, no adult mortality was recorded during the running time of the bioassay.

\subsection{Effect of systemic application of the seed oil on $A$. fabae}

Although a slight significant difference was observed between treatments $\left(F_{2,33}=\right.$ $27.62, p<0.05)$, the systemic application of the seed oil induced a low mortality on the young nymphs of $A$. fabae. The first mortality occurred 4 days after the set-up of the bioassay. After 5 days of soil application, only $10 \%$ of the aphids were dead after feeding on plants treated with $2 \%$ of seed oil. Also no significant effect of feeding on seed oil treated plants was observed on the old nymphs of $A$. fabae (Tukey's HSD; $p>0.05$ ) where $6.66 \%$ of the aphids were dead after 5 days. Moreover, the seed oil caused a very low toxicity on the adults of $A$. fabae and no significant difference was observed in comparison with the control 
(Tukey's HSD; $p>0.05$ ). Only $5 \%$ of the adults were recorded dead at the end of the experiment.

\subsection{Effect of seed oil on the reproductive performance of $A$. fabae}

After 5 days from release, the total number of aphids differed significantly between treatments $\left(F_{3,44}=32.12, p<0.001\right.$; Figure 2$)$. It reached $34.5 \pm 2.55$ aphids on control plants and $24.08 \pm 1.16$ aphids on plants sprayed with $1 \%$ of seed oil (Tukey's HSD; $p<0.001$ ). At a concentration of $2 \%$ of seed oil, we found $16.83 \pm 1.30$ aphids of $A$. fabae on the host plants. An important suppressive effect of the seed oil was observed on the reproduction of aphids on plants sprayed with $3 \%$ of seed oil (Tukey's HSD; $p<0.001$ ). On these plants, only 12.5 \pm 0.82 aphids were found which is close to the initial number of released aphids (10 aphids).

In continuation with the previous findings, the number of offspring produced by the females was significantly different $\left(F_{3,44}=32.05, p<0.001\right)$. The females released on control plants gave birth to a progeny significantly larger than on plants treated with $1 \%$ of seed oil (Tukey's HSD; $p<0.001$ ). After 5 days, we recorded $24.5 \pm 2.55$ new aphids on the control faba bean plants whereas only $13 \pm 1.57$ aphids were observed on plants sprayed with $1 \%$ of seed oil. Moreover, the reproductive performance of the females of $A$. fabae decreased as long as the concentration of the bioinsecticde increased. For example, at a concentration of $2 \%$ and $3 \%$ of seed oil were respectively recorded $6.83 \pm 1.30$ and $2.5 \pm 0.82$ new aphids on the sprayed plants.

According to the results of the reproduction, a significant difference was evident between treatments in term of number of new established colonies $\left(F_{3,44}=99.14, p<0.001\right)$. The results showed that among the 10 full females initially released, $9.25 \pm 0.21$ females were able to found new viable colonies on control treatment after 2 days from release. In contrast to the control, only $5.41 \pm 0.48$ females found growing colonies on plants sprayed with $1 \%$ seed oil whereas $3.66 \pm 0.37$ colonies were recorded on plants treated with $2 \%$ seed oil. In comparison with the control, a high inhibitory effect on the reproduction of aphids was induced when females were exposed to a concentration of $3 \%$ of the oil of J. curcas (Tukey's HSD; $p<0.001$ ). At this concentration, very few females were able to reproduce and give viable progeny. In this treatment, we recorded only $1.16 \pm 0.20$ colonies which made females unable to colonize efficiently the host. 


\section{Discussion}

\subsection{Contact toxicity of the PEs and the seed oil on S. avenae}

The topical and spray application of a concentration of $2 \%$ of PEs and seed oil caused a sudden death of aphids. The aphicidal effect of these compounds was fast and took few hours to induce a high mortality. According to previous studies done on J. curcas (Ratnadass et al., 2012), the PEs and the seed oil had never been reported as neurotoxic substances to induce a similar knockdown effect. However, this could be explained by the oily texture of these extracts. As the mineral oil did, this rapid killing effect was due to the physical action of these oils more than a complex chemical reaction (Butler et al., 2011). According to Stadler et al., (2009), oils appeared to induce mortality due to asphyxia by obstruction of tracheae and tracheoles. This theory could be supported to explain the results of our study. The viscosity of the PEs and the seed oil played a major role in the mortality process. When sprayed or topically applied on the aphids, the oil covered the insect cuticle, blocked the spiracle and caused the suffocation of the aphid (Taverner et al., 2001). The blockage of the insect tracheal system has been also stated by Richling et al., (2008) on Acheta domestica (Orthoptera: Gryllidae); they reported a metabolism-independent mortality by accumulation of $\mathrm{CO}_{2}$ in the insect organism after oils application.

The necrosis and cell darkening observed on the cuticle of aphids were also reported by Najar-Rodríguez et al., (2007). After topical application, the lipophilic nature of oils helps to penetrate the cell, accumulate inside the cytoplasm and affect their structural and functional properties. The seed oil of J. curcas was also reported as a cuticle irritating compound (Sabandar et al., 2013) and had been shown to cause cell disintegration and necrosis followed by a general burn effect of the insect cuticle (Devappa et al., 2010b).

\subsection{Ingestion toxicity of the PEs and the seed oil on S. avenae}

As stated by Ratnadass et al., (2012), our study proved that the seed oil and the PEs of $J$. curcas had high ingestion toxicity on Hemipteran species (Myzus persicae, Aphis gossypii and Lipaphis erysimi). The seed oil of J. curcas caused the mortality of aphids after feeding on wheat plant sprayed with $2 \%$ of this extract. The oil is rich with dipterpenoids which are considered to be the most important compounds synthesized by J. curcas (Devappa et al., 2011). Also, the aphids mortality could be explained by the high amount of curcin (toxalbumin) contained in the seeds of J. curcas. This compound inhibits the translation 
activity of proteins (or $\mathrm{N}$-glycosidase activity) and could disrupt the digestive mechanism after being administrated to insects (Lin et al., 2003). Moreover, the seed kernel of J. curcas is rich with tannins associated with toxic and anti-nutritional properties (Makkar et al., 2009) causing aphids to be starved then dead.

Feeding on plants sprayed with PEs induced a higher mortality of $S$. avenae than this caused by the seed oil. After ingestion, PEs act as an analogue of diacylglycerol (DAG) and activates the proteins kinase C (Silinsky et al., 2003). A normal signal transduction is triggered after the activation of the PKC by DAG (diacylglycerol), which is then rapidly hydrolyzed (Goel et al., 2007). However, when introduced to organisms, the phorbol esters mimic the DAG and act independently as a stronger PKC activator that is hardly metabolized by cell. They induce subsequently a hyperactivation of PKC, initiate cell proliferation and interfere with cellular metabolic functions (Devappa et al., 2010c). In our study, the mortality of aphids could be due to the ingestion of a pure concentrated PEs extract, described by Haas et al., (2002) as the most toxic secondary metabolite in J. curcas. The insecticidal effect of PEs was already reported by Devappa et al. (2012) on the fall armyworm Spodoptera frugiperda (Lepidoptera: Noctuidae) in in vitro bioassays.

Our results demonstrated also a lower efficacy of the ingestion bioassay than the topical application. We observed a moderate toxicity after ingestion of $2 \%$ of PEs and a low mortality after feeding on $2 \%$ of seed oil. This limited efficacy could be due to the fact that plants were not perfectly covered with the bioinsecticides. Because of this deficiency in plant spray, aphids were able to find non-sprayed areas on the host and feed safely without coming in contact with the compounds.

\subsection{Repellent effect of the root extract on S. avenae}

The root extract of $J$. curcas showed a high protective effect against the grain aphid $S$. avenae. This effect was relevant in in vitro conditions when wheat plants were sprayed with the primary and secondary root extract. This efficacy declined under semi-real conditions for the primary root extract but persisted for the secondary root extract. Based on our observations, these extracts could prevent the colonization of the plant by aphids with 2 properties: repellency and deterrence. A repellent is a volatile compound that prevents feeding by repelling the insect prior to contact with the food source. Thus, a repellent can be active at a longer distance from the food source. However, a compound that prevents or reduces feeding after the insect has already tasted the plant material is termed a deterrent 
(Norris, 1986). The bioassay showed that these extracts acted as repellent for the aphids that did not come definitely in contact with treated plants and deterrent for the minority of aphids that settled temporarily on treated plants then moved to the control wheat plants. This aphid's moving behavior is known as "departure after landing" (Powell et al., 2006).

These properties are due to a complex of phytochemicals known for their toxic effect. The screening of the chemical constituent of Jatropha plants by Devappa et al. (2010d) and Da Silva et al. (2015) lead to the isolation of alkaloids, cyclic peptides, terpenes (monoterpenes, sesquiterpenes, diterpenes and triterpenes), flavonoids, lignans, coumarins and fatty acids. In addition, El Diwani et al. (2009) found after HPLC analysis that the roots of J. curcas were rich with phenolic compounds and tannins. The major compounds were gallic, ellaguic and coumaric acids. Ellagic acid and salicylic acid were found as traces. These findings were also supported by the study of Oskoueian et al. (2011) on the kernel meal of J. curcas where HPLC analysis of the hot water extract revealed mainly the presence of gallic acid and pyrogallol as phenolic compounds, rutin and myricetin as flavonoid and daidzein (isoflavonoid). Devappa et al. (2011) reported the richness of the roots of J. curcas with diterpens and stated the presence of Caniojane, Curcusone and Jatrophol which was isolated from methylene chloride-hexane root extract of J. curcas.

The biological activity of most of these compounds has not been reported in previous studies. Also, the repellent and/or deterrent effect of the root extract of J. curcas has not been shown so far on aphids. Nevertheless, the repellent effect of J. curcas was already stated by Acda (2009) on the Philippine milk termite (Coptotermes vastator) (Isoptera: Rhinotermitidae) by a sand-barrier bioassay. The findings showed that the seed oil of $J$. curcas affected the locomotry behavior of termites which avoided tunneling in the sand chambers treated with the seed oil. In other hand, the deterrent effect of J. curcas was reported by Cantrell et al. (2011) on the mosquito Aedes aegypti (Diptera: Culicidae) by a mosquito biting experiment. The study showed that the triacyglycerols and the free fatty acids present in J. curcas induced a biting deterrent effect on Aedes aegypti. The gallic acid contained in the root extract of $J$. curcas would play a major role in reinforcing this deterrent property. Reese et al. (1976c) reported that the gallic acid affected the assimilation of food, inhibited growth, survival, pupation in the black cutworm Agrotis ipsilon (Lepidoptera: Noctuidae). Moreover, the tannins predominantly present in the root extract could be involved in the plant rejection by S. avenae after the insertion of the stylet. Mansour et al. 
(1997) proved a negative linear relationship between the number of piercing/sucking insects per plant (aphids, white flies and jassides) and the amount of tannins in cotton leaves. Barbehenn et al. (2011) concluded also that tannins are feeding deterrent to many invertebrates including sap sucking insects. In Petri dishes experiments, both extracts showed a high repellent/deterrent effect during the time of the bioassay conversely to the experiments conducted under semi-real conditions where the efficacy decreased, especially for the primary root extract. These compounds could be rapidly volatilized (repellent) but provide a residual toxic activity after spray on the plant (deterrent). This decline of efficacy in natural plant products was also reported by Zhu et al. (2014) after testing the antifeedancy and repellency of Catnip oil, Geraniol and an organic fatty acids mixture on horn flies Haematobia irritans (Diptera: Muscidae). Reifenrath et al. (1989) suggested mixing the extracts together instead of applying them individually to prolong their effective period.

\subsection{Biocidal effect of Jatropha seed oil on A. fabae}

Spraying a concentration of $2 \%$ was an effective barrier against young nymphs but less effective against old nymphs and adults of $A$. fabae. These results did not correlate with the findings on S. avenae where contact application of seed oil induced a high mortality of aphids. This limited efficacy on $A$. fabae could be explained by the spatial distribution of aphids on the host plant and their moving behavior from one feeding site to another.

After release on the faba bean plants, young nymphs were slow-moving or relatively immobile and tended to remain on the releasing area (Walling, 2008). Subsequently, their feeding areas were well exposed and aphids were easily targeted by spray. In this context, Northover et al. (2002) indicated that spraying essential oils has an effective use and good performance when pest is small in size and restricted to a small area during its lifecycle (e.g phytophagous mites and their eggs, nymphs of pear psylla, nymphs of grape leafhopper and nymphs of aphids).

However, old nymphs and adults were more mobile and left the releasing point few minutes after plant infestation. In this case, old forms were usually hidden on undersides of leaves, beneath the foliage and the growing points of the plant which made them hardly observed and did not interfere with the seed oil of J. curcas. Parry et al. (2013) stipulated that apterous (wingless) aphids move from a site to another in small distances, at a speed of $5-20 \mathrm{~cm} / \mathrm{mn}$ or may run from $15-35 \mathrm{~cm} / \mathrm{mn}$, depending on species. Although shorter, these 
movement were thought to be enough significant for aphids to find locally a safe habitat after disturbances such as wind, pesticides, predators, crowding (Bailey et al., 1995).

\subsection{Effect of the systemic application of the seed oil on A. fabae}

The plant extract used in this study failed, after systemic application, to prevent the settling of $A$. fabae on treated plants. In contrast with neem, reported as systemically taken-up by the roots of faba bean plants (Pavela et al., 2004), the seed oil of J. curcas was not absorbed by the roots when applied to the soil. The effectiveness of the systemic application of bioinsecticides should be enhanced by the use of bioactivators, which may act as absorption enhancers and surface activators, improving penetration, translocation and effectiveness of crop protection products such as oils (Pavela, 2007). In this study, oils were used in their crude primitive form following mechanical press without any addition of bioactivators which could explain the failure to be taken-up by the roots.

\subsection{Effect of the seed oil on the reproductive performance of $A$. fabae}

The reproduction inhibitory effect of the seed oil, shown by our study, was already reported by Ratnadass et al. (2012) on Mussidia nigrivenella (Lepidoptera: Pyralidae), Callosobruchus maculatus (Coleoptera: Chrysomelidae) and Sitophilus granaries (Coleoptera: Curculionidae). Host plant selection is a crucial step for aphids before starting reproducing. It is the result of a cascade of decisive behaviors guided by cues collected from the host plant (Powell et al., 2006). After spraying the plant with $2 \%$ and $3 \%$ of seed oil, the fecundity of aphids was highly reduced. This effect could be explained by the richness of this extract with saturated fatty acids (palmitic acid, oleic acid, linoleic acid, myristic acid and lauric acid) which would make aphids reject the host and thus might affect the taking-up of nutritive elements needed for reproduction (Pérez-Gutiérrez et al., 2011).

The oily film covering the plant surface and rich with fatty acids would inhibit nutrition, caused the starvation of insect and subsequently affect the reproduction performance of $A$. fabae. Mat Sarip et al. (2016) showed that in addition to its contact toxicity on Aphis gossypii, the lauric acid present also in the seed oil of J. curcas, could also affect aphid reproduction system, restrict aphid growth development and reduce aphids feeding activity. Pérez-Gutiérrez et al. (2011) found also that oleic, palmitic and stearic acids extracted from Papaya (Carica papaya) were toxic to the fall armyworm Spodoptera frugiperda (Lepidoptera: Noctuidae) when admixed to the artificial diet of this pest and 
caused the pest starvation. Moreover, Ramos-López et al. (2012) showed that linolenic and linoleic acids purified from the castor-oil plant (Ricinus communis), and also highly present in the oil of J. curcas, exhibited insectistatic and insecticidal activities against S. frugiperda and caused nutrient stress on pests.

Grüber et al. (1988) demonstrated that as a response to nutrient stress, during the starvation of the rose-grain aphid (Metopolophium dirhodum), the fat reserves content of the soma, necessary to provide lipids to the ovaries, decreased by nearly $50 \%$ and was mobilized in profit of the insect survive (Arrese et al., 2010). Mat Sarip et al. (2016) stipulated also that the lauric acid, detected in the oil of J. curcas, had a similar effect to Cinnamaldehyde and Malathion and clearly affected the reproduction of Aphis gosyypii (Hemiptera: Aphididae). Therefore, the fecundity of aphids feeding on a plant of low nutritional quality was significantly lower. This response was expressed as a flexible reproductive strategy to nutritional stress conditions (Grüber et al., 1988) and explained the anti-reproduction effect of the extracts of J. curcas.

\section{Conclusion}

This study demonstrated that the extracts of $J$. curcas exhibited a wide spectrum of aphicidal activities. Our research proved the killing, repellent, antifeedant and antireproduction effect of the extracts of J. curcas. The PEs and the seed oil showed a contact and ingestion toxicity on the grain aphid S. avenae. These compounds exhibited a high mortality by topical and spray application caused by disruption of respiratory functions. When sprayed or topically applied on the aphids, the oil covered the insect cuticle, blocked the spiracle and caused the suffocation of aphid. Some necroses were also developed. After topical application, the lipophilic nature of oils helps to penetrate the cell, accumulate inside the cytoplasm and affect their structural and functional properties.

This research also showed that the seed oil had an age-dependent toxicity on the black bean aphid $A$. fabae. The young nymphs were more susceptible to the seed oil then the old and adults. The spatial distribution of aphids on the host plant and their moving behavior made the young immobile nymphs easily targeted than the mobile old stages by spraying the seed oil. Our study showed also a reproduction inhibitory effect of the seed oil. The oily film covering the plant surface and rich with fatty acids would inhibit nutrition, caused the starvation of insect and subsequently affect the reproduction performance of $A$. fabae. 
The study showed also that the root extract of $J$. curcas induced a repellent effect on the grain aphid S. avenae resulting in a high protective effect against this aphid. This effect was relevant in in vitro conditions when wheat plants were sprayed with the primary and secondary root extract. The bioassay showed that these extracts would act as repellent for the aphids that did not come definitely in contact with treated plants and deterrent for the minority of aphids that settled temporarily on treated plants then moved to the control wheat plants.

This study revealed the insecticidal properties of $J$. curcas. The seed oil and the PEs extracted from this plant could be promising alternatives to synthetic chemicals for the control of aphids. The efficacy of these compounds could be valorized in crop protection and enhanced by combination with other safe plant protection agents such as entomopathogenic fungi. The repellent properties of the root extract could be improved by the elucidation and purification of the major compounds involved in this effect. 


\section{References}

Acda M.N. 2009. Toxicity, tunneling and feeding behavior of the termite, Coptotermes vastator, in sand treated with oil of the physic nut Jatropha curcas. Journal of Insect Science, 9: 1-8.

Arrese E. L., Soulages J. L. 2010. Insect fat body: energy, metabolism and regulation. Annual Review of Entomology, 55: 207-225.

Bailey S. M., Irwin M. E., Kampmeier G. E., Eastman C. E., Hewings A. D., 1995. Physical and Biological Perturbations: Their effect on the Movement of Apterous Rhopalosiphum padi (Homoptera: Aphididae) and Localized Spread of Barley Yellow Dwarf Virus. Environmental Entomology, 24: 24-33.

Barbehenn RV., Constabel C. 2011. Tannins in plant-herbivore interactions. Phytochemistry, 72: 1551-1565.

Buteler M., Stadler T. 2011. A review on the mode of action and current use of petroleum distilled spray oils. Pesticides in the Modern World - Pesticides Use and Management, ISBN: 978-953-307-459-7.

Cantrell CL., Ali A., Duke S.O., Khan I. 2011. Identification of Mosquito Biting Deterrent Constituents from the Indian Folk Remedy Plant Jatropha curcas. Journal of Medical Entomology, 48: 836-845.

Da Silva C., Minguzzi S., Da Silva R., Matos M., Tofoli D., De Carvalho J., Ruiz A., Da Costae W., Simionattoa E., 2015. Chemical Composition and Cytotoxic Activity of the root essential oil from Jatropha ribifolia (Pohl) Baill (Euphorbiaceae). Journal of the Brazilian Chemical Society, 26: 233-238.

Devappa R.K., Angulo-Escalante Miguel A., Makkar H.P.S., Becker K. 2012. Potential of using phorbol esters as an insecticide against Spodoptera frugiperda. Industrial Crops and Products, 38: 50- 53.

Devappa R.K., Maes J., Makkar H.P.S., De Greyt W., Becker K. 2010a. Quality of biodiesel prepared from phorbol ester extracted Jatropha curcas. Journal of American Oil Chemist's Society, 87:697-704.

Devappa R.K., Makkar H.P.S., Becker K. 2010b. Jatropha toxicity: a review. Journal of Toxicology and Environmental Health, 13: 476-507.

Devappa R.K., Makkar H.P.S., Becker K. 2010c. Biodegradation of Jatropha curcas phorbol esters in soil. Journal of the Science of Food and Agriculture, 90:2090-2097.

Devappa R.K., Makkar H.P.S., Becker K. 2010d. Optimization of conditions for the extraction of phorbol esters from Jatropha oil. Biomass and Bioenergy, 34: 1125-1133. 
Devappa R.K., Makkar H.P.S, Becker K. 2011. Jatropha Diterpenes: a Review. Journal of the American Oil Chemists' Society, 88: 301-322.

Dias L., Leme L., Laviola B., Pallini A., 2007. Cultivo de Pinhão Manso (Jatropha curcas L.) para Produção de Óleo Combustível. UFV, Viçosa. 40

El Diwani G., El Rafie S., Hawash S. 2009. Antioxidant activity of extracts obtained from residues of nodes leaves stem and root of Egyptian Jatropha curcas. African Journal of Pharmacy and Pharmacology, 3: 521-530.

Goel G., Makkar H., Francis G., Becker K. 2007. Phorbol Esters: structure, biological activity, and toxicity in animals. International Journal of Toxicology, 26:279-88.

Grüber K., Dixon A.F.G. 1988. The effect of nutrient stress on development and reproduction in an aphid. Entomologia Experimentalis et Applicata, 47: 23-30.

Haas, W., Sterk, H., Mittelbach, M. 2002. Novel 12-Deoxy-16-hydroxyphorbol diesters isolates from the seed oil of Jatropha curcas. Journal of Natural Products, 65:1434-1440.

Heller J. 1996. Physic Nut Jatropha curcas L. Promoting the conservation and use of underutilized and neglected Crops. Institute of Plant Genetics and Crop Plant Research (IPGRI), Gatersleben / International Plant Genetic Resources Institute: Rome, Italy, p. 66

JatroSolutions $\mathbf{G m b H}$, 2014. Safety instructions sheet for the use of phorbol esters. pp12

Jing L., Fang Y., Ying X., Wenxing H., Meng X., Syed M. N., Fang C. 2005. Toxic impact of ingested Jatropherol-I on selected enzymatic activities and the ultrastructure of midgut cells in silkworm, Bombyx mori L. Journal of Applied Entomology, 129: 98-104.

Larsson. H. 2004. A crop loss model and economic thresholds for the grain aphid, Sitobion avenae (F.), in winter wheat in southern Sweden. Crop Protection, 24: 397-405.

Lin J., Chen, Y., Xu, Y., Yan F., Tang L., Chen F. 2003c. Cloning and expression of curcin, a ribosome-inactivating protein from the seeds of Jatropha curcas. Acta Botanica. Sinica. Botanical Society of China and Institute of Botany, the Chinese Academy of Sciences, 45 : 858-863.

Llewellyn K.S., Loxdale H.D., Harrington R., Brookes C.P., Clark S.J and Sunnucks P. 2003. Migration and genetic structure of the grain aphid (Sitobion avenae) in Britain related climate and clonal fluctuations revealed using microsatellites. Molecular Ecology, 12: 21-34.

Lu H., Liu Y., Zhou H., Yang Y., Chen M., Liang B. 2009. Production of biodiesel from Jatropha curcas L. oil. Computers and Chemical Engineering, 33: 1091-1096.

Makkar, H.P.S., Becker, K. 2009. Jatropha curcas, a promising crop for the generation of biodiesel and value-added coproducts. European Journal of Lipid Science and Technology, 111: 773-787. 
Mansour M. H., Zohdy N. M., El-Gengaihi S. E., Amr A. E., 1997. The relationship between tannins concentration in some cotton varieties and susceptibility to piercing sucking insects. Journal of Applied Entomology, 121. 321-325.

Mat Sarip S.H., Abdul-Aziz A, Yaakob H., Puad K. 2016. Toxicological effect of lauric acid based insecticide on the reproduction system, growth development and feeding activity of aphids, Aphis gossypii Glover. International Journal of Biotechnology for Wellness Industries, 5: 76-81.

Norris, D.M. 1986. Anti-Feeding Compounds. In Chemistry of Plant Protection; SpringerVerlag, Berlin, pp 97-146

Northover, J., Timmer, L.W. 2002. Control of plant diseases with petroleum- and plant derived oils. In: Spray Oils Beyond 2000, 512-526, Univ. of Western Sydney Press, Australia, 512-526

Openshaw, K., 2000. A review of Jatropha curcas: an oil plant of unfulfilled promise. Biomass Bioenergy, 19: 1-15.

Oskoueian E., Abdullah N., Ahmad, S. Saad W. Z., Omar A.R., Ho Y. W. 2011. Bioactive compounds and biological activities of Jatropha curcas L. kernel meal extract. International Journal of Molecular Sciences, 12: 5955-5970.

Parry H.R. 2013. Cereal aphid movement: general principles and simulation modelling. Movement Ecology, 1: 14.

Pavela R., Barnet M., Kocourek F., 2004. Effect of Azadirachtin Applied Systemically through Roots of Plants on the Mortality, Development and Fecundity of the Cabbage Aphid (Brevicoryne brassicae). Phytoparasitica, 32: 286-294.

Pavela R. 2007. Possibilities of botanical insecticide in plant protection. Pest Technology, 1: 47-51. Global sciences Books

Pérez-Gutiérrez S., Zavala-Sánchez M.A., González-Chávez M. M., Cárdenas-Ortega N. C., Ramos-López M. A. 2011. Bioactivity of Carica papaya (Caricaceae) against Spodoptera frugiperda (Lepidoptera: Noctuidae). Molecules, 16: 7502-7509.

Powell G., Tosh C.R., Hardie J. 2006. Host plant selection by aphids: Behavioral, evolutionary, and applied perspectives. Annual Review of Entomology, 51:309-30.

Ramos-López M. A, González-Chávez M. M., Cárdenas-Ortega N. C., Zavala-Sánchez M. A. Pérez G.S. 2012. Activity of the main fatty acid components of the hexane leaf extract of Ricinus communis against Spodoptera frugiperda. African Journal of Biotechnology, 11: 42744278.

R Development Core Team .2008. R: A language and environment for statistical computing. $R$ Foundation for Statistical Computing, Vienna, Austria. ISBN 3-900051-07-0, URL http://www.R-project.org. 
Ratnadass A., Wink M. 2012. The Phorbol Ester Fraction from Jatropha curcas seed oil: Potential and limits for crop protection against insect pests. International Journal of Molecular sciences, 13: 16157-16171.

Reese J.C., Beck S.D. 1976c. Effects of allelochemicals on the black cutworm Agrotis ipsilon: Effects of resorcinol, phloroglucinol and gallic acid on larval growth, development and utilization of food. Annals of the Entomological Society of America, 69: 999-1003.

Reifenrath W., Hawkins G., Kurtz M., 1989. Evaporation and skin penetration characteristics of mosquito repellent formulations. Journal of the American Mosquito Control association, 5:45-51.

Richling I., Böckeler, W.2008. Lethal effects of treatment with a special dimeticone formula on head lice and house crickets (Orthoptera, Ensifera: Acheta domestica and Anoplura, Phthiraptera: Pediculus humanus). Arzneimittelforschung, 58: 248- 254.

Sabandar C., Norizan A., Faridahanim Mohd J, Sahidin I. 2013. Medicinal property, phytochemistry and pharmacology of several Jatropha species (Euphorbiaceae): A review. Phytochemistry, 85: 7-29.

Silinsky, E. M., Searl T. J. 2003. Phorbol esters and neurotransmitter release; more than just protein kinase C? British Journal of Pharmacology, 138: 1191-1201.

Silva G.N.; Faroni, L.R.A.; Sousa, A.H.; Freitas, R.S. 2012. Bioactivity of Jatropha curcas L. to insect pests of stored products. Journal of Stored Products Research, 48:111-113.

Stadler, T., and Buteler, M. 2009. Modes of entry of petroleum distilled spray-oils into insects: a review. Bulletin of Insectology, 62: 169-177.

Taverner, P.D., Gunning, R.V., Kolesik, P., Bailey, P.T., Inceoglu, A.B.; Hammock, B., Roush, R.T. 2001. Evidence for direct neural toxicity of a "light" oil on the peripheral nerves of lightbrown apple moth. Pesticide Biochemistry and Physiology, 69: 153-165.

Vereijken, P.H., 1979. Feeding and multiplication of three cereal aphid species and their effect on yield of winter wheat. Agricultural Research Reports (Veralagen van Landbouwkundige Onderzoekingen) 888. Pudoc Wageningen, the Netherlands. 58 pp

Walling L.L. 2008. Avoiding Effective defenses: Strategies employed by phloem-feeding insects. American Society of Plant Biologists. Plant Physiology, 146: 859-866.

Webster G. 1994. Synopsis of the genera and suprageneric taxa of Euphorbiaceae. Annals of the Missouri Botanical Garden, 81: 33-144

Ye M., Li C., Georges F., Makkar H.P.S. 2009. Current situation and prospects of Jatropha curcas as a multipurpose tree in China. Agroforest Systems, 76:487-497. 
Zhu J. J., G. Brewer J., Boxler D.J., Friesena K., Taylora D.B. 2015. Comparisons of antifeedancy and spatial repellency of three natural product repellents against horn flies, Haematobia irritans (Diptera: Muscidae) Pest Managemant Science, 71:1553-1560. 


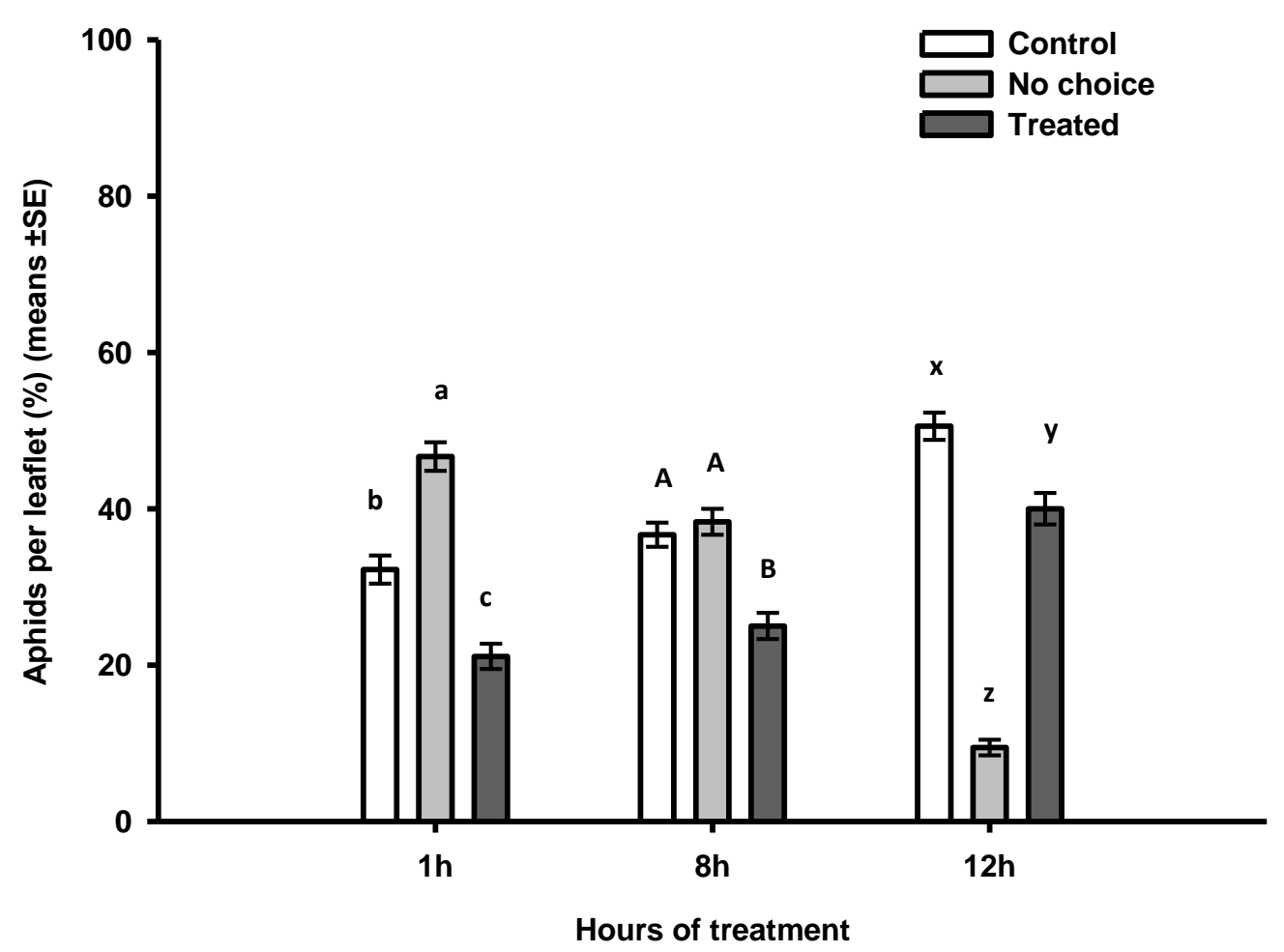

Figure 1a: Repellent effect of the primary root extract of J. curcas on the grain aphid $S$. avenae in in vitro conditions. Bars denoted within the same group with different letters are significantly different (All Pairwise Multiple Comparison Procedures Tukey's test, $p<0.05$ ).

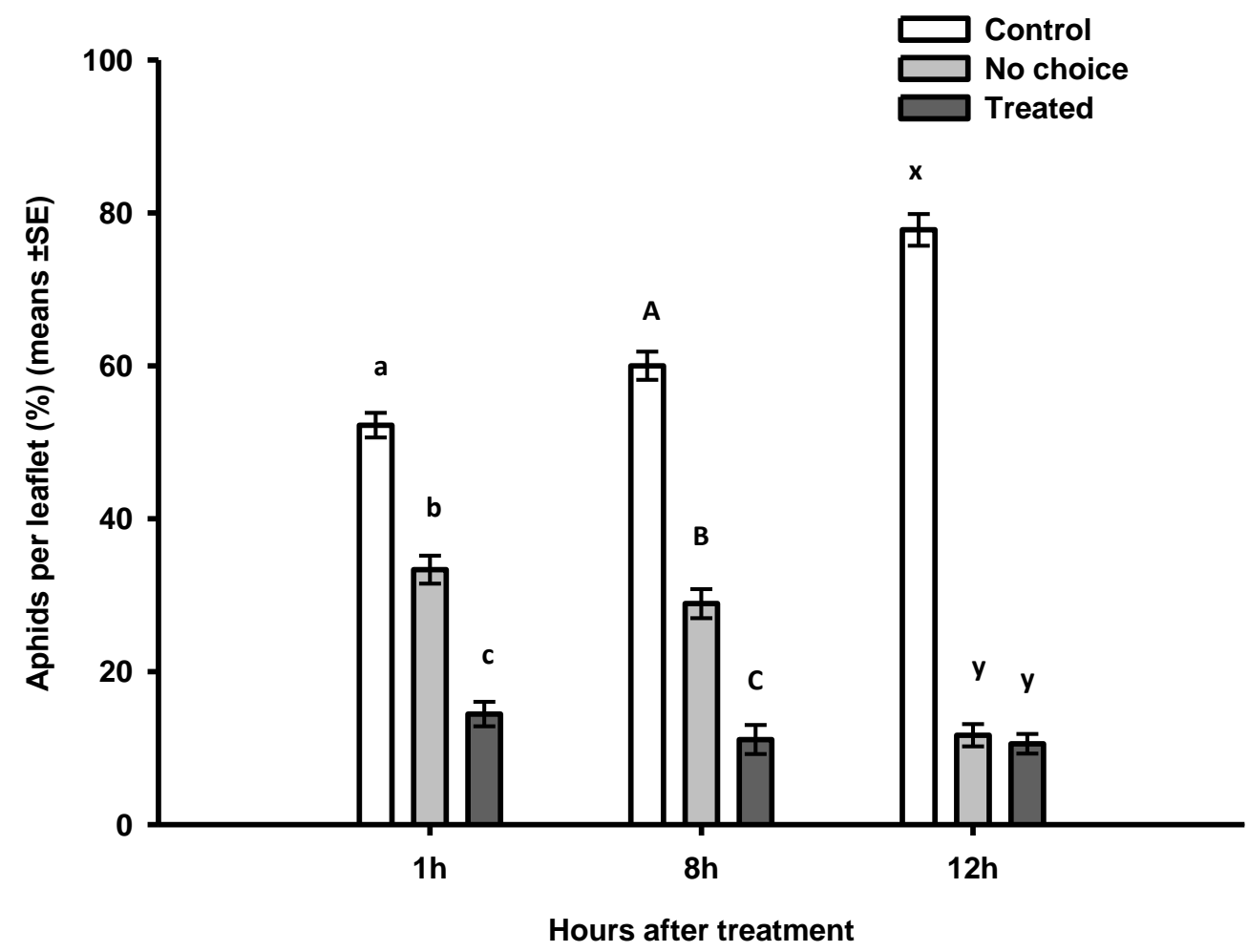

Figure 1b: Repellent effect of the secondary root extract of $J$. curcas on the grain aphid $S$. avenae in in vitro conditions. Bars denoted within the same group with different letters are significantly different (All Pairwise Multiple Comparison Procedures Tukey's test, $p<0.05$ ). 


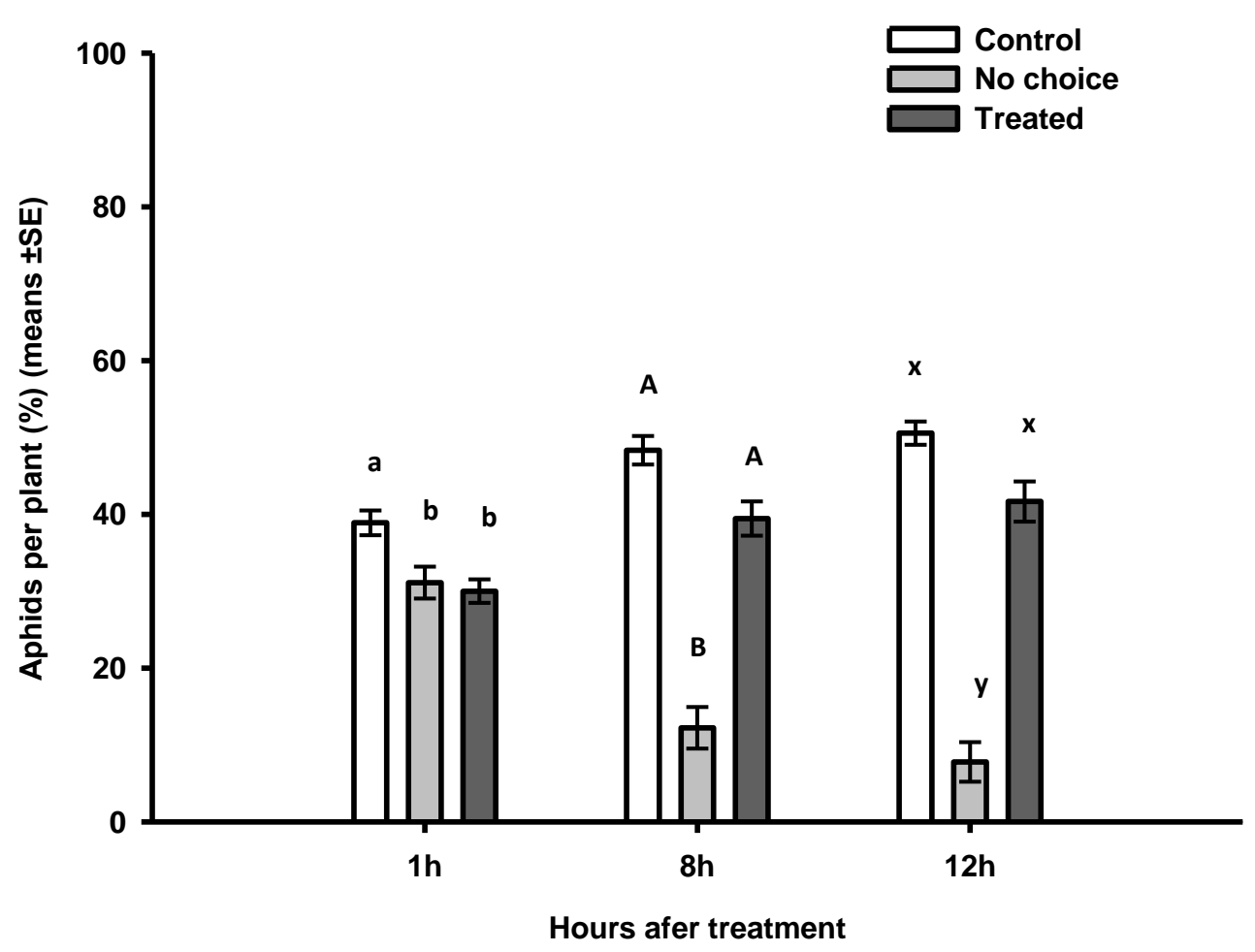

Figure 1c: Repellent effect of the primary root extract of J. curcas on the grain aphid $S$. avenae on wheat plants. Bars denoted within the same group with different letters are significantly different (All Pairwise Multiple Comparison Procedures Tukey's test, $p<0.05$ ).

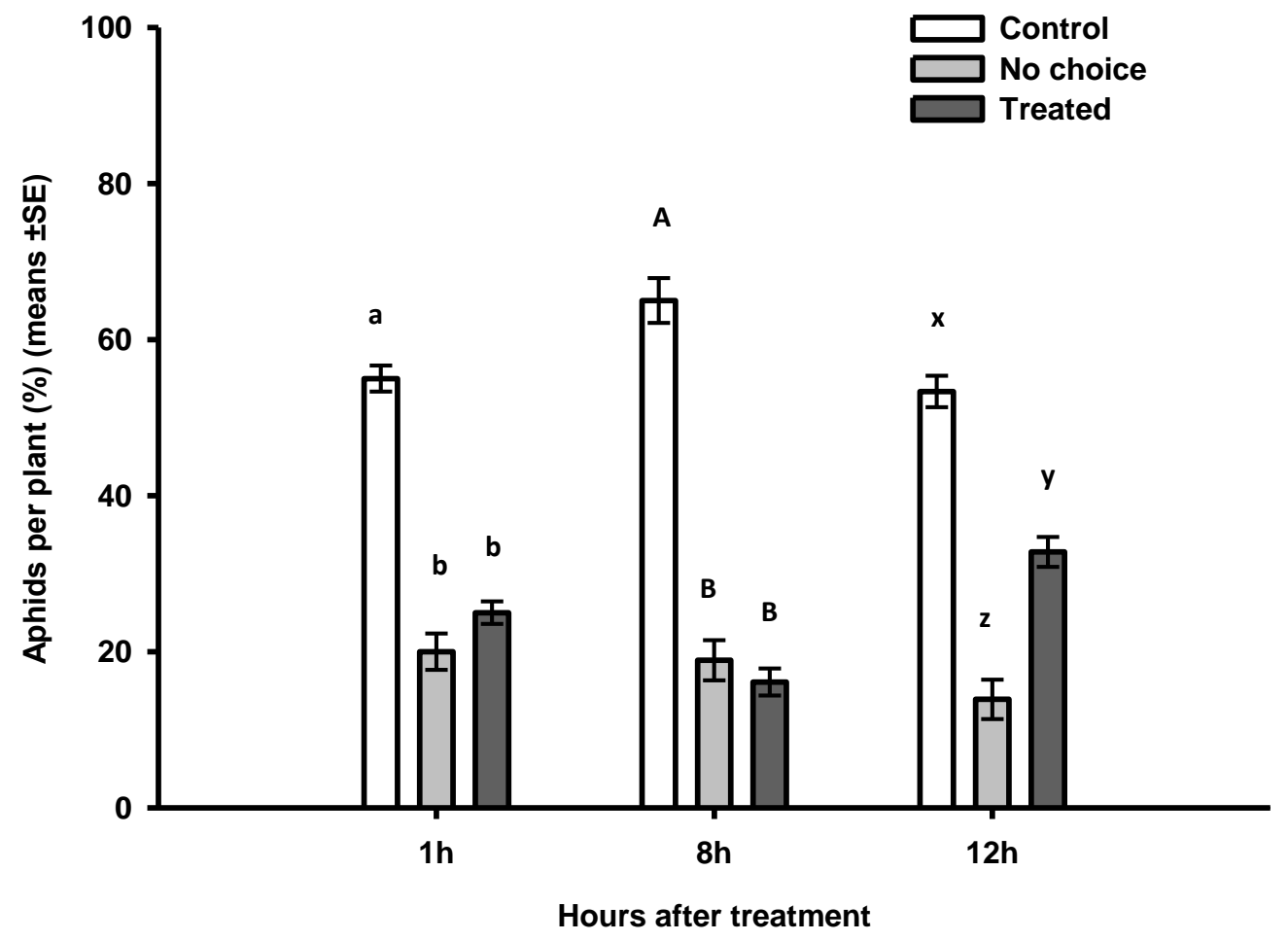

Figure 1d: Repellent effect of the secondary root extract of J. curcas on the grain aphid $S$. avenae on wheat plants. Bars denoted within the same group with different letters are significantly different (All Pairwise Multiple Comparison Procedures Tukey's test, $p<0.05$ ). 


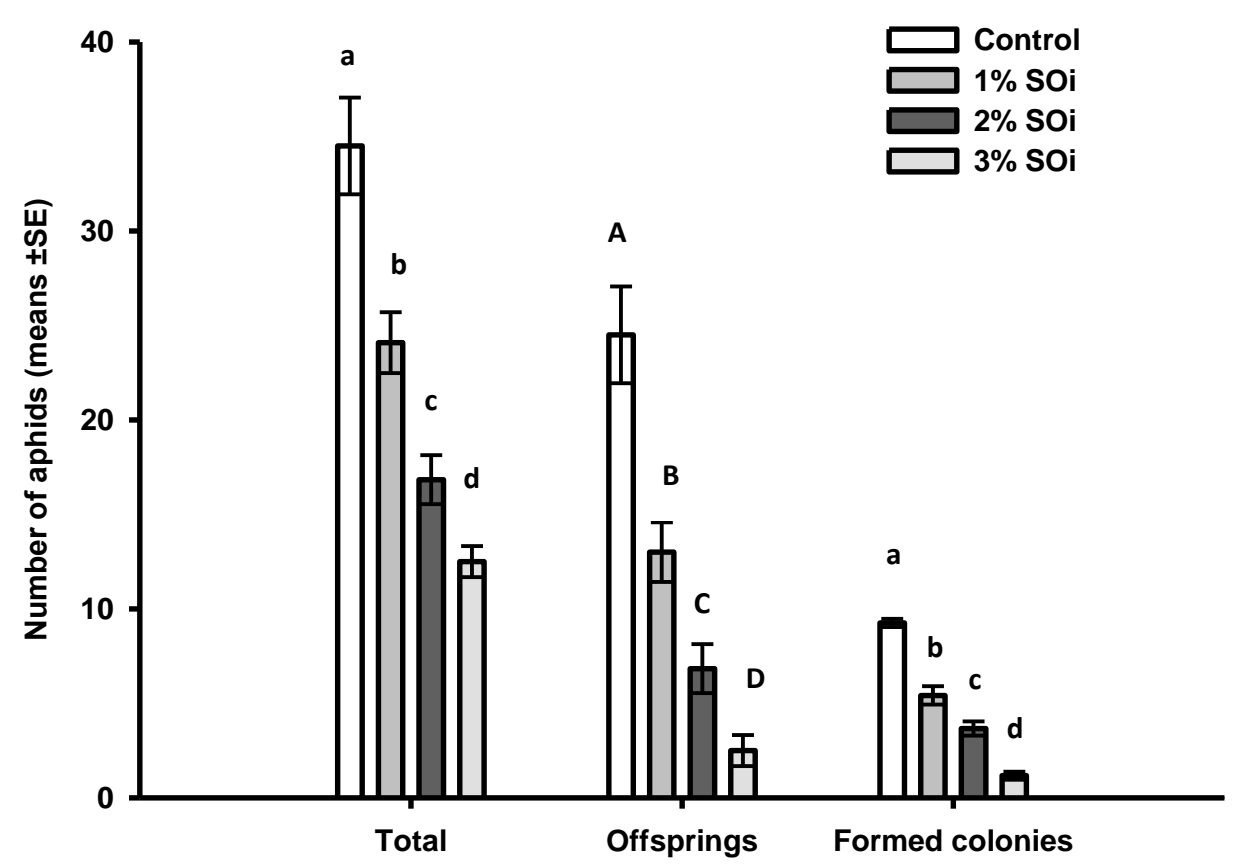

Figure 2: Anti-reproduction effect of the seed oil (SOi) of J. curcas on the black bean aphid A. fabae. The Total included the number of the females initially released and their offsprings; Offsprings showed the number of nymphs produced by the surviving females on host plants and Formed colonies expressed the number of colonies established by the surviving females. The data derived from each measured parameter (total, offsprings and formed colonies) were independently analyzed and statistically compared within the same parameter. Bars denoted within the same group with different letters are significantly different (All Pairwise Multiple Comparison Procedures Tukey's test, $p<0.05$ ). 


\section{Chapter 3}

\section{Study of the killing and antifeedant effects of some botanical extracts from the physic nut tree Jatropha curcas on the Diamondback moth (DBM) Plutella xylostella (Lepidoptera: Plutellidae)}

\section{Summary}

The physic nut tree Jatropha curcas was investigated for its toxicity on the diamondback moth Plutella xylostella. The study showed that the Phorbol Esters Enriched Fraction (PEEF) and the Phorbol Esters (PES) induced a moderate toxicity when topically applied on the early $2^{\text {nd }}$ instar larvae of $P$. xylostella. After 4 days, a significant difference was found between the mortality caused by the PEEF and the control treatment (Tukey's HSD; $p<0.01$ ) while the PEs showed a non-significant contact toxicity (Tukey's HSD; $p=0.27$ ). At the end of the bioassay, $18 \%$ of larvae were recorded dead after being treated with PEs and $26 \%$ of larvae were killed after exposure during 6 days to PEEF.

The ingestion of $2 \%$ of PEs induced the mortality of $16 \%$ of the larvae and $28 \%$ after feeding for $48 \mathrm{~h}$ on PEEF treated discs. After 4 days, the killing effect of the compounds increased slightly to $20 \%$ and $38 \%$ respectively for PEs and PEEF. In this case, a significant difference was evident for the PEs (Tukey's HSD; $p<0.001$ ) and a highly significant for the PEEF (Tukey's HSD; $p<0.001$ ) compared to the control. After 6 days, more larvae of $P$. xylostella were dead and a significant difference was observed between treatments $\left(F_{2,27}=\right.$ $27.44, p<0.001)$. After 6 days, the killing effect of the compounds increased slightly to $20 \%$ and $38 \%$, respectively for PEs and PEEF.

The PEEF affected also the larval feeding behavior of $P$. xylostella. After $12 \mathrm{~h}$, the $1^{\text {st }}$ instar larvae of $P$. xylostella preferred to feed on the control cabbage leaf discs and avoided PEEF where only $10.55 \%$ of larvae were recorded (Tukey's HSD; $p<0.001$ ). The $2^{\text {nd }}$ instar of $P$. xylostella showed also avoidance to PEEF. After $12 \mathrm{~h}$, the larval presence increased steadily to reach $69.44 \%$ on the control leaf discs (Tukey's HSD; $p<0.001$ ). In contrast to the early larval stages, the $3^{\text {rd }}$ instar larvae of $P$. xylostella did not show any preference to any treatment during the bioassay (Tukey's HSD; $p=0.70$ ). Larvae fed freely on both leaves without making a clear choice: $46.66 \%$ larvae were recorded on the control discs while 41.11\% observed on PEEF treated leaves. 
Jatropha based extracts affected the larval weight of $P$. xylostella $\left(F_{3,44}=16.14\right.$, $\mathrm{p}<0.001)$. After 3 days, larvae fed on leaf discs dipped in $0.75 \%$ PEEF had a lower weight and leaves were less consumed. The leaf extract affected also the larval growth and showed also a protective effect (Tukey's HSD; $p<0.001$ ), while no effect of the stem bark extract was observed (Tukey's HSD; $p=0.83$ ). As a consequence for being underfed, the pupal weight of P. xylostella was slightly affected $\left(F_{3,44}=4.90, \mathrm{p}<0.05\right)$. Under greenhouse conditions, Jatropha extracts did not show the same efficacy as it was observed under laboratory conditions. In fact, no effect of the leaf extract on the weight was observed (Tukey's HSD; $p=0.35$ ). However, the suppressive effect of PEEF on the body weight was still observed after 5 days of feeding. The PEEF induced the highest protective effect for the leaf surface (Tukey's HSD; $\mathrm{p}$ <0.05). However, the stem bark extract did not show any significant protection in greenhouse conditions (Tukey's HSD; $p=0.94$ ).

Keywords: Jatropha curcas, Plutella xylostella, Phorbol Esters fraction, Phorbol Esters Enriched Fraction, antifeedant, larval growth. 


\section{Introduction}

Botanical insecticides have been long used as environmentally friendly alternatives to synthetic chemicals for pest management. Plants produce a range of chemical substances to prevent attack by herbivores (Ohmura et al., 2000; Barbehenn et al., 2009; Dowd et al., 2011). Several extracts of plants have been evaluated for their activity against agriculturally important insects and being evaluated further for use in plant protection (Koul et al., 2008).

The genus Jatropha, rich with phytochemicals and investigated for its toxic properties, is native to tropical America and widely distributed in the tropical and subtropical areas of South America, Central America, Asia, Australia and Africa (Gübitz et al., 1999). It belongs to the tribe Jatropheae, orders Malpighiale in the Euphorbiaceae family and contains more than 170 known species (Wurdack, 2008). The most widespread specie around the world is Jatropha curcas (Ratnadass et al., 2012), assessed in our study for its toxicity on the diamondback moth Plutella xylostella.

The diamondback moth Plutella xylostella (DBM) is a serious pest of Brassica (Talekar et al., 1993; Sarfraz et al., 2005) and causes high losses on cruciferous vegetables (e.g. cabbages, broccoli and cauliflowers) and oilseed crops (e.g. canola and mustard) (Furlong et al., 2013). This pest is believed to be the most universally distributed of all Lepidoptera (Shelton, 2004). However, the high diversity of its natural enemies and the large host complex recorded in South Africa supported this area as the center of origin of this pest and its spread later on with the host plant all over the world (Kfir, 1998). Nonetheless, the study of the genetic traits among various populations of $P$. xyllostella in different parts of the world (South Africa, France, Japan, Australia...) have shown large genetic variations, which makes it difficult to fix this pest to a precise geographic origin (Pichon et al., 2006). P. xylostella has a wide ecological plasticity, which allows it to develop in various climatic conditions. The moths overwinter as adults among field debris of cruciferous crops, and are still active during warm winter episodes $\left(15^{\circ} \mathrm{C}-18^{\circ} \mathrm{C}\right)$. In warm conditions, the lifecycle including 4 larval stages takes about 3 weeks and the adults can complete 18 generations on Brassica.

P. xylostella is an oligophagous pest, which feeds only on plants of the family Brassicaceae. It damages the leaves of its host plants from the seedlings until harvest period, but only the larval stage is herbivorous (Amit et al., 2001). The larva is a voracious surface feeder but does not destroy the veins. With its chewing mouthparts, the larva feeds on the 
undersides of leaves leaving a translucent epidermis. As the leaf grows, the damaged surface rips creating holes and destroying the leaf. The larvae can also nibble the chlorophyll-rich green areas of stems and pods (Cabi, 2016) and hamper the plant development. The damage is often first evident on plants growing on ridges and knolls in the field (Canola Council of Canada, 2014). When the plant is seriously infested, the larval population may heavily destroy the foliar tissue and disrupt the head formation in cabbage, broccoli, and cauliflower. Also, many caterpillars or cocoons are sometimes hidden in the heads, and these may be rejected for commercialization.

Although the control of the diamondback moth is mainly based on chemicals (Canola Council of Canada, 2014), the use of bioinsecticides occupies a major place in management programs against this pest (Liang et al. (2003); Nadeem et al. (2012)). The purpose of this study was to assess the toxicity of different extracts from the physic nut tree J. curcas on $P$. xylostella. The Phorbol Esters fraction (PEs), the Phorbol Esters Enriched Fraction (PEEF), the seed oil, the aqueous leaf extract, the stem bark and the root extracts were screened for their toxic effects on this pest. The insecticidal properties of these compounds were compared with standard bioinsecticides such as NeemAzal and Spinosad, known as effective formulations to control the populations of the diamondback.

We addressed the following questions:

- Does the topical application of the Phorbol Esters fraction (PEs) induce the mortality of the larvae of $P$. xylostella?

- Is the Phorbol Esters Enriched Fraction (PEEF) highly toxic to larvae than PEs?

- Can the ingestion of PEs or PEEF affect the survivorship of larvae?

- Does PEEF affect the larval feeding behavior of $P$. xylostella? Does this effect depend on the larval instar stage?

- Do the stem bark and the leaf extract induce an antifeedant effect on the $2^{\text {nd }}$ instar larvae?

\section{Material and methods}

\subsection{Host plants}

Cabbage plants Brassica oleracea var. capitata L. (Cultivar: "Furchenkohl"; Norddeutsche Pflanzenzucht Hans-Georg Lembke KG) were used as host for the toxicity bioassays on P. xylostella. The cabbage plants were grown in plastic trays from seeds in a 
greenhouse chamber $\left(22 \pm 3{ }^{\circ} \mathrm{C} ; 80 \%\right.$ relative humidity; $16 \mathrm{~L}$ : 8D photoperiod). After 10 days, seedlings were transplanted into $11 \mathrm{~cm}$ diameter pots filled with non-sterile soil (Fruhstorfer Erde Typ 25, Hawita Gruppe $\mathrm{GmbH}$, Vechta, Germany, peat fine structure with volcanic clay, $\mathrm{pH}$ : 5.7-6.3, Fertilization of $200-300 \mathrm{mg} \mathrm{N}$ ) and sand mixture (3:1 volume). Plants were grown in the chamber, regularly irrigated and fertilized once a week (fertilizer: Hakaphos $2 \mathrm{~g} / \mathrm{L}$ (15\% N, 11\% P2O5, 15\% K2O, 1\% Mg, 0.1\% Fe, 0.1\% Mn, 0.04\% Cu, $0.025 \% \mathrm{~B}$ and $0.005 \% \mathrm{Mo})$ ).

\subsection{Insect culture}

Larvae and adults of DBM were obtained from a laboratory culture maintained in a wood cage $(90 \mathrm{~cm} \times 50 \mathrm{~cm} \times 50 \mathrm{~cm})$ in a climate controlled room $\left(21 \pm 1^{\circ} \mathrm{C}\right.$ temperature, $60 \pm$ $5 \%$ relative humidity and L16:D8 photoperiod) and reared on fresh cabbage plants (cultivar: Furchenkohl). Adults were provided weekly with 2 weeks-old fresh cabbage plants as oviposition support and food resource for the larvae. Old plants were removed from the cage to avoid the contamination of the rearing by potential saprophyte pathogens such as fungus and some species of spider mites.

\subsection{Jatropha bioinsecticides}

In this study, many different extracts of J. curcas were screened for their insecticidal effect: the seed oil (SOi), the Phorbol Ester (PEs), the Phorbol Ester Enriched Fraction (PEEF), the leaf extract and the stem bark extract. The oils were provided by the company of JatroSolutions GmbH (Stuttgart, Germany) where they have been extracted and purified following the method of Devappa et al. (2010a) then stocked in a cold room to be used in bioassays. The other botanical extracts of J. curcas were prepared from greenhouse cultivated plants.

The leaf and stem bark based extracts were prepared in laboratory. The plant material was collected from vigorous plants of J. curcas grown under glasshouse conditions (temperature and $65 \%$ humidity $23 \circ \mathrm{C}$ ) in an environment similar to the area of origin (Madagascar). Plants were gently harvested and the sand was removed with water pressure until roots were completely clean. Fully grown green leaves were cut from the upper part of the plants. We used only young leaves whereas old leaves were discarded. The stem was firstly cleaned with a moistened tissue to remove the dust; then the bark was gently shelled from the middle part of the stem. After being cleaned, the leaves and the stem bark of $J$. curcas were cut in small pieces and freeze dried at -20 C. After one week, the plant 
material was separately milled to a fine powder, weighed, filled in hermetic plastic bags and conserved at $-20 \cong \mathrm{C}$ for further use. The aqueous leaf and stem bark extracts were obtained by soaking the plant powder in an Erlenmeyer flask containing bidest water. The solution was kept overnight mixing on a horizontal shaker (120 rpm) (HS 250, IKA Labortechni, Germany) before being heat-treated for 1 hour in a water-bath (Köttermann GmbH \& Co. KG, Uetze, Germany) at $65{ }^{\circ} \mathrm{C}$. It was then decanted with a funnel filter paper (grade 595.5, $185 \mathrm{~mm}$ diameter) (Schleicher and Schuell Bioscience GmbH, Dasse, Germany) and placed in cold room for further use.

\subsection{Experimental bioassays}

\subsubsection{Contact toxicity of PEs and PEEF}

The contact toxicity of Jatropha compounds was tested on $2^{\text {nd }}$ instar larvae of $P$. xylostella collected from a stock colony reared in laboratory conditions $\left(21 \pm 1^{\circ} \mathrm{C}\right.$ temperature, $60 \%$ relative humidity and L16:D8 photoperiod). The methodology consisted of topically treating the larvae by applying $0.5 \mu \mathrm{l}$ of different concentrations of the compounds on the anterior pronotum using a micro-pipette. The bioassay was composed of 3 different treatments: the control group with larvae simply treated with water mixed with $0.05 \%$ (V/V) TWEEN $^{\circledR}$ 80, the Phorbol Esters 2\% (V/V) (PEs) and the Phorbol Ester Enriched Fraction (PEEF) 2\% (V/V). The treated larvae were then released per group of 5 larvae on 3 weeks old non-treated cabbage plants to feed freely on young leaves. The bioassay was conducted under greenhouse conditions $\left(22 \pm 3^{\circ} \mathrm{C}\right.$ temperature, $60 \%$ relative humidity and $16 \mathrm{~L}$ : $8 \mathrm{D}$ photoperiod) until the larvae pupated. The larval mortality was checked at 2 days, 4 days and 6 days after treatment. Larvae were considered dead when no reaction/movement to the stimulation with a blunt needle was observed. At the end of the experiment, the pupae were gently collected with forceps and kept on a filter paper in white boxes $(18 \mathrm{~cm}$ length $\times 13 \mathrm{~cm}$ width $\times 5.5 \mathrm{~cm}$ height) until emergence in a climatic chamber (WB $750 \mathrm{KFL}$; Mytron Bio-Und Solartechnik $\mathrm{GmbH}$, Germany) with the same conditions of the greenhouse. There were 10 cabbage plants per treatment infested each with 5 larvae of Plutella.

\subsubsection{Ingestion toxicity of PEs and PEEF}

The ingestion toxicity of the PEs and PEEF was tested on 3 days old larvae of P. xylostella. Newly hatching larvae were gently collected with a fine camel brush from the stock colony; then transferred to feed for 3 days on clean cabbage plants before use in the 
bioassay. TWEEN ${ }^{\circledR} 80$ was used as emulsifier. The experiment was set-up with 3 different treatments in a greenhouse cabinet $\left(22 \pm 3^{\circ} \mathrm{C}\right.$ temperature, $60 \%$ relative humidity and $16 \mathrm{~L}$ : 8D photoperiod): control plants treated with water, plants treated with PEs and plants treated with PEEF. The plants were sprayed until run-off with $2 \%(\mathrm{~V} / \mathrm{V})$ of the extracts then left for 1 hour to completely dry. In order to avoid feeding pressure on the host, each plant was infested with only 5 larvae of $P$. xylostella feeding freely on cabbage leaves until pupation. Pupae were collected and kept until emergence in a climatic chamber, the same as in the previous bioassay.

\subsubsection{Effect of the PEEF on the feeding behavior of the $1^{\text {st }}, 2^{\text {nd }}$ and $3^{\text {rd }}$ instar larvae}

In this bioassay, the larvae of $P$. xylostella were exposed in vitro to a feeding choice test. Leaf discs of $4 \mathrm{~cm}$ diameter were cut with a clean leaf borer from 3 weeks old cabbage plants reared in greenhouse conditions. In this dual choice test, the control leaf discs were immersed for $1 \mathrm{mn}$ in a solution of bidest water, whereas the treated leaf discs were immersed in a solution of $2 \%$ (V/V) of PEEF contained in a beaker of 200 ml. TWEEN ${ }^{\circledR} 80$ was used in both treatments as emulsifier. Leaf discs were left to dry under laboratory conditions on a clean surface then placed with forceps separated by $5 \mathrm{~cm}$ in a $14 \mathrm{~cm}$ Petri dish on a moistened filter paper (125 mm diameter, Cat № 1001 125) (Schleicher and Schuell Bioscience $\mathrm{GmbH}$, Dasse, Germany). 15 healthy larvae of Plutella ( $1^{\text {st }}$ or $2^{\text {nd }}$ or $3^{\text {rd }}$ instar) were introduced in each Petri dish at $6 \mathrm{~cm}$ away from the leaf discs. The larvae were left to make a choice and the Petri dishes were sealed with parafilm to avoid dryness of the leaf discs. Larvae were counted on each disc at $1 \mathrm{~h}, 8 \mathrm{~h}$ and $12 \mathrm{~h}$ after release. The Petri dishes (12 per instar larvae) were randomly distributed and kept in a climatic chamber under controlled conditions $(22 \pm 1 \circ \mathrm{C}, 16: 8 \mathrm{~h}(\mathrm{~L}: \mathrm{D})$ and $60 \% \mathrm{RH})$.

\subsubsection{Anti-feedant effect of the PEEF, the stem bark extract and the leaf extract}

In this experiment, the antifeedant properties of the PEEF, the stem bark $\left(B R_{e x}\right)$ and the leaf extract $\left(\mathrm{Lf}_{\mathrm{ex}}\right)$ were firstly studied under in vitro conditions in Petri dishes $(86.5 \mathrm{~mm}$ diameter x $14.5 \mathrm{~mm}$ height) (Sarstedt, Aktiengesellschaft \& CO Nuembrecht, Germany). In this part, the same methodology as in the previous bioassay was followed to treat the cabbage leaf discs. The experiment had 4 different treatments: the control leaf discs, the leaf discs treated with $0.75 \%(V / V)$ of PEEF, the leaf discs treated with $2 \%$ of $B R_{e x}(W / V)$ and the discs treated with $2 \% \mathrm{Lf}_{\mathrm{ex}}(\mathrm{W} / \mathrm{V})$. The $2^{\text {nd }}$ instar larvae were firstly weighed on a microbalance 
(Sartorius MC5 ((-OCE), SC2 (-OCE), Max $5.1 \mathrm{~g})$, Göttingen, Germany) then individually introduced in Petri dishes where leaf discs were already placed.

The second bioassay was conducted under greenhouse conditions $\left(22 \pm 3^{\circ} \mathrm{C}\right.$ temperature, $80 \%$ relative humidity and $16 \mathrm{~L}$ : $8 \mathrm{D}$ photoperiod) on 3 weeks old cabbage plants. The same concentrations of PEEF, $B R_{e x}$ and $L f_{e x}$ were tested for their effectiveness under semi-real conditions. For that, one young cabbage leaf was gently treated with the bioinsecticide solution then left to dry for 1 hour. After that, one newly molted $2^{\text {nd }}$ instar larva of Plutella was clip-caged (5 cm diameter $\times 1 \mathrm{~cm}$ height) on the abaxial face of the plant. In laboratory and greenhouse experiments, larvae were left feeding freely on the leaf surface for 4 days. At the end of the $4^{\text {th }}$ day larvae were weighed, leaves were labeled and larvae were individually transferred to new treated leaves where they fed until pupation. At the end of the bioassay, the consumed leaf area was assessed by the Digi-trace program for image analysis (IMATEC Elektronische Bildanalyse Systeme $\mathrm{GmbH}$ ) and pupae were weighed. There were 12 replicates per treatments in a completely random design.

\subsection{Data analysis}

Statistical processing of results was carried out by standard methods using the statistical software R (v 3.0.2) (R Development Core Team, 2008). Prior to analysis, all data were tested for homogeneity of variances and normality. To detect the difference between treatments, we performed One-way analysis of variance (ANOVA). If significant differences between groups were detected, means were compared by performing Tukey's test at $\alpha=$ 0.05. The mortality of larvae after treatment with the extracts of J. curcas was analyzed using generalized linear models (GLM) taking into account the binomial distribution of the data (alive or dead). To correct the anomalies in data variation (overdispersion / underdispersion), we proceeded to the quasi-binomial distribution error in data analysis. Thereafter, Tukey's test at $\alpha=0.05$ was employed to detect differences between means.

Giving that some larvae did not make a choice during the feeding choice test, the non-choice category was also considered during the data analysis which made counts divided into 3 major groups (Control, treated and no-choice). This non-binary aspect of data deriving from choice bioassays (Control, Treated or No-choice) made it unsuitable to perform a binomial test for data analysis. In this case, we proceeded to generalized linear models (GLM) using Poisson distribution followed by quasi-poisson models analysis in case 
of dispersion anomalies. In case of significant differences between groups, data were subject to a Tukey's test at $\alpha=0.05$ to separate the means.

\section{Results}

\subsection{Contact toxicity of the PEs and PEEF}

Jatropha based extracts induced a moderate toxicity when topically applied on the early $2^{\text {nd }}$ instar larvae of $P$. xylostella (Figure 1). After 2 days of application, the PEs and PEEF induced a low mortality rate which reached respectively $6 \%$ and $14 \%$. After 4 days, a significant difference was found between the mortality caused by the PEEF and the control treatment (Tukey's HSD; $p<0.01$ ) while the PEs showed a non-relevant contact toxicity (Tukey's HSD; $p=0.27$ ). After 6 days, we observed an increase of the larval mortality rate and a significant difference was observed between treatments $\left(F_{2,27}=12.60, p<0.001\right)$. At the end of the bioassay, $18 \%$ of larvae were recorded dead after being treated with PEs and $26 \%$ of larvae were killed after exposure during 6 days to PEEF. After this time, no mortality was recorded. All the surviving larvae in all treatments continued their development to reach the pupal stage. All pupae hatched and gave healthy flying adults. We observed no larval mortality in the control groups.

\subsection{Ingestion toxicity of PEs and PEEF}

We found a significant difference after 2 days of feeding on cabbage leaf discs $\left(F_{2,27}=12.34, p<0.001\right.$; Figure 2$)$. In comparison with the control, the ingestion of $2 \%$ of PEs induced the mortality of $16 \%$ of the larvae (Tukey's HSD; $p<0.05$ ) and a highly significant larval mortality which reached $28 \%$ after feeding for $48 \mathrm{~h}$ on PEEF treated leaf discs (Tukey's HSD; $p<0.001$ ). After 4 days, the killing effect of the compounds increased slightly to $20 \%$ and $38 \%$ respectively for PEs and PEEF. In this case, a significant difference still evident for the PEs (Tukey's HSD; $p<0.001$ ) and a highly significant for the PEEF (Tukey's HSD; $p<0.001$ ) compared to the control. After 6 days, more larvae of $P$. xylostella were dead and a significant difference was observed between treatments $\left(F_{2,27}=27.44, \mathrm{p}<0.001\right)$. The overall mortality after ingestion of the PEs and PEEF reached $28 \%$ and $38 \%$, respectively, much higher than the mortality rate induced by contact toxicity. After incubation, all surviving pupae hatched and gave healthy adults. There was no mortality of larvae fed on control leaf discs. 


\subsection{Effect of the PEEF on the feeding behavior of the $1^{\text {st, }} 2^{\text {nd }}$ and $3^{\text {rd }}$ instar larvae}

In this choice test, a significant difference was observed between treatments few hours after the set-up of the experiment $\left(F_{2,33}=126.79, \mathrm{p}<0.001\right.$; Figure 3a). At 1 hour after release, $55 \%$ of the $1^{\text {st }}$ instar larvae chose to feed on the control leaf discs. Only $10.5 \%$ of the larvae were found on the leaf discs treated with PEEF. These results were significantly different from the control (Tukey's HSD; $p<0.001$ ). After 8 hours, more larvae moved from the PEEF treated leaf discs to feed on the control leaves which led to the decrease of the larval presence on PEEF discs to $11.11 \%$. After $12 \mathrm{~h}$, the $1^{\text {st }}$ instar larvae of $P$. xylostella showed a clear feeding preference to the control leaf discs simply dipped in water (Tukey's HSD; $p<0.001$ ) and only $10.55 \%$ of larvae were recorded in the PEEF treatment.

The second instar of $P$. xylostella significantly preferred the control leaf discs after $1 \mathrm{~h}$ compared to the PEEF treated leaves (Tukey's HSD; $\mathrm{p}<0.001$; Figure $3 \mathrm{~b}$ ). We recorded 44.44\% larvae feeding on control leaf discs against $24.5 \%$ present on the leaves dipped in PEEF. After $8 \mathrm{~h}$, this difference between treatments became larger $\left(F_{2,33}=109.96, p<0.001\right)$, where $50 \%$ of larvae avoided settling on the PEEF treated discs and chose to feed on the control leaves (Tukey's HSD; $p<0.001$ ). Only $13.88 \%$ were observed on PEEF based treatment. After $12 \mathrm{~h}$, the larval presence increased steadily to reach $69.44 \%$ on the control leaf discs and showed consequently a highly significant difference in comparison with the PEEF treated discs (Tukey's HSD; $p<0.001$ ). We observed also a small increase of the larval number on bioinsecticide treated discs to $18 \%$.

In contrast to the early larval stages, the $3^{\text {rd }}$ instar larvae of $P$. xylostella did not show any preference to any treatment during the bioassay (Figure 3c). After 1 hour, $31.66 \%$ of $3^{\text {rd }}$ instar larvae were feeding on the control cabbage discs while about $30 \%$ on the discs dipped in PEEF. There was no statistical difference between the two treatments (Tukey's HSD; $p=0.70$ ). After $8 \mathrm{~h}$, the PEEF leaf application did not affect the feeding behavior of larvae. The ones that did not make a choice during the previous hours tended to be homogenously distributed between the two treatments. Subsequently, no significant difference was observed (Tukey's HSD; $\mathrm{p}=0.06$ ). After $12 \mathrm{~h}$, the $3^{\text {rd }}$ instar larvae of $P$. xylostella fed freely on both treatments without showing any feeding preference: $46.66 \%$ larvae were recorded on the control discs while $41.11 \%$ observed on PEEF treated leaves. There was no statistical difference between the two treatments (Tukey's HSD; $p=0.39$ ). 


\subsection{Anti-feedant effect of the PEEF, the stem bark extract and the leaf extract}

Under in vitro conditions, Jatropha-based extracts affected significantly the larval weight of $P$. xylostella after feeding on cabbage leaves $\left(F_{3,44}=4.84, p<0.05\right)$. In comparison with the control, larvae fed on leaf discs dipped in $0.75 \%$ PEEF had a significantly lower weight than the control (Tukey's HSD; $p<0.05$ ). The leaf extract applied on cabbage leaves affected also the weight of larvae after feeding (Tukey's HSD; $p<0.05$ ), while no effect of the stem bark extract was observed on larval growth (Tukey's HSD; $p>0.05$ ). After 4 days of feeding, the highest larval weight was observed in the control treatment where larvae reached a weight of $4.12 \pm 0.09 \mathrm{mg}$. The PEEF and the leaf extract treatments showed a clear suppressive effect on larvae which weighed respectively $3.53 \pm 0.13 \mathrm{mg}$ and $3.57 \pm 0.12 \mathrm{mg}$.

As a consequence for being underfed, the pupal weight of $P$. xylostella was slightly affected. It was significantly different among treatments $\left(F_{3,44}=4.90, \mathrm{p}<0.01\right)$. We observed a significant difference of the pupal weight after feeding on $0.75 \%$ of PEEF (Tukey's HSD; $p<0.05$ ) and $2 \%$ of leaf extract (Tukey's HSD; $p<0.05$ ) compared to the control. The stem bark showed no significant effect on the pupal weight (Tukey's HSD; p>0.05). In in vitro conditions, the leaf area consumed during 4 days was significantly different between treatments $\left(F_{3,44}=16.75, \mathrm{p}<0.001\right)$. The cabbage leaf discs treated with PEEF were less consumed than the control leaves (Tukey's HSD; $p<0.001$ ). The leaf extract showed also a significant protective effect when applied on the leaf surface in comparison with the control (Tukey's HSD; $p<0.05$ ). In this case larvae consumed $3.92 \pm 0.12 \mathrm{~cm}^{2}$ while $4.51 \pm 0.09 \mathrm{~cm}^{2}$ of the leaf area was damaged in the control treatment. The stem bark extract of $J$. curcas did not show any effect on the feeding voracity of $P$. xylostella. The larvae consumed $4.64 \pm 0.14$ $\mathrm{cm}^{2}$ of the leaf area which was not significantly different from the control (Tukey's HSD; $p=0.91)$.

Under greenhouse conditions, Jatropha-based extracts did not show the same efficacy as it was observed under laboratory conditions. Despite the statistical difference between treatments after 4 days of feeding $\left(F_{3,44}=3.03, p<0.05\right)$, no effect was observed on the larval weight after feeding on plants treated with the leaf extract (Tukey's HSD; $p>0.05$ ). After 4 days of feeding, the larval weight reached $4.22 \pm 0.06 \mathrm{mg}$ for larvae fed on leaf extract treated plants and $4.30 \pm 0.12 \mathrm{mg}$ for larvae fed on control cabbage plants. A statistical difference was however evident of the weight of larvae fed on PEEF treated plants (Tukey's 
HSD; $p<0.05)$, while no significant difference was observed for the stem bark treatment (Tukey's HSD; p>0.05).

Consequently, the pupal weight of $P$. xylostella was significantly different between treatments $\left(F_{3,44}=4.42, \mathrm{p}<0.01\right)$. The weight of pupae was affected by the PEEF treatment (Tukey's HSD; $p<0.05$ ) but not by feeding on leaves treated with leaf extract (Tukey's HSD; $\mathrm{p}=0.97$ ) of $J$. curcas. In continuation with the previous results, the consumed leaf area during 4 days was significantly different between treatments $\left(F_{3,44}=10.77, \mathrm{p}<0.001\right)$. The PEEF induced the highest protective effect for the leaf surface (Tukey's HSD; $p<0.001$ ). In this treatment, the larvae fed on $3.96 \pm 0.10 \mathrm{~cm}^{2}$ of the leaf surface. Although obviously less damaged compared to the control, the stem bark extract showed no significant inhibitory effect on the feeding performance of the larvae (Tukey's HSD; p>0.05). In contrast to the laboratory experiment, the leaf extract did not show any protective effect of the leaf surface when applied in greenhouse conditions (Tukey's HSD; $p>0.05$ ). In this case, the larvae damaged $4.65 \pm 0.14 \mathrm{~cm}^{2}$ of the cabbage leaf surface during 4 days from the set-up of the bioassay.

\section{Discussion}

\subsection{Contact toxicity of PEs and PEEF}

The toxicity of oily compounds on $P$. xylostella has already been studied by Ratnadass et al. (2012) and Kumrungsee et al. (2014). However, the toxicity of the oil of J. curcas in particular was rarely investigated. According to our findings, the PEs caused a low mortality, when topically applied on the cuticle of the $2^{\text {nd }}$ instar larvae of $P$. xylostella. However, the PEEF extract, mainly containing purified phorbol esters, caused a moderate mortality. Except the bioassays conducted by Wink et al. (1997), the toxicity of the PEs of J. curcas on the diamondback moth has not been so far reported. Wink et al. (1997) reported a mortality rate of 33\% after 6 days when using the topical application of PEs. These results were supported by our experiment where the morality rate reached $26 \%$ after 6 days given a topical application of $2 \%$ of PEEF. Although no mortality was observed in our bioassay beyond 6 days after topical application, Wink et al. (1997) stated an increasing mortality to $60 \%$ after 13 days, which was not shown by our bioassay. The topical application of PEs and especially PEEF caused the larvae to become uncoordinated and convulsive. The dead larvae showed a necrotic cuticle with dark spots. These symptoms proved the cuticle irritating 
effect of the tested compounds (Devappa et al., 2010b) resulting in the damage of the integrity of cuticular waxes (Buteler et al., 2011).

\subsection{Ingestion toxicity of PEs and PEEF}

The mortality caused by the ingestion of PEs and PEEF reached $28 \%$ and $38 \%$, respectively. The PEs fraction was described as the most toxic compound contained in J. curcas (Goel et al., 2007). The mortality of Lepidopteran larvae after administration of PEs based compound has been firstly reported by the study of Ratnadass et al. (2009). It attested an ingestion toxicity of PEs on all larval instars of the cotton bollworm Helicoverpa armigera (Lepidoptera: Noctuidae), after treating the artificial diet with acetonic solution of PEs. Moreover, Devappa et al. (2012) reported a moderate ingestion toxicity of PEs and PEEF on the fall armyworm Spodoptera frugiperda (Lepidoptera: Noctuidae), similar to our results on P. xylostella. This study showed a weak mortality rate that reached $40 \%$ after feeding on corn leaves treated with PEEF based extracts. The PEs are analogues of diacylglycerol, an activator of protein kinase C (PKC). PKCs act as regulators of many metabolic processes. As diacylglycerol has a short biological half-life in the cell, the activation of PKC is temporary. However, the activation of PKCs by PEs, is much extended, which subsequently disrupts a number of cell process and leads to the cell exhaustion (Kumar et al., 2012). Devappa et al. (2011a) reported also that some Phorbol-type compounds (e.g. Jatropherol-1) increased the PKC activity of midgut silkworm Bombyx mori (Lepidoptera: Bombycidae), coupled with modifications in the function of several midgut enzymes and pathological alterations in midgut epithelial cells (Jing et al., 2005).

\subsection{Effect of the PEEF on the feeding behavior of the $1^{\text {st, }} 2^{\text {nd }}$ and $3^{\text {rd }}$ instar larvae}

The data obtained from our bioassays clearly supported the fact that terpenoids such as phorbol esters are strong antifeedant/deterrent compounds against herbivores (Luo et al., 2012). Several types of diterpenes (based on a 20-carbon skeleton) including phorbol esters were illustrated for affecting feeding behavior of insects and acting as gustatory deterrents (Devappa et al., 2011b). The effect of PEEF on the $1^{\text {st }}$ and $2^{\text {nd }}$ instar of $P$. xylostella complied with the definition of deterrents advanced by Isman (1997). In our study, the PEEF acted as a behavior modifying substance that deterred feeding through a direct action on peripheral sensilla of larvae. This effect was perceived a short time after larvae came in contact with the applied compound (Isman, 2006). 
The deterrence of larvae of $P$. xylostella after exposure to plant based products was shown in several studies. Shinoda et al. (2002) reported that the larvae of P. xylostella rejected the cabbage leaf discs treated with a triterpenoid saponin extracted from crucifer plant (Barbarea vulgaris). Also, Purwatiningsih et al. (2012) illustrated a larval deterrent effect after feeding on broccoli leaves treated with lemon-scented tea tree oil (Leptospermum petersonii). Moreover, Perera et al. (2000) and Liang et al. (2003) investigated the antifeedant properties of neem based products and found a high antifeedant/deterrent effect on larvae of $P$. xylostella. Concerning the PEEF, its deterrent effect was investigated by Devappa et al. (2012) on the fall armyworm Spodoptera frigiperda (Lepidoptera: Noctuidae). The results showed that the dietary intake by S. frugiperda was severely affected when fed on corn leaves treated with the PEEF.

In contrast with the 2 first instars, the PEEF did not show any deterrence on the $3^{\text {rd }}$ instar and cabbage leaf discs were completely palatable by larvae. In fact, the old stages of P. xylostella are known to be resistant to insecticidal treatments (Gong et al., 2013). The results of the study showed that the old larvae were obviously able to overcome the toxic effect of phorbol esters. The only known metabolic mechanism that could help larvae to feed on PEEF is the sequestration of toxic metabolites. Nishida et al. (2002) reported that some lepidopteran larvae sequester plant toxins during the larval stage and discard a large portion or all of the sequestrates when molting to a pupa or an adult.

Although its high toxicity on a wide range of insects, J. curcas is subject in the nature to herbivores infestation. Lama et al. (2015) drew-up the inventory of the pests of the physic nut tree and found 44\% Hemiptera, 14\% Coleoptera and 13\% Lepidoptera, with mainly sucking and chewing insects. Moreover, Wink et al. (2000) reported the high ability of the aposematically coloured bug Pachycoris klugii (Heteroptera: Scutelleridae) to feed on J. curcas. The HPLC analysis of the hemolymph of this pest showed the presence of phorbol esters in the adults and old larval stages compared to eggs and neonates which suggested that old stages were more tolerant to PEs, as found in our study on P. xylostella.

The only study related to the sequestration of phorbol esters by Lepidoptera was reported by Marsh et al. (1984): Larvae of the spurge hawk moth (Hyles euphorbiae) feed on highly toxic Euphorbia plants and sequester cytotoxic ingenane diterpene esters. However, Hundsdoerfer (2005) showed that these larvae did not sequester the ingested phorbol esters since no accumulation of this toxin was found in the hemolymph and the teguments. 
Contrary, the phorbol esters were mostly metabolized (about 70-90 \%) and detoxified in the larval gut.

\subsection{Anti-feedant effect of the PEEF, the stem bark extract and the leaf extract}

The PEEF and the leaf extract of $J$. curcas showed an antifeedant effect on the $2^{\text {nd }}$ instar larvae of $P$. xylostella in in vitro conditions. After 5 days of feeding on treated leaves, a clear inhibitory effect on the larval growth and the leaf consumption was observed. The screening for biocompounds from J. curcas by Blessing et al. (2011) showed the presence of high amounts of tannins, flavonoids, alkaloids and saponins; less present in the stem bark extract which could explained its inefficacy.

Tannins are typically defined as water-soluble phenolic compounds and proteinbinding agents (Rossi et al., 2004) in aqueous solutions (Salminen et al., 2011). It was conventionally hypothesized that tannins decreased the digestion of proteins in insects and subsequently the growth performances (Barbehenn et al., 2009a). The supposed digestionreducing activity of tannins was ascribed to their capacity for precipitating the dietary proteins in the digestive tract (Barbehenn et al., 2011) when high amounts of tannins were admixed to the insect food (Juntheikki, 2000). However, recent studies did not prove the effect of tannins on protein utilization when pure hydrolysable tannins and condensed tannins were administrated with tree leaves to the caterpillars of the gypsy moth Lymantria dispar (Lepidoptera: Erebidae) (Barbehenn et al., 2009a).

Plants contain a variety of flavonoids that could influence insect behavior (Simmonds, 2003). Flavonoids are widely distributed in plants and known to be implied in resistance against pests attacks (Ohmura et al., 2000). Flavonoids could modify insect feeding, fitness and development. Simmonds (2003) reported the antifeedant activity of some flavonoids and their related compounds on different Lepidopteran species including the African cotton leafworm Spodoptera littoralis (Noctuidae), the Black armyworm Spodoptera exempta (Noctuidae) and the tobacco Hornworm Manduca sexta (Sphingidae). Moreover, Ohmura et al. (2000) showed an antiffedant effect of flavonoid derived compound on the subterranean termite Coptotermes formosanus (isoptera: Rhinotermitidae). This ingestion of this compound might be also implied in the antifeedant effect against the larvae of $P$. xylostella in vitro.

The antifeedant effect of Saponins on Lepidoptera was reported by Dowd et al. (2011) on the corn earworm Helicoverpa zea (Lepidoptera: Noctuidae) and the fall armyworm 
Spodoptera frugiperda (Lepidoptera: Noctuidae). The screening showed that the larval response to saponins was concentration dependent and each compound triggered a specific antifeedant effect on larvae. De Geyter et al. (2007) reported also that the larvae of Spodoptera littoralis (Lepidoptera: Noctuidae) showed a strong inhibition of the larval growth after feeding on diet mixed with saponins. This phytocompound caused a low larval weight and an important delay in term of development time as seen on P. xylostella. Agrell et al. (2003) reported also that S. littoralis avoided feeding on alfalfa leaves damaged since 5 to 7 days due to the high amounts of saponins contained in leaves tissues.

Alkaloids have been shown to be strong antifeedants against Lepidopteran species (Isman, 1997) and could be involved in the low larval growth of $P$. xylostella. Kathuria et al. (2005) reported that alkaloids extracted from the leaves of Indian Ipecac plant Tylophora indica (Asclepiadaceae) and river red gum tree Eucalyptus camaldulensis (Myrtaceae) caused a dose-dependent feeding inhibition on the $5^{\text {th }}$ instar larvae of the cotton bollworm Helicoverpa armigera (Lepidoptera: Noctuidae). Moreover, Shields et al. (2008) showed a high sensitivity of the gypsy moth larvae to 9 alkaloids. The two-choice feeding assay revealed an increase in feeding deterrence (decrease in consumption) with increasing concentration of alkaloid tested after exposing the $5^{\text {th }}$ instar larvae to red oak treated leaf disks.

The aqueous leaf extract of J. curcas has not been so far reported for its antifeedant effect on insects, in particular on the diamondback moth. However, Bullangpoti et al. (2012) stated that the leaf extract of J. gosspifolia caused mortality when topically applied on the fall armyworm Spodoptera frugiperda (Lepidoptera: Noctuidae) and decreased food intakes after being mixed with artificial diet. This study revealed also that the larval weight and the length of the biological cycle were highly impacted. Bullangpoti et al. (2012) showed also that the extract from the senescent leaves of J. gosspifolia inhibited detoxification enzymes including P450, general esterase and acetylcholinesterase activities, necessary to metabolize phytotoxic compounds.

In our bioassay, The PEEF of J. curcas acted as strong antifeedant compound against the larvae of $P$. xylostella in in vitro bioassays and under greenhouse conditions. This extract has been reported by Devappa et al. (2012) for its effect on the feeding behavior and growth of $S$. frugiperda after exposure to a range of PEEF concentrations. In contrast with PEEF which is an oily based compound, the water based leaf extract of J. curcas was rapidly 
vaporized after application on the leaf surface. Moreover, the hydrophobicity of cabbage leaves might be another factor that explained the failure of the leaf extract in the greenhouse. Following application, the adaxial leaf surface was not perfectly coated with the extract. Subsequently, the clip-caged larvae detected the non-treated areas, make a hole on the leaves and move to the abaxial face where they feed superficially on the epidermis.

\section{Conclusion}

This study showed many aspects of the insecticidal properties of J. curcas on the diamondback moth P. xylostella. The investigation of the killing effect of the PEs and PEEF revealed a slight efficacy after topical and ingestion treatment. The PEs caused low mortality when topically applied on the cuticle or ingested by larvae of P. xylostella whereas the PEEF caused a moderate toxicity.

The PEEF and the leaf extract of $J$. curcas showed an antifeedant effect on the $2^{\text {nd }}$ instar larvae of $P$. xylostella in in vitro conditions. The study supported the hypothesis that PEEF are strong deterrent compounds against herbivores. The supposed digestion-reducing activity of this compound was ascribed to the PEs diterpenoid fraction affecting the digestion of dietary nutrients when admixed to the insect food. PEEF was suggested to cause either a primary antifeedant effect (deterrence) by rejection of food, after short perception by taste gustatory receptors, or secondary antifeedant effect (post-ingestion).

Although having a wide spectrum of insecticidal aspects, the compounds of J. curcas were not frequently investigated. The killing and antifeedant properties of $J$. curcas could be valorized in the management of $P$. xylostella in Brassicaceae crops. The seed oil and the PES extracted from J. curcas seeds could be promising alternative compounds to synthetic chemicals for the control of the diamondback moth. However, more toxicological studies and environmental assessments must be carried out to explore the side effects that these compounds could engender before their registration in crop protection. 


\section{References}

Agrell J., Oleszek W., Stochmal A., Olsen M., Anderson P. 2003. Herbivore-induced responses in Alfalfa (Medicago sativa). Journal of Chemical Ecology, 29: 303-320.

Amit S., Thompson G., Downard P. 2001. Challenges in implementing spinosad Diamondback Moth resistance management strategies in intensive vegetable growing areas in Asia, pp. 313-318. In Endersby, N. M., and Ridland, P. M. (eds.), the Management of Diamondback Moth and Other Crucifer Pests. Proceeding of the Fourth International Workshop, 26-29.

Barbehenn R.V., Jaros A., Lee G., Mozola C., Weir Q., Salminen J.P. 2009a. Tree resistance to Lymantria dispar caterpillars: importance and limitations of foliar tannin composition. Oecologia. 159: 777-788.

Barbehenn R.V., Constabel C. P. 2011. Review: Tannins in plant-herbivore interactions. Phytochemistry, 72: 1551-1565.

Blessing A.N., Agbagwa O.I., Okoli B.E. 2011. Comparative phytochemical screening of Jatropha L. species in the Niger Delta. Research Journal of Photochemistry, 5:107-114.

Bullangpoti V., Wajnberg E., Audant P., Feyereisen R. 2012. Antifeedant activity of Jatropha gossypifolia and Melia azedarach senescent leaf extracts on Spodoptera frugiperda (Lepidoptera: Noctuidae) and their potential use as synergists. Pest Management Science, 68: 1255-1264.

Buteler M., Stadler T. 2011. A Review on the mode of action and current use of petroleum distilled spray oils. Pesticides in the Modern World - Pesticides Use and Management, ISBN: 978-953-307-459-7.

Cabi, 2016. Data sheet Plutella xylostella (Diamondback Moth) http://www.cabi.org/isc/datasheet/42318

Canola Council of Canada, 2014. Diamondback moth. Canola Encyclopedia., Canada: Canola Council of Canada. http://www.canolacouncil.org/canolaencyclopedia/insects/diamondback-moth/\#fnote14

De Geyter E., Lambert E., Geelen D., Smagghe G. 2007. Novel advances with plant saponins as natural insecticides to control pest insects. Pest Technology, 1: 96-105.

Devappa R.K., Angulo-Escalante Miguel A., Makkar H.P.S., Becker K. 2012. Potential of using phorbol esters as an insecticide against Spodoptera frugiperda. Industrial Crops and Products, 38: 50- 53.

Devappa R.K., Maes J., Makkar H.P.S., De Greyt W., Becker K. 2010a. Quality of biodiesel prepared from phorbol ester extracted Jatropha curcas. Journal of American Oil Chemist's Society, 87: 697-704. 
Devappa R.K., Makkar H.P.S., Becker K. 2010b. Jatropha toxicity: a review. Journal of Toxicology and Environmental Health, 13: 476-507.

Devappa R.K., Makkar H.P.S., Becker K. 2011a. Jatropha Diterpenes: a Review. Journal of the American Oil Chemists' Society, 88: 301-322.

Devappa R.K., Rajesh S.K., Kumar V., Makkar H.P.S., Becker K. 2011b. Activities of Jatropha curcas phorbol esters in various bioassays. Ecotoxicology and Environmental Safety, 78: 5762.

Dowd P.F., Berhow M.A., Johnson E.T. 2011. Differential Activity of multiple saponins against omnivorous insects with varying feeding preferences. Journal of Chemical Ecology, 37:443-449.

Furlong M. J., Wright D.J., Dosdall L. M. 2013. Diamondback Moth ecology and management: problems, progress, and prospects. Annual Review of Entomology, 58:517-41.

Goel G., Makkar H., Francis G., Becker K. 2007. Phorbol esters: structure, biological activity, and toxicity in animals. International Journal of Toxicology, 26:279-88.

Gong Y.J, Wang Z.H., Shi B.C., Kang Z.J., Zhu L., Jin G.H., Wei S.J. 2013. Correlation between pesticide resistance and enzyme activity in the diamondback moth, Plutella xylostella. Journal of Insect Science, 13:135.

Gübitz G.M., Mittelbach, M., Trabi, M. 1999. Exploitation of the tropical oil seed plant Jatropha curcas L. Bioresource Technology, 67: 73-82.

Hundsdoerfer A.K., Tshibangu J. N., Wetterauer B., Wink M. 2005. Sequestration of phorbol esters by aposematic larvae of Hyles euphorbiae (Lepidoptera: Sphingidae)? Chemoecology, 15:261-267.

Isman M. 1997. Insect antifeedant. Pesticide Outlook. The Royal Society of Chemistry, 4: 152-157

Isman M. 2006. Botanical insecticides, deterrents and repellents in modern agriculture and increasingly regulated world. Annual Review of Entomology,51: 45-66.

Jing L., Fang Y., Ying X., Wenxing H., Meng X., Syed M. N., Fang C. 2005. Toxic impact of ingested Jatropherol-I on selected enzymatic activities and the ultrastructure of midgut cells in silkworm, Bombyx mori L. Journal of Applied Entomology, 129: 98-104.

Juntheikki, M.-R., Julkunen-Tiitto, R., 2000. Inhibition of $\beta$-glucosidase and esterase by tannins from Betula, Salix, and Pinus species. Journal of Chemical Ecology, 26: 1151-1165.

Kathuria V., Kaushik N. 2005. Feeding inhibition of Helicoverpa armigera (Hübner) by Eucalyptus camaldulensis and Tylophora indica extracts. Insect Science, 12 : 249-254 . 
Kfir, R. 1998. Origin of the Diamondback Moth (Lepidoptera: Plutellidae). Annals of Entomological Society of America, 91: 164-167.

Koul O., Walia S., Dhaliwal G.S. 2008. Essential oils as green pesticides: potential and constraints. Biopesticides International, 4: 63-84.

Kumar G.R.K., Bapat V.A., Johnson T. S. 2012. Phorbol esters and other toxic constituents of Jatropha curcas L. Challenges for a New Energy Crop. Farming, Economics and Biofuel, 1: 441-460.

Kumrungsee N., Pluempanupat W., Koul O., Bullangpoti V. 2014. Toxicity of essential oil compounds against Diamondback Moth, Plutella xylostella, and their impact on detoxification enzyme activities Journal of Pest Science, 87:721-729.

Lama A. D., Vuorisalo T., Niemelä P. 2015. Global patterns of arthropod herbivory on an invasive plant, the physic nut (Jatropha curcas L.). Journal of Applied Entomology, 139: 1-10.

Liang G.M., Chen W., Liu T.X. 2003. Effects of three neem-based insecticides on Diamondback Moth (Lepidoptera: Plutellidae). Crop Protection, 22: 333-340.

Luo S.H., Hua J., Li C.H., Jing S.X., Liu Y., Li X.N. Zhao X., Li S.H. 2012. New antifeedant C20 terpenoids from Leucosceptrum canum. American Chemical Society. Organic Letters, 14: 5768-5771.

Marsh N., Rothschild M. 1984. A new look at Lepidoptera toxins. In The Biology of Butterflies. 135-139

Nadeem A., Ansari M.S., Nazrussalam. 2012. Effect of neemarin on life table indices of Plutella xylostella (L.). Crop Protection, 38: 7-14.

Nishida R. 2002. Sequestration of defensive substances from plants by Lepidoptera. Annual review of Entomology, 47:57-92.

Ohmura W., Doi S., Aoyama M., Ohara S. 2000. Antifeedant activity of flavonoids and related compounds against the subterranean termite Coptotermes formosanus Shiraki. Journal of Wood Science, 46:149-153.

Perera D.R., Armstrong G., Senanayake N., 2000. Effect of antifeedants on the diamondback moth (Plutella xylostella) and its parasitoid Cotesia plutellae. Pest Management Science, 56:486-490.

Pichon A., Arvanitakis L., Roux O., Kirk A.A., Alauzet C., Bord D. 2006. Genetic differentiation among various populations of the diamondback moth, Plutella xylostella (Lepidoptera: Yponomeutidae). Bulletin of Entomological Research, 96:137-144.

Purwatiningsih, Heather N., Hassan E. 2012. Efficacy of Leptospermum petersonii oil, on Plutella xylostella, and its Parasitoid, Trichogramma pretiosum. Horticultural entomology. Journal of Economic Entomology, 105:1379-1384. 
R Development Core Team .2008. R: A language and environment for statistical computing. R Foundation for Statistical Computing, Vienna, Austria. ISBN 3-900051-07-0, URL http://www.R-project.org

Ratnadass A., Togola M., Cissé B., Vassal J.M. 2009. Potential of sorghum and physic nut (Jatropha curcas) for management of plant bugs (Hemiptera: Miridae) and cotton bollworm (Helicoverpa armigera) on cotton in an assisted trap-cropping strategy. Journal of semi-arid tropical research, 7, 7p

Ratnadass A., Wink M. 2012. The Phorbol Ester Fraction from Jatropha curcas seed oil: Potential and limits for crop protection against insect pests. International Journal of Molecular sciences, 13:16157-16171.

Rossi A.M., Stiling P., Moon D.C., Cattell M.V., Drake B.G. 2004. Induced defensive response of myrtle oak to foliar insect herbivory in ambient and elevated $\mathrm{CO}_{2}$. Journal of Chemical Ecology, 30: 1143-1151.

Salminen J.P., Karone M. 2011. Evolutionary ecology of plant defenses: Chemical ecology of tannins and other phenolics: we need a change in approach. Functional Ecology, 25: 325338.

Sarfraz M., Keddie A.B., Dosdall L.M. 2005. Biological control of the Diamondback Moth, Plutella xylostella: a review. Biocontrol Science and Technology, 15: 763-789.

Simmonds M.S.J. 2003. Review: Flavonoid-insect interactions: recent advances in our knowledge. Phytochemistry, 64:21-30.

Shelton A.M, Nault B.A. 2004. Dead-end trap cropping: a technique to improve management of the diamondback moth, Plutella xylostella (Lepidoptera: Plutellidae). Crop Protection, 23:497-503.

Shields V.D.C., Smith K. P., Arnold N.S., Gordon I.M., Shaw T. E., Waranch D. 2008. The effect of varying alkaloid concentrations on the feeding behavior of gypsy moth larvae, Lymantria dispar (L.) (Lepidoptera: Lymantriidae). Arthropod-Plant Interactions, 2:101-107.

Shinoda T., Nagao T., Nakayama M., Serizawa H., Koshioka M. Okabe H., Kawal A. 2002. Identification of a triterpenoid saponin from a crucifer Barbarea vulgaris, as a feeding deterrent to the Diamond back Moth, Plutella xylostella. Journal of Chemical Ecology, 28: 587-599.

Talekar N.S., Shelton A.M. 1993. Biology, ecology and management of the diamondback moth. Annual Reviews of Entomology, 38: 275-301.

Wink M., Grimm C., Koschmieder C., Sporer F., Bergeot O., 2000. Sequestration of phorbol esters by the aposematically coloured bug Pachycoris klugii (Heteroptera: Scutelleridae) feeding on Jatropha curcas (Euphorbiaceae). Chemoecology, 10: 179-184. 
Wink M., Koschhmider C., Sauerwein M., Sporer F. 1997. Phorbol Esters of Jatropha curcasBiological activities and potential applications. Biofuels and industrial products from $J$. curcas, 160-166.

Wurdack KJ. 2008. Molecular evolution and phylogenetics of Euphorbiaceae: Beyond the model organisms. Plant and Animal Genomes XVI Conference San Diego, CA. http://www.intl-pag.org/16/abstracts/PAG16_W21_155.html. 


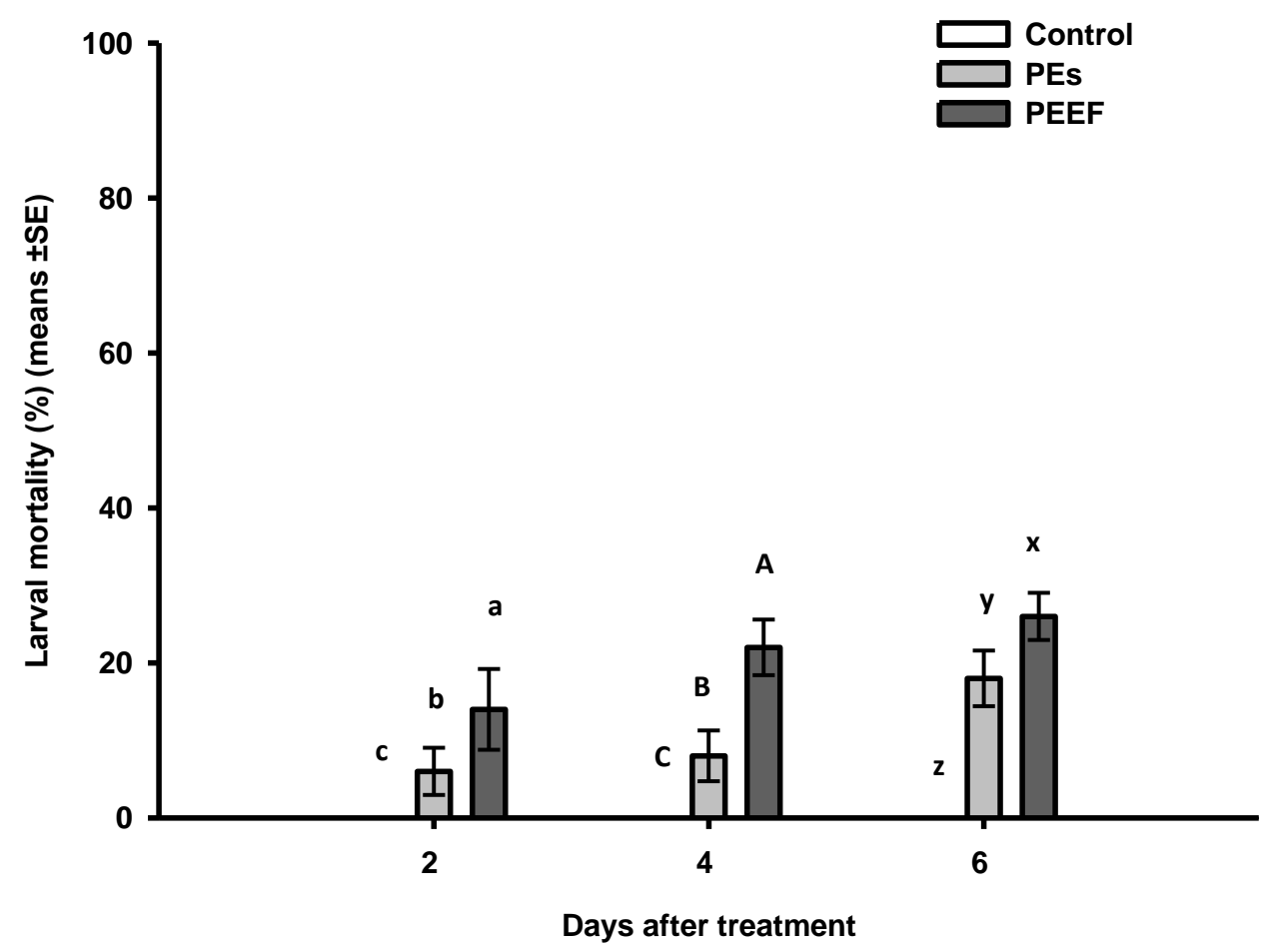

Figure 1: Topical toxicity of $2 \%$ of Phorbol Esters (PEs) and 2\% of Phorbol Esters Enriched Fraction (PEEF) on $2^{\text {nd }}$ instar larvae of $P$. xylostella. There was no mortality in the control group of larvae. Bars denoted within the same group with different letters are significantly different (All Pairwise Multiple Comparison Procedures Tukey's test, $p<0.05$ ).

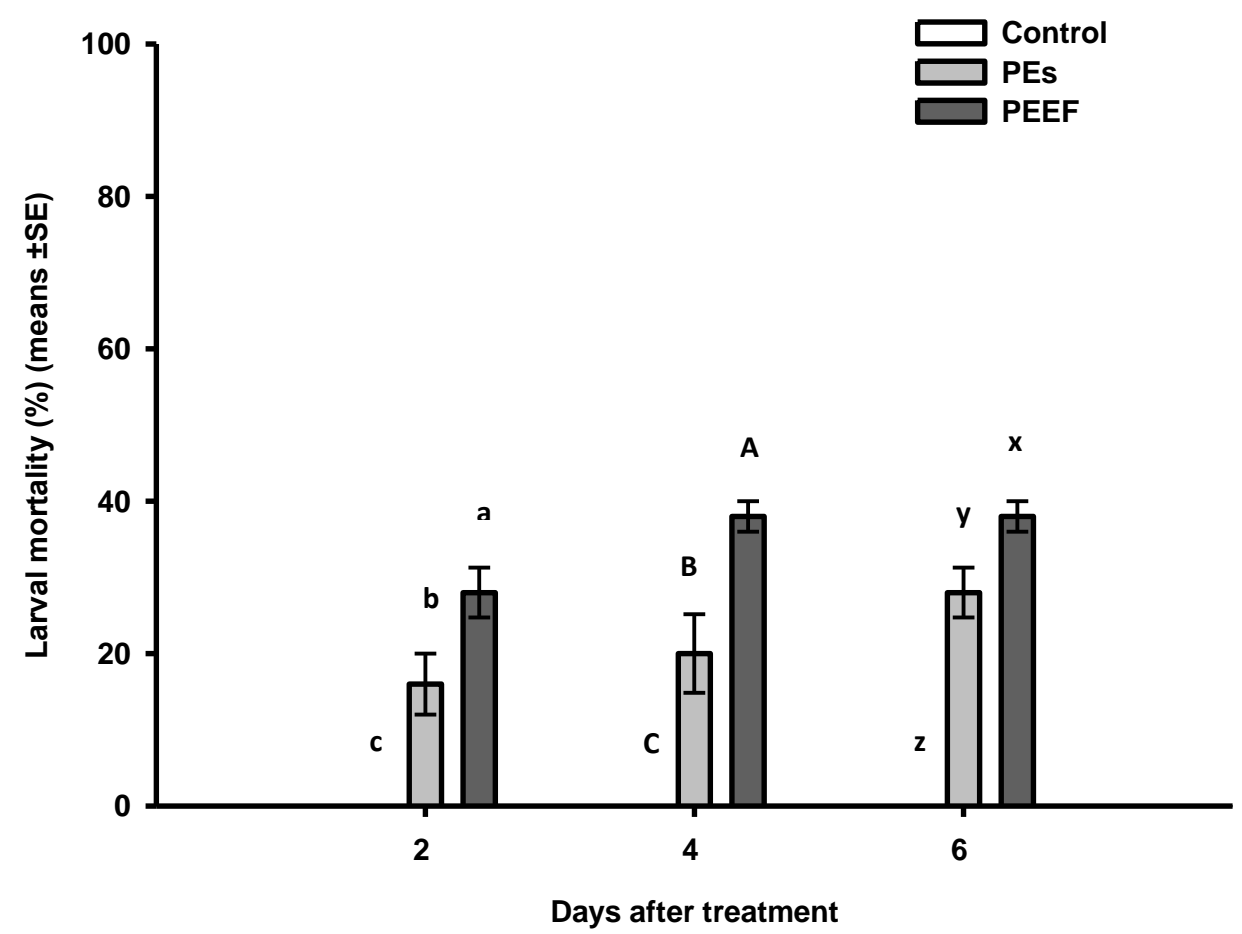

Figure 2: Ingestion toxicity of 2\% Phorbol Esters (PEs) and 2\% of Phorbol Esters Enriched Fraction (PEEF) on neonates larvae of $P$. xylostella. There was no mortality in the control group of larvae. Bars denoted within the same group with different letters are significantly different (All Pairwise Multiple Comparison Procedures Tukey's test, $p<0.05$ ). 


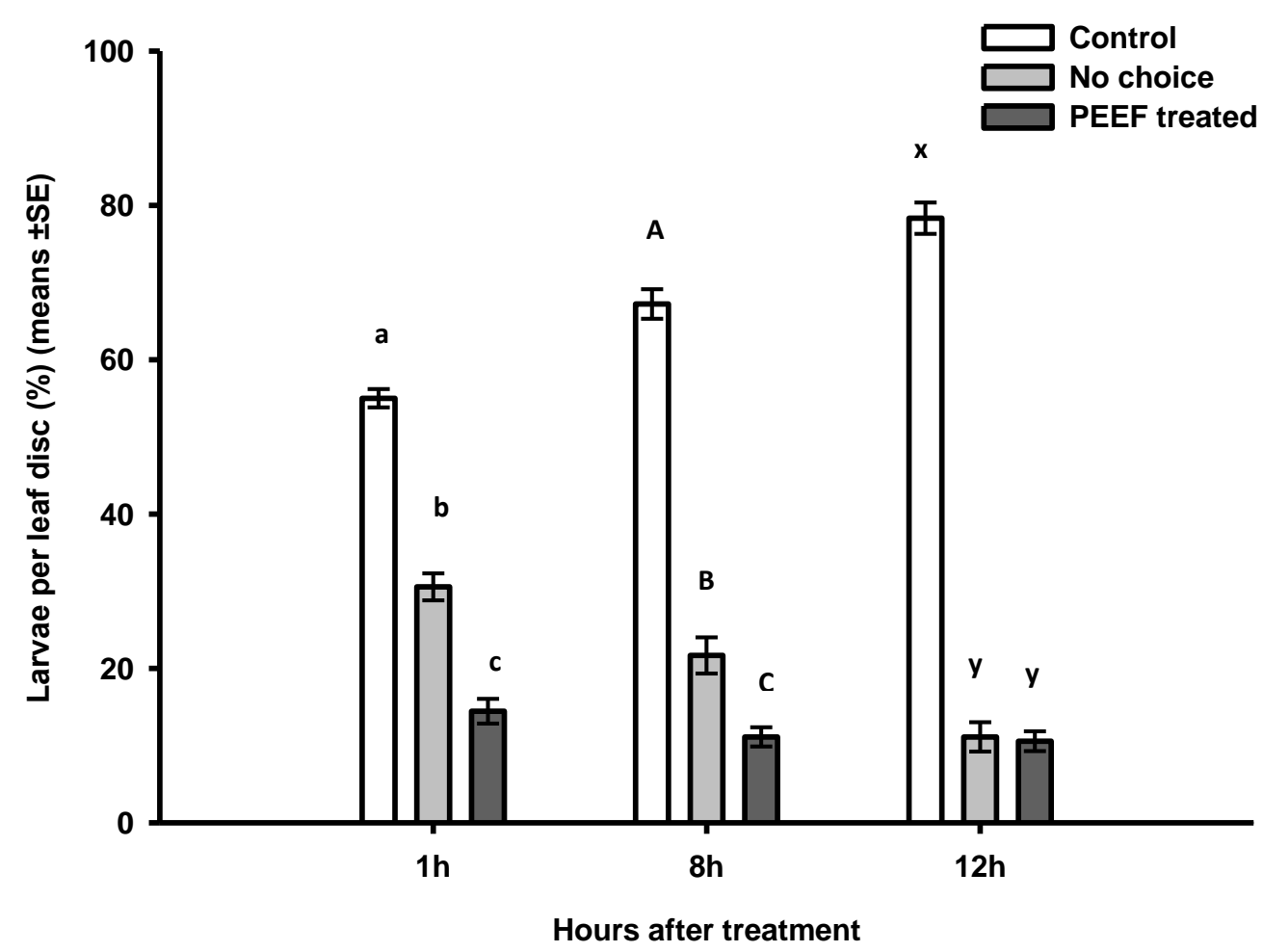

Figure 3a: Effect of $2 \%$ of PEEF on the feeding behavior of the $1^{\text {st }}$ instar larvae of $P$. xylostella Bars denoted within the same group with different letters are significantly different (All Pairwise Multiple Comparison Procedures Tukey's test, $p<0.05$ ).

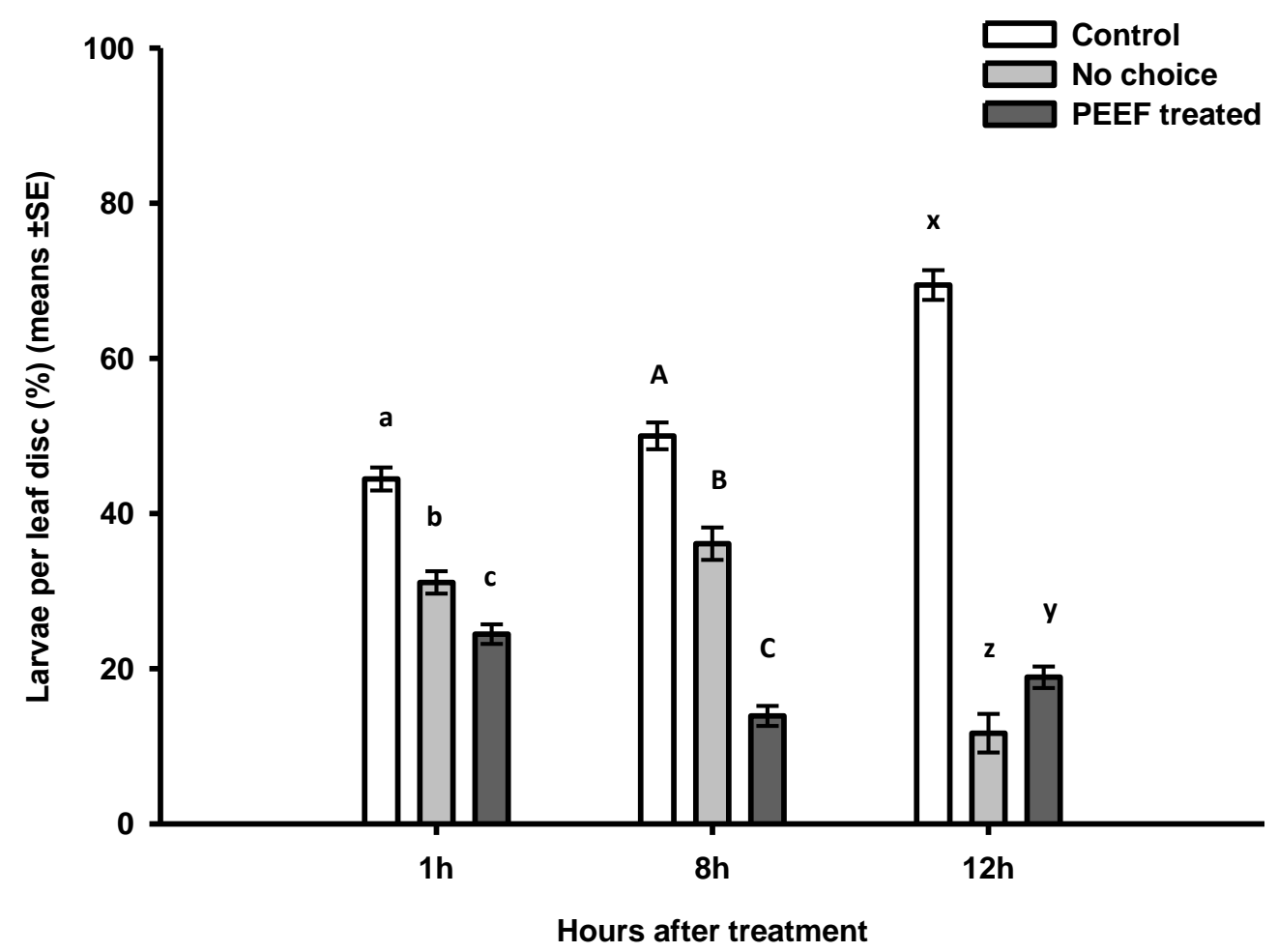

Figure 3b: Effect of $2 \%$ of PEEF on the feeding behavior of the $2^{\text {nd }}$ instar larvae of $P$. xylostella. Bars denoted within the same group with different letters are significantly different (All Pairwise Multiple Comparison Procedures Tukey's test, $p<0.05$ ). 


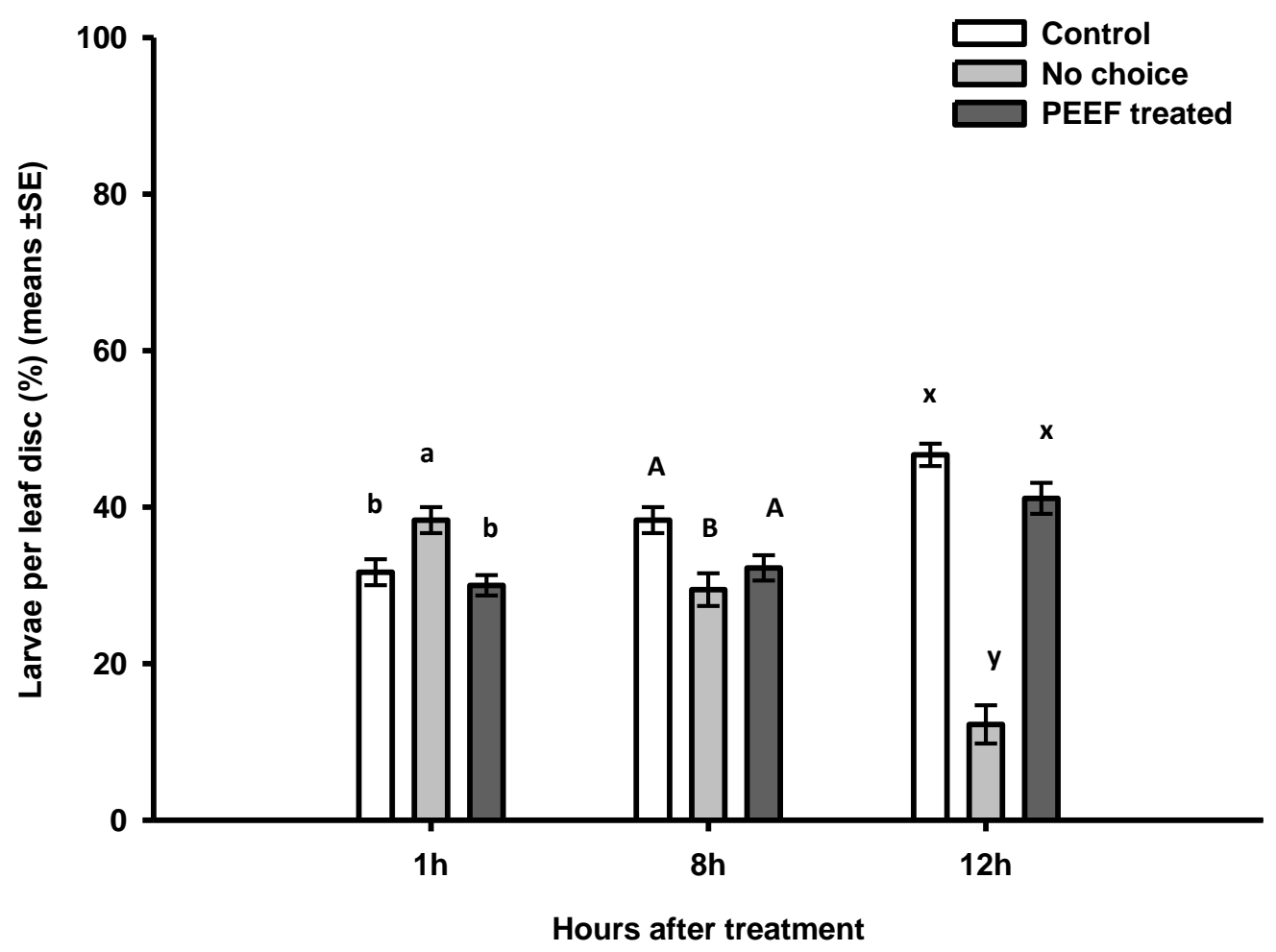

Figure 3c: Effect of $2 \%$ of PEEF on the feeding behavior of the $3^{\text {rd }}$ instar larvae of P. xylostella. Bars denoted within the same group with different letters are significantly different (All Pairwise Multiple Comparison Procedures Tukey's test, $p<0.05$ ) 


\section{Chapter 4}

\section{Efficacy of some botanical extracts from the physic nut tree Jatropha curcas in the control of the cabbage root fly Delia radicum (CRF) (Diptera: Anthomyiidae).}

\section{Summary}

Botanical insecticides have been long used as safe alternatives to synthetic chemicals for pest management. In this study, we assessed the insecticidal effect of the seed oil of Jatropha curcas (SOi) and the Phorbol Ester Enriched Fraction (PEEF) on the root feeding insect the Cabbage Root Fly Delia radicum (CRF) (Diptera: Anthomyiidae).

The ovicidal tests on D. radicum were carried out in Petri dishes. The method consisted of exposing 12 freshly laid eggs divided on 12 Petri dishes to 3 different concentrations of PEEF [0.5\% (V/V), 1.25\% (V/V) and 2\% (V/V)] and SOi [0.5\% (V/V), 1.25\% (V/V) and 2\% (V/V)] in two separated bioassays. Petri dish were sealed with parafilm and kept in dark phase in a climatic chamber at $22 \pm 1{ }^{\circ} \mathrm{C}$ and $60 \% \mathrm{RH}$. During incubation, the Petri dishes were daily observed under binocular and the embryos development was recorded. At the end of the bioassays, the number of eggs that failed to hatch after exposure to $1.25 \%$ and $2 \%$ of PEEF was significantly higher than the control (Tukey's HSD; $p<0.001$ ). A concentration of $0.5 \%$ did not induce any ovicidal effect (Tukey's HSD; $p=0.18$ ). The same inefficacy was observed after treatment with $0.5 \%$ of seed oil. However, a clear ovicidal effect was observed after exposure to $1.25 \%$ and $2 \%$ of SOi compared to the control (Tukey's HSD; $p<0.001$ ).

The larvicidal effects of the PEEF and the SOi were tested on the neonate larvae of $D$. radicum. In this case, neonates were transferred in groups of 12 larvae to the surface of 12 turnip pieces as a food substrate already treated with Jatropha extracts. For that, one day before infestation with larvae, the pieces of turnip were dipped overnight in a Beaker filled with different solutions of PEEF $[0.5 \%(\mathrm{~V} / \mathrm{V}), 1.25 \%(\mathrm{~V} / \mathrm{V}), 2 \%(\mathrm{~V} / \mathrm{V})]$ and SOi $[0.5 \%(\mathrm{~V} / \mathrm{V})$, $1.25 \%(V / V), 2 \%(V / V)]$ and covered with an aluminum paper. After infestation, the pieces of turnip were placed in white boxes and covered with $2 \mathrm{~cm}$ height sterile sand. After 4 th week, the sand of all treatments was sieved and the pupae were collected to deduce the pupation rate per treatment. The highest toxic effect was observed after feeding, during the larval stage, on turnip pieces treated with $2 \%$ of PEEF (Tukey's HSD; $p<0.001$ ). The ingestion of $0.5 \%$ of PEEF did not affect the pupation success. In this treatment, no significant difference 
to the control was detected (Tukey's HSD; $p=0.27$ ). After feeding on the turnip treated with seed oil, the pupation success of larvae was not significantly reduced in the bioassays $\left(F_{3,44}=\right.$ $2.84, p>0.05$ ). Feeding on $2 \%$ of the seed oil during the larval stage reduced the pupation success of larvae to $10.33 \pm 0.48$ pupae $(86.11 \%)$ pupae per box (Tukey's HSD; $>>0.05$ ).

Under greenhouse conditions, cabbage plants were infested with 8 eggs of $D$. radicum. Eggs were carefully placed a few millimeters above the soil surface on the stem base of each cabbage plant and covered with some sand. After infestation, plants were drenched 2 times ( 1 day after infestation and 10 days after infestation) with $15 \mathrm{ml}$ of PEEF applied around the stem base. There were 4 different treatments: the control plants neither infested nor treated, control plants infested but not treated, plants treated with $1.5 \%$ of PEEF and plants treated with $2 \%$ of PEEF. We observed that drenching the soil with a concentration of $2 \%$ of PEEF reduced significantly the number of pupae in comparison with the control (Tukey's HSD; $p<0.001$ ). The roots of cabbage plants treated with $2 \%$ of PEEF were less damaged by the feeding activity of larvae and had significantly higher weight than the infested but not treated cabbage plants (Tukey's HSD; $p<0.001$ ).

Keywords: Jatropha curcas, Delia radicum, Phorbol Esters Enriched Fraction, toxic seed oil, insecticide, root feeding insect. 


\section{Introduction}

During the early years of use in crop protection, pesticides were considered to be generally safe with limited threats for health and environment. However, the intensive use of chemical insecticides and the rapid progress of agricultural techniques have led some major related issues to appear (Casida et al., 1998). Pest resistance, ecological impacts and lasting health perils made it necessary to assess, review and frame the inappropriate use of these insecticides (Aktar et al., 2009). These new concerns motivated the investigations into alternative pest control compounds to overcome or relatively reduce the repercussions generated by synthetic insecticides. Plant derived insecticide is regarded an alternative that could be investigated and applied in pest control programs (Isman, 2006).

Botanical insecticides have been long used as ecologically safe alternatives to synthetic chemicals for pest management. They are renewable, degradable in the environment and relatively safe to natural enemies, non-target organisms and human beings. Plants produce a range of chemical compounds to prevent attack by herbivores. Several extracts of plants have been evaluated for their activity against agriculturally important insects and being evaluated further for use in plant protection (Koul et al., 2009). Such chemicals are secondary plant metabolites which include alkaloids, flavonoid and terpenoids.

The physic nut tree J. curcas possesses pesticidal properties. Several studies showed that extracts from J. curcas can be integrated in the management practices of agricultural pests (Acda et al., 2009; Devappa et al., 2012; Ratnadass et al., 2012). The main insecticidal effect of this plant was ascribed to the phorbol esters, a diterpenoid fraction contained mainly in the seed oil (Devappa et al., 2011). Extracts of the physic nut tree has been tested on a variety of insect species belonging to different orders: Hemiptera; Lepidoptera, Coleoptera, Diptera Orthoptera, Thysanoptera (Ratnadass et al., 2012). Extracts that were studied and showed biological activity against insect pests of crops were mainly oil extracts, particularly phorbol esters tested on sap-sucking, leaf-chewing and root-feeding insects.

Root feeders are defined as insects feeding on belowground plant tissues during some part of their life cycle (usually as nymphs or larvae) including species feeding on root crowns (Blossey et al., 2003). Root herbivores may disturb plant life cycle, affect the plant fitness and disrupt the food webs. Such a destructive root feeder is the cabbage root fly Delia radicum associated with Brassicaceae plants. The cabbage root fly Delia radicum (CRF) 
is a pest of economic importance in cruciferous crops in North America and Europe (Bruck et al., 2005). The economic losses due to root fly damage in these regions have been estimated to $\$ 100$ million in some years (Shuhang et al., 2016). Seedlings not protected by insecticides are often severely damaged by Delia pests. In some seasons, D. radicum infestations kill $90 \%$ of the plants in some untreated brassica crops in North America and mainland Europe (Finch, 1989). All pre-imaginal life stages including the 3 larval instars occur in the soil in the rhizosphere. After repairing the suitable host for oviposition, females lay eggs around the base of the cruciferous plants. After hatching, the larvae feed on the roots for about 3 to 4 weeks before pupating around the plant in the soil near to the surface. The number of generations of $D$. radicum depends upon climatic factors and there are usually three generations per year (Muška et al., 2008). The adults of the overwintered last generation emerge in April-May, and the $2^{\text {nd }}$ generation appears in late June to July (Finch, 1969). In Central Europe, the $3^{\text {rd }}$ generation occurs before the end of the summer before overwintering as pupa in the soil.

The first generation of cabbage maggot is considered to be the most noxious to rapeseed, and most of the Brassicaecae vegetables (Muška et al., 2008). In temperate zones root fly damage is important in spring and early summer (Griffiths et al., 1986, Soroka et al., 2011) when young plants and seedlings are infested by overwintered adult whereas in warmer climatic zones the root fly persists the whole year producing multiple overlapping generation throughout the year (Joseph et al., 2014). The newly hatched larvae of $D$. radicum feed superficially on the root before burrowing into the root tissues with the increasing food requirements. This feeding behavior interrupts gradually the absorption and assimilation of nutrients and may lead to the reduction of yield (Jensen et al., 2002). In spring, larval tunneling into the root system progressively weakens the plant and may cause the destruction of the seedlings (Fournet et al., 2000). Larvae can also affect the quality of root crops such as turnip, making them non-commerciable. Moreover, the feeding injuries are potential pathways for fungal infection which may result in growth retardation or even plant mortality (Shuhang et al., 2016).

Herbivores often cause extensive plant damages associated with secondary stress factors such as drought or grazing (Blossey et al., 2003). However, the crucial lack of data about belowground pest makes them usually difficult to control (Hunter, 2001; Blossey et al., 2003): they are hidden in the soil and therefore hard to detect and to reach (Kupferschmied 
et al., 2013). The present research is an attempt to search for alternative compounds to control root-feeding pests. It consists on the investigation of the insecticidal effect of $J$. curcas extracts on the pre-imaginal stages of the cabbage root fly under laboratory and greenhouse conditions. The main tested compounds are the Phorbol Esters Enriched Fraction (PEEF) and the seed oil (SOi). We addressed the following questions:

- Does the PEEF and the SOi have a toxic effect on the eggs of $D$. radicum in laboratory conditions?

- Does the ingestion of PEEF or SOi induce a larvicidal effect on the neonates of $D$. radicum?

- Is PEEF less effective under greenhouse conditions compared to laboratory conditions?

\section{Material and methods}

\subsection{Host plant}

Cabbage plants Brassica oleracea var. capitata L. (cultivar: "Furchenkohl"; Norddeutsche Pflanzenzucht Hans-Georg Lembke KG) was used as host for the toxicity assays on the cabbage root fly $D$. radicum. The cabbage plants were grown in plastic trays from seeds in a greenhouse chamber $\left(22 \pm 3^{\circ} \mathrm{C}\right.$ temperature, $60 \%$ relative humidity and $16 \mathrm{~L}$ : 8D photoperiod). After 10 days, seedlings were transplanted into $11 \mathrm{~cm}$ diameter pots filled with non-sterile soil (Fruhstorfer Erde Typ 25, Hawita Gruppe GmbH, Vechta, Germany, peat fine structure with volcanic clay, $\mathrm{pH}$ : 5.7-6.3, Fertilization of 200-300mg N) and sand mixture (3:1 volume). Plants were grown in the chamber, regularly irrigated and fertilized once a week (fertilizer: Hakaphos 2g/L (15\% N, 11\% P2O5, 15\% K2O, 1\% Mg, 0.1\% Fe, 0.1\% Mn, $0.04 \% \mathrm{Cu}, 0.025 \% \mathrm{~B}$ and $0.005 \% \mathrm{Mo}))$.

\subsection{Insect culture}

The cabbage root fly was obtained from a laboratory stock culture maintained in a climate rearing room $\left(21 \pm 1^{\circ} \mathrm{C}\right.$ temperature, $60 \pm 5 \%$ relative humidity and LD 16h: $8 \mathrm{~h}$ photoperiod). This laboratory rearing was established from flies originally provided by the JKI (Julius-Kühn-Institut, Braunschweig, Germany) in November 2003. Adult flies were detained in cubic screened cages $(30 \mathrm{~cm} \times 30 \mathrm{~cm} \times 30 \mathrm{~cm})$ and fed with artificial diet following the method of Finch et al. (1969) with some modifications: A cube of Kohlrabi (100 g) (Brassica oleracea var. gongylodes) was placed on a layer of washed quartz sand in a Petri dish to attract the females and stimulate the oviposition in the nearing sand. The sand was mixed 
with water and the eggs were collected by floating. The water containing the floating eggs was filtrated in a funnel through a filter paper then transferred to a fresh kohlrabi piece with a shallow cut-surface. The kohlrabi was covered with sand and placed for 3 weeks in white boxes $(18 \mathrm{~cm}$ length $\times 13 \mathrm{~cm}$ width $\times 5.5 \mathrm{~cm}$ height) until the pupation of larvae then pupae were collected by floating out of the sand. Two types of food were provided to the adults: dry powder and sticky honey. The powdery food was made of dextrose, organic skim milk powder, soy flour and brewer's yeast (10g:10g:1g:1g); the sticky honey was made of commercially available honey, soy flour and brewer's yeast $(5 \mathrm{~g}: 5 \mathrm{~g}: 1 \mathrm{~g})$. Adults were provided with water in a moistened filter paper.

\subsection{Jatropha bioinsecticides}

In this study, two different extracts of $J$. curcas were screened for their insecticidal effect: the seed oil (SOi) and the Phorbol Ester Enriched Fraction (PEEF). The oils were provided by the company of JatroSolutions $\mathrm{GmbH}$ (Stuttgart, Germany) where they have been extracted and purified following the method of Devappa et al. (2010a) then stocked in a cold room to be used in bioassays.

\subsection{Experimental bioassays}

\subsubsection{Ovicidal effect of the PEEF and the seed oil (SOi)}

This bioassay was conducted in in vitro conditions. Freshly laid eggs of $D$. radicum were collected by the floating method from a laboratory culture. The eggs were observed under binocular (Leica, Wild, M3Z, Wetzlar, Germany) to sort out the healthy eggs for the experiment. The bioassay consisted of 4 different treatments: The control group exposed to bidest water, the eggs exposed to $0.5 \%(\mathrm{~V} / \mathrm{V}), 1.25 \%(\mathrm{~V} / \mathrm{V})$ and $2 \%(\mathrm{~V} / \mathrm{V})$ of the PEEF. The toxicity test was done in Petri dishes $(5.5 \mathrm{~cm}$ diameter $\times 1.5 \mathrm{~cm}$ height) and consisted of exposing eggs of $D$. radicum to different compounds of Jatropha on a filter paper $(50 \mathrm{~mm}$ diameter, MN 615) (Macherey-Nagel GmbH, Düren, Germany) imbibed with one of the bioinsecticides (the seed oil and the PEEF). Eggs were carefully collected with camel brush, placed in each Petri dish then sealed with Parafilm $M^{\circledR}$ (Bemis Company, Inc., Neenah, USA) and kept in dark phase in a climatic chamber (WB 750 KFL; Mytron Bio-Und Solartechnik $\mathrm{GmbH}$, Germany) at $22 \pm 1 \circ \mathrm{C}$ and $60 \% \mathrm{RH}$. During incubation, the Petri dishes were daily observed under binocular and the development of embryos was recorded. The number of eggs that failed to hatch was recorded to assess the ovicidal effect of the compounds. The 
same methodology was followed and the same concentrations as the PEEF were tested to assess the toxicity of the seed oil on the eggs of $D$. radicum. Every treatment had 12 repetitions (Petri dishes) with 12 eggs and the experiment was done once.

\subsubsection{Larvicidal effect of the PEEF and the seed oil (SOi)}

Fresh laid eggs of $D$. radicum were placed in groups of 20 eggs in Petri dishes $(5.5 \mathrm{~cm}$ $x 1.5 \mathrm{~cm}$ ) lined with a moistened filter paper (50 mm diameter, MN 615) for hatching. The Petri dishes were sealed with Parafilm $\mathrm{M}^{\circledR}$ and incubated in dark phase in a climatic chamber at $22 \pm 1{ }^{\circ} \mathrm{C}$ and $60 \% \mathrm{RH}$. After hatching, filter papers were moistened with $500 \mu \mathrm{l}$ of sterile bidest water, the larvae were shortly flooded and gently collected with a pipette (Eppendorf AG, Hamburg, Germany). The neonates were transferred in groups of 12 larvae to the surface of turnip pieces already treated with Jatropha extracts. One day before inoculation with larvae, the pieces of turnip (Brassica napus subsp. Rapifera) were cut in cubes of $50 \mathrm{~g}$ weight and dipped overnight in a beaker $(200 \mathrm{ml})$ filled with different solutions of PEEF [(0.5\% (V/V), 1.25\%(V/V) and 2\%(V/V)] and SOi [(0.5\%(V/V), 1.25\%(V/V) and 2\%(V/V)] and covered with an aluminum paper. Some superficial crossing lines of $1 \mathrm{~cm}$ depth were made on the surface of turnip to facilitate the first food intakes of the neonate larvae of $D$. radicum. In the following day, the pieces were removed with forceps from the bioinsecticide solutions and left to dry for $30 \mathrm{mn}$ on sterile paper towels (TORK, Mannheim, Germany) in laboratory conditions before being infested with larvae.

After infestation, the pieces of turnip were placed in white boxes $(18 \mathrm{~cm}$ length $x$ $13 \mathrm{~cm}$ width $\times 5.5 \mathrm{~cm}$ height) on a $3 \mathrm{~cm}$ height layer of sand and covered again with $2 \mathrm{~cm}$ height sterile sand autoclaved at $120^{\circ} \mathrm{C}$. The boxes were placed in controlled room conditions ( $22 \pm 1{ }^{\circ} \mathrm{C}$ temperature, $16: 8 \mathrm{~h}(\mathrm{~L}$ : D) and $60 \% \mathrm{RH})$ and sprayed twice a week with sterile water to avoid turnip dryness. During the $4^{\text {th }}$ week after the set-up of the bioassay, the sand surface of the control treatment was stirred to check the presence of pupae which indicated the end of the experiment. The sand of all treatments was sieved and the pupae were collected and counted to deduce the pupation rate per treatment. Pupae were then individually incubated in a climatic chamber (WB 750 KFL; Mytron Bio-Und Solartechnik $\mathrm{GmbH}$, Germany) at $22 \pm 1{ }^{\circ} \mathrm{C}$ and $60 \% \mathrm{RH}$ to observe their emergence success. There were 4 different treatments per bioinsecticide; each treatment was replicated 12 times in a completely randomized design. 


\subsubsection{Insecticidal effect of PEEF under greenhouse conditions}

The objective of this experiment was to assess the efficacy of Jatropha compounds in semi-real agricultural conditions. For that, 4 weeks old cabbage plants grown in $11 \mathrm{~cm}$ pots were used in this bioassay. Plants were grown from seeds in soil (Fruhstorfer Erde Typ 25, Hawita Gruppe $\mathrm{GmbH}$, Vechta, Germany, peat fine structure with volcanic clay, pH: 5.7-6.3, Fertilization of $200-300 \mathrm{mg} \mathrm{N}$ ) and sand mixture (3:1 volume) as a growth substrate. Freshly laid eggs of $D$. radicum were collected from a stock colony and kept on a moistened filter paper at $22^{\circ} \mathrm{C}$. After 24 hours, healthy eggs were collected under binocular and used in this bioassay whereas the others were discarded.

In order to not expose the plants to a high larval feeding pressure, cabbage plants were infested with only 8 eggs. Eggs were carefully placed with a camel fine brush few millimeters above the soil surface on the stem base and covered with some sand. After infestation, plants were drenched 2 times ( 1 day after infestation and 10 days after infestation) with $15 \mathrm{ml}$ of PEEF applied around the stem base. There were 4 different treatments: the control plants neither infested nor treated, control plants infested but not treated, plants treated with $1.5 \%(\mathrm{~V} / \mathrm{V})$ of PEEF and plants treated with $2 \%(\mathrm{~V} / \mathrm{V})$ of PEEF. TWEEN $^{\circledR} 80$ was used as emulsifier. After 4 weeks of the experiment set-up, plants were harvested and the pupae were collected. The roots were washed under running water, the sand was twice filtered (sieve №4 (4.75 mm opening) and sieve №10 (2 mm opening)) and pupae were collected with forceps in labelled Petri dishes. Pupae were left to dry in Petri dishes (90 mm x $14.5 \mathrm{~mm}$ ) (Sarstedt, Aktiengesellschaft \& CO Nuembrecht, Germany) lined with a filter paper, counted then weighed and measured. Plants were oven dried at $60{ }^{\circ} \mathrm{C}$ (Model 30-106. Memmert GmbH + Co. KG, Schwabach, Germany) for one week to determine their biomass and assess damages. The experiment was conducted under greenhouse conditions ( $22 \pm 3^{\circ} \mathrm{C}$ temperature, $60 \%$ relative humidity and $16 \mathrm{~L}: 8 \mathrm{D}$ photoperiod) with 10 plants per treatment in a completely randomized design.

The pupae of the previous bioassay were incubated in white plastic box $(18 \mathrm{~cm}$ length $\times 13 \mathrm{~cm}$ width $\times 5.5 \mathrm{~cm}$ height) in a climatic chamber (WB $750 \mathrm{KFL}$; Mytron Bio-Und Solartechnik $\mathrm{GmbH}, \mathrm{Germany})$ at $22 \pm 1{ }^{\circ} \mathrm{C}$ and $60 \% \mathrm{RH}$. After recording the emergence rate, adults from the 3 treatments were released in 3 egg-laying cages $(30 \mathrm{~cm} \times 30 \mathrm{~cm} \times 30 \mathrm{~cm}$ ) and provided with two types of diet: dry powder and sticky honey. The powdery food was made of dextrose, organic skim milk powder, soy flour and brewer's yeast (10g:10g:1g:1g); 
the sticky honey was made of commercially available honey, soy flour and brewer's yeast (5g:5g:1g). Adults were provided with water in a reversed glass put upside down on a filter paper on the lid of a sterile Petri dish (90 mm x $14.5 \mathrm{~mm}$ ). As oviposition support, a cube of kohlrabi (100 g) (Brassica oleracea var. gongylodes) was placed on a layer of washed quartz sand in a Petri dish to attract the females and stimulate the oviposition in the nearing sand. After 5 days, the Petri dishes were removed, the sand was mixed with water and the eggs were collected by floating followed by filtration. The eggs were counted under a binocular (Leica, Wild, M3Z, Wetzlar, Germany) to determine the fecundity of females. This bioassay was conducted in a controlled conditions room at $22 \pm 1{ }^{\circ} \mathrm{C}, 16: 8 \mathrm{~h}(\mathrm{~L}: \mathrm{D})$ and $60 \% \mathrm{RH}$. There were 3 cages with 12 couples of $D$. radicum.

\subsection{Data analysis}

Statistical processing of results was carried out by standard methods using the statistical software R (v 3.0.2) (R Development Core Team, 2008). Prior to analysis, all data were tested for homogeneity of variance and normality. To detect the difference between treatments, we performed One-way analysis of variance (ANOVA). If significant differences between groups were detected, means were compared by performing Tukey's test at $\alpha=$ 0.05. The mortality of insects after treatment with the extracts of J. curcas (seed oil, PEEF or PEs) was analyzed using generalized linear models (GLM) taking account of the binomial distribution of the data (alive or dead). To correct the anomalies in data variation (overdispersion / underdispersion), we proceeded to the quasi-binomial distribution error in data analysis. Thereafter, Tukey's test at $\alpha=0.05$ was employed to detect differences between means.

\section{Results}

\subsection{Ovicidal effect of the PEEF and the seed oil (SOi)}

The exposure of the eggs of $D$. radicum to PEEF showed a significant difference between concentrations in term of hatching rate $\left(F_{3,44}=31.47, \mathrm{p}<0.001\right.$; Figure $\left.1 \mathrm{a}\right)$. Many eggs significantly failed to hatch after being treated with $2 \%$ of PEEF in in vitro conditions (Tukey's HSD; $p<0.001$ ). In the control treatment and after exposure to $2 \%$ of PEEF hatched respectively $11.16 \pm 0.27$ eggs (93.05\%) and $6.33 \pm 0.33$ eggs (52.77\%) after incubation. The treatment with $1.25 \%$ of PEEF reduced the eggs hatchability to $8.33 \pm 0.39$ eggs (69.44\%) which was significantly different from the control (Tukey's HSD; $p<0.001$ ). A Concentration 
as low as $0.5 \%$ of PEEF did not induce any potent ovicidal activity (Tukey's HSD; $p=0.18$ ). We recorded 10.25 (85.41\%) hatching eggs. A correlation was evident between the eggs hatchability and the concentration ( $R=0.81, d f=46, p<0.001$, Pearson correlation).

The seed oil of J. curcas caused a significantly different mortality between treatments $\left(F_{3,44}=22.01, \mathrm{p}<0.001 ;\right.$ Figure $\left.1 b\right)$. At a concentration of $2 \%, 5.83 \pm 0.48$ eggs (48.61\%) hatched which is significantly lower than the control where it reached $10.5 \pm 0.28$ eggs (87.5\%) (Tukey's HSD; p 0.001). Egg mortality was concentration dependent. The toxic effect became lower after exposure to a concentration of $1.25 \%$. In this case, we observed a moderate ovicidal effect of the seed oil but it was still effective compared to the control (Tukey's HSD; $p<0.001$ ). The treatment of eggs with $1.25 \%$ of the seed oil of J. curcas reduced their hatchability to $7.58 \pm 0.49$ eggs (63.19\%) among the 12 eggs initially exposed to the bioinsecticide. In comparison with the control, no significant effect was observed at $0.5 \%$ of seed oil on the eggs. We recorded a hatching rate of $9.75 \pm 0.31$ eggs (81.25\%). Also, no correlation was detected between the rate of hatching failure and the concentration of the seed oil ( $R=0.02, d f=46, p=0.87$, Pearson correlation).

\subsection{Larvicidal effect of the PEEF and the seed oil (SOi)}

The pupation rate induced by the ingestion of PEEF differed significantly between treatments $\left(F_{3,44}=36.05, p<0.001\right.$; Figure 2a). The highest toxic effect was observed after feeding, during the larval stage, on turnip pieces treated with $2 \%$ of PEEF (Tukey's HSD; $\mathrm{p}<0.001)$. This concentration reduced the pupation to $5.66 \pm 0.37$ pupae $(47.22 \%)$ which was much lower than the control treatment recording $11.25 \pm 0.35$ (93.75\%) of pupated larvae. Only $7.83 \pm 0.45$ larvae (65.27\%) fed on $1.25 \%$ of PEEF reached the pupal stage. The ingestion of $0.5 \%$ of PEEF did not affect the larval survival and the pupation success. In this treatment, no significant difference to the control was detected (Tukey's HSD; $p=0.27$ ).

Pupation rates were higher after treatment with seed oil in comparison with PEEF. After feeding on the turnip treated with seed oil, the pupation success of larvae was not significantly reduced in the bioassays $\left(F_{3,44}=2.84, p=0.058\right.$; Figure $\left.2 b\right)$. After ingestion of $2 \%$ of seed oil, the statistical analysis showed a non-significant difference with the control. Feeding on $2 \%$ of the seed oil during the larval stage reduced the pupation success of larvae to $10.33 \pm 0.41$ (86.11\%) pupae per box (Tukey's HSD; $p=0.065$ ). There was also no significant difference in the number of pupae when larvae develop on turnip treated with $1.25 \%$ of seed oil. We collected $10.5 \pm 0.28$ pupae out of the 12 larvae initially released on the pieces 
of turnip (Tukey's HSD; $p=0.11$ ). Moreover, larvae fed on $0.5 \%$ of seed oil were not affected in comparison with the control and 11.08 (92.36\%) pupae were collected from the sand.

\subsection{Insecticidal effect of PEEF on $D$. radicum under greenhouse conditions}

Pupation rates of $D$. radicum differed significantly between treatments $\left(F_{2,27}=161.5\right.$, $\mathrm{p}<0.001)$. The PEEF showed a high inhibitory effect of the pupation of the cabbage root fly under greenhouse conditions (Figure 3a). Drenching the soil with a concentration of $2 \%$ of PEEF reduced significantly the number of pupae in comparison with the control (Tukey's HSD; $p<0.001)$. We collected in the control and the PEEF treatment respectively $7.6 \pm 0.16$ pupae (95\%) and $2.9 \pm 0.23$ pupae (36.25\%).

When applied on the soil surface on the base of cabbage plants, the concentrations of $1.5 \%$ affected the egg hatching and/or larval development and led to a significant decrease of the pupation rate (Tukey's HSD; $p<0.001$ ). At this concentration, only $4.7 \pm 0.15$ pupae $(58.75 \%)$ out of the 8 eggs, initially used for plant infestation, pupated. The statistical analysis showed also no significant difference in the pupal weight of males $\left(F_{2,67}=0.70\right.$, $\mathrm{p}=0.49)$ and females pupae $\left(F_{2,67}=1.53, \mathrm{p}=0.22\right)$ between treatments. After incubation in the climatic chamber, only one pupa collected from cabbage plants treated with $2 \%$ of PEEF did not emerge. The fecundity of females was not affected by this Jatropha compound. The number of eggs laid in every egg laying cage was similar to the control (Tukey's HSD; $p>0.05)$, collected by floating from the sand used as oviposition substrate.

The root dry weight of the cabbage plants was significantly different between treatments $\left(F_{3,36}=93.88, \mathrm{p}<0.001 ;\right.$ Figure $\left.3 \mathrm{~b}\right)$. The roots of infested non-treated plants were heavily damaged by the feeding activity of the larvae and had significantly lower weight than the cabbage plants treated with $2 \%$ of PEEF (Tukey's HSD; $p<0.001$ ). The soil application of a concentration of $1.5 \%$ of PEEF protected significantly roots from the larval damages in comparison with the control (Tukey's HSD; $p<0.01$ ) but showed lower efficacy than drenching the soil with $2 \%$ of PEEF (Tukey's HSD; $p<0.01$ ). No significant difference was observed between root dry weight of the cabbage plants treated with $2 \%$ of PEEF and noninfested cabbage plants (Tukey's HSD; $p=0.60$ ). 


\section{Discussion}

\subsection{Ovicidal effect of the PEEF and the seed oil (SOi)}

The PEEF and the seed oil of J. curcas showed toxicity on the eggs of $D$. radicum in in vitro conditions. The eggs treated with high concentrations of these compounds developed normally until the $3^{\text {rd }}$ day before they started to turn brown. The eggs that showed a change in color did not hatch. Plant oils have been reported for their ovicidal effect on different insect species. Tripathi et al. (2003) obtained 99.5\% reduction in egg hatching after applying the essential oil of the bael tree Aegle marmelos on the eggs of Spilosoma obliqua (Lepidoptera: Erebidae). Malarvannan et al. (2009) showed that the oil of Clausena dentata had a high ovicidal effect when topically applied on the eggs of the cotton bollworm Helicoverpa armigera (Lepidoptera: Noctuidae).

Some plant oils have been reported for their ovicidal effect on Dipteran species such as D. radicum. Prowse et al. (2006) reported that the garlic juice concentrate caused significant mortality in eggs and adults of Delia radicum and Musca domestica. Kumar et al. (2013) revealed also a high potential of the essential oil of Cymbopogon citratus (Poales: Poaceae) in controlling house flies. Furthermore, Govindarajan et al. (2011) showed a strong ovicidal effect of Caesalpinia pulcherrima (Fabales: Fabaceae) extract at a concentration of $5.0 \mathrm{mg} / \mathrm{cm}^{2}$ on the eggs of Culex quinquefasciatus, Aedes aegypti and Anopheles stephensi (Diptera: Culicidae).

The ovicidal effect of $J$. curcas has been reported by few studies. Agboka et al. (2009) showed a high toxicity of the seed oil on the eggs of the maize cob borer Mussidia nigrivenella (Lepidoptera: Pyralidae). As shown by our study, their findings showed also concentration dependent toxicity with $L_{50}$ of $1.3 \%$ of the seed oil of $J$. curcas. Moreover, Khani et al. (2012) revealed significant reductions in egg hatchability after treatment of the eggs of the rice meal moth Corcyra cephalonica (Lepidoptera: Pyralidae) with petroleum ether extract of J. curcas. In this case, the reduction of hatchability reached $58 \%$ after mixing rice with $2 \mu \mathrm{L} / \mathrm{mL}$ petroleum ether extract of seed oil. Buteler et al. (2011) suggested that oils induced the eggs mortality by suffocation. Essential oils create a thin layer on the surface of eggs and stop the gas exchanges. They might also cause hardness in eggs which make it difficult for larvae to hatch. 


\subsection{Larvicidal effect of the PEEF and the seed oil (SOi)}

The PEEF induced a reduction of the pupation rate of the larvae of $D$. radicum after feeding on a concentration of $2 \%$ of PEEF. This effect was not observed after feeding on the pieces of turnip treated with the seed oil of J. curcas. It was suggested that the toxic effect of PEEF was generated by the combined toxicity induced by the pure PEs fraction and the fatty acids complex contained in the extract. Devappa et al. (2013) reported that among its richness with highly purified PEs, the PEEF contained also an amount of fatty acids such as palmitic, palmitoleic, stearic, oleic and alpha-linoleic acid, which was not the case of the seed oil containing low amounts of PEs.

The ingestion toxicity of PEs has been reported by few studies. The larval toxicity after ingestion of PEs rich compounds has been first mentioned by Ratnadass et al. (2009) on the cotton bollworm Helicoverpa armigera (Lepidoptera: Noctuidae). They reported a significant toxicity of PEs by feeding bioassays on all larval instars, after treating the artificial diet with acetonic solution of this compound. In addition, Devappa et al. (2012) observed an ingestion toxicity of PEEF on the fall armyworm Spodoptera frugiperda (Lepidoptera: Noctuidae) after feeding on corn leaves dipped in a solution containing $0.25 \mathrm{mg} / \mathrm{ml}$ of PEs. In our study, the moderate toxicity of the PEs has been already shown on the diamondback moth P. xylostella after feeding on cabbage leaf discs treated with PEEF.

Fatty acids have been also reported for their insecticidal effect. Ramos-López et al. (2012) showed that linolenic and linoleic acids purified from the castor-oil plant (Ricinus communis), and also highly present in the oil of J. curcas, exhibited insectistatic and insecticidal activities against Spodoptera frugiperda. Moreover, Mat Sarip et al. (2016) showed that in addition to its contact toxicity on Aphis gossypii, the ingestion of lauric acid present also in the seed oil of J. curcas, could also affect insect's growth and induce mortality. Also, Pérez-Gutiérrez et al. (2011) found that oleic, palmitic and stearic acids extracted from Papaya (Carica papaya) were toxic to the fall armyworm Spodoptera frugiperda (Lepidoptera: Noctuidae) when admixed to the artificial diet of this pest and caused the pest starvation leading to death.

\subsection{Insecticidal effect of PEEF under greenhouse conditions on $D$. radicum}

PEEF was efficient under greenhouse conditions at $2 \%$ concentration. As it was observed in in vitro conditions, the number of larvae that reached the pupal stage was significantly reduced after treating the soil with this compound. In relation with the previous 
results, this decrease of survival could occur during the larval stage when feeding on PEEF treated roots or earlier during the egg development phase. The PEEF has been proved by Devappa et al. (2012) to cause an antifeedant effect on the third instar larvae of the fall armyworm Spodoptera frugiperda (Lepidoptera: Noctuidae). It was also shown in our study that this compound induced an antifeedant / deterrent effect on the diamondback moth $P$. xylostella (Lepidoptera: Plutellidae) and led either to mortality by starvation or formation of small pupae. However, in this bioassay the pupal weight of $D$. radicum was not affected after feeding during the larval stage on PEEF. This suggested that PEEF did not have a long time efficacy when mixed to the soil and larvae could feed normally on roots.

Devappa et al. (2010b) and Roach et al. (2012) studied the biodegradation of PEs with different approaches and demonstrated that the shelf-time of this compound was widely dependent on the soil characteristics and the bioassay conditions (temperature, moisture or light). Devappa et al. (2010b) showed also that the seed cake of J. curcas was rapidly degraded in non-autoclaved than in autoclaved soil, which suggested that the soil fauna played a major role in the degradation process. In addition, Najjar et al. (2014) showed that PEs of J. curcas were completely degraded by Trichoderma spp., a genus of fungi communally present in agricultural soils, Paecilomyces sp. and Cladosporium sp.. and concluded that these fungi were potential microbes for the detoxification of PEs.

Devappa et al. (2010b) demonstrated by HPLC analysis that the PEs in soil were completely degraded after 9 days at a temperature of $32^{\circ} \mathrm{C}$ and 12 days at $23^{\circ} \mathrm{C}$. In our case, giving that the PEEF was applied twice on the $1^{\text {st }}$ and the $10^{\text {th }}$ day of the bioassay, this was not sufficient to cover the whole biological cycle of $D$. radicum lasting about 30 days. Because of its short shelf-time, the application of PEEF under greenhouse conditions would cover only 20 days of the life cycle of $D$. radicum before being completely degraded. It was hypothesized that at the end of the bioassay, PEEF lost its antifeedant property and allowed the aged surviving larvae to feed on roots and reach a normal pupal weight. Subsequently, the plant growth was not affected because the feeding activity occurred tardily when the root system was well developed and tolerate the damages caused by the larvae of $D$. radicum. Also, it was supposed that the mortality of immature stages occurred at the egg and early larval stages when the PEEF was still effective. 


\section{Conclusion}

This study showed the potential effect of $J$. curcas as a plant derived insecticide on root-feeding insects. The PEEF and the seed oil of J. curcas showed toxicity on the eggs of $D$. radicum in in vitro conditions. Essential oils create a thin layer on the surface of eggs surface and stops the gas exchanges. They might also cause hardness in eggs which make it difficult for larvae to hatch. The PEEF induced also a reduction of the pupation rate of the larvae of D. radicum after feeding on a concentration of $2 \%$ of PEEF. These extracts from J. curcas induced a killing effect depending on the concentration of PEs. The corn root worm showed more tolerance to the compounds of J. curcas. These results showed that the extracts of $J$. curcas in particular the PEEF could be used at a certain extend as an alternative to chemical insecticides. The limited longevity of these extracts might be enhanced by association with other plant protection agents that could have an additive or synergetic activity when mixed with these compounds. 


\section{References}

Acda M.N. 2009. Toxicity, tunneling and feeding behavior of the termite, Coptotermes vastator, in sand treated with oil of the physic nut, Jatropha curcas. Journal of Insect Science, 9: 1-8.

Agboka K., Mawufe A.K, Tamo M., Vidal S. 2009. Effects of plant extracts and oil emulsions on the maize cob borer Mussidia nigrivenella (Lepidoptera: Pyralidae) in laboratory and field experiments. International Journal of Tropical Insect Science, 29:185-19.

Aktar M.W., Sengupta D., Chowdhury A. 2009. Impact of pesticides use in agriculture: their benefits and hazards. Interdisciplinary Toxicology, 2: 1-12.

Blossey B., Hunt-Joshi T.R. 2003. Belowground herbivory by insects: Influence on plants and aboveground herbivores. Annual review of Entomology, 48:521-47.

Bruck D.J., Snelling J.E., Dreves A.J., Jaronski S.T. 2005. Laboratory bioassays of entomopathogenic fungi for control of Delia radicum (L.) larvae. Journal of Invertebrate Pathology, 89: 179-183.

Buteler M., Stadler T. 2011. A review on the mode of action and current use of petroleum Distilled Spray Oils. Pesticides in the Modern World - Pesticides Use and Management, ISBN: 978-953-307-459-7.

Casida J.E., Quistad G.B. 1998. Golden age of insecticide research: Past, Present, or Future? Annual Review of Entomology, 43:1-16.

Devappa R., Angulo-Escalante Miguel A., Makkar H.P.S., Becker K. 2012. Potential of using phorbol esters as an insecticide against Spodoptera frugiperda. Industrial Crops and Products, 38: 50- 53.

Devappa R., Maes J., Makkar H.P.S., De Greyt W., Becker K. 2010a. Quality of biodiesel prepared from phorbol ester extracted Jatropha curcas. Journal of American Oil Chemist's Society, 87:697-704.

Devappa R., Makkar H.P.S., Becker K. 2010b. Biodegradation of Jatropha curcas phorbol esters in soil. Science of Food and Agriculture, 90: 2090-2097.

Devappa R., Makkar H.P.S., Becker K. 2011. Jatropha Diterpenes: a Review. Journal of the American Oil Chemists' Society, 88: 301-322.

Devappa R., Makkar H.P.S., Becker K. 2013. Shelf-life of isolated phorbol esters from Jatropha curcas oil. Industrial Crops and Products, 49: 454-461.

Finch S. 1989. Ecological considerations in the management of Delia pest species in vegetable crops. Annual reviews of Entomology, 34:117-137. 
Finch S., Coaker T.H. 1969. A method for the continuous rearing of the cabbage root fly Erioischia brassicae (Bch.) and some observations on its biology. Bulletin of Entomological Research, 58: 619-627.

Fournet S., Stapel J.O., Kacem N., Nenon J.P., Brunel E. 2000. Life history comparison between two competitive Aleochara species in the cabbage root fly, Delia radicum: implications for their use in biological control. Entomologia Experimentalis et Applicata, 96: 205-211.

Govindarajan M., Mathivanan T., Elumalai K., Krishnappa K., Anandan A. 2011. Ovicidal and repellent activities of botanical extracts against Culex quinquefasciatus, Aedes aegypti and Anopheles stephensi (Diptera: Culicidae). Asian Pacific Journal of Tropical Biomedecine, 1: 43-48.

Griffiths G.C.D. 1986. Relative abundance of the root maggots Delia radicum (L.) and D. floralis (Fallén) (Diptera: Anthomyiidae) as pests of canola in Alberta. Quaestiones Entomologicae, 22: 253-260.

Hunter M.D. 2001. Out of sight, out of mind: the impacts of root-feeding insects in natural and managed systems. Agricultural and Forest Entomology, 3: 3-9.

Isman M. 2006. Botanical insecticides, deterrents and repellents in modern agriculture and increasingly regulated world. Annual review of entomology, 51: 45-66.

Jensen E., Felkl G., Kristiansen K., Andersen S. 2002. Resistance to the cabbage root, Delia radicum, within Brassica fruticulosa. Euphytica, 124: 379-386.

Joseph S.V., Martinez J. 2014. Incidence of cabbage maggot (Diptera: Anthomyiidae) infestation and plant damage in seeded Brassica fields in California's central coast. Crop Protection, 62: 72-78.

Khani M., Awang R.M., Omar D., Rahmani M. 2012. Bioactivity Effect of Piper nigrum L. and Jatropha curcas L. Extracts against Corcyra cephalonica (Stainton). Agrotechnology, 2:105. $6 \mathrm{pp}$.

Koul O., Walia S. 2009. Comparing impacts of plant extracts and pure allelochemicals and implications for pest control, 49: 1-30.

Kumar P., Mishra S., Malik A., Satya S. 2013. Housefly (Musca domestica L.) control potential of Cymbopogon citratus Stapf. (Poales: Poaceae) essential oil and monoterpenes (citral and 1,8-cineole). Parasitology researcher, 112: 69-76.

Kupferschmied P. Maurhofer, M., Keel C. 2013. Promise for plant pest control: rootassociated pseudomonads with insecticidal activities. Frontiers in Plant Science. PlantMicrobe Interaction, 4:287. 
Malarvannan S., Giridharan R., Sekar. S., Prabavathy V.R., Nair S. 2009. Ovicidal activity of crude extracts of few traditional plants against Helicoverpa armigera (Hübner) (Noctuidae: Lepidoptera). Journal of Biopesticides, 2: 64-71.

Mat Sarip S.H., Abdul-Aziz A, Yaakob H., Puad K. 2016. Toxicological effect of lauric acid based insecticide on the reproduction system, growth development and feeding activity of aphids, Aphis gossypii Glover. International Journal of Biotechnology for Wellness Industries, 5: 76-81.

Muška F., Kazda J., Cerkal R. 2008. Cabbage maggot (Delia radicum) as a potential rapeseed (Brassica napus L.) pest in the Czech Republic. Can we make use of the German experience? Die Kohlfliege (Delia radicum) als potenzieller Schädling an Raps in der Tschechischen Republik. Nutzen wir Erfahrungen aus Deutschland? Nachrichtenbl. Deut. Pflanzenschutzd, $60: 252-258$.

Najjar A., Abdullah N., Saad W., Ahmad S. Oskoueian E., Abas F., Gherbawy Y. 2014. Detoxification of Toxic Phorbol Esters from Malaysian Jatropha curcas Linn. Kernel by Trichoderma spp. and Endophytic Fungi. International Journal of Molecular Sciences, 15: 2274-2288.

Pérez-Gutiérrez S., Zavala-Sánchez M.A., González-Chávez M. M., Cárdenas-Ortega N. C., Ramos-López M. A. 2011. Bioactivity of Carica papaya (Caricaceae) against Spodoptera frugiperda (Lepidoptera: Noctuidae). Molecules, 16: 7502-7509.

Prowse G.M., Galloway T. S., Foggo A. 2006. Insecticidal activity of garlic juice in two dipteran pests. Agricultural and Forest Entomology, 8: 1-6.

R Development Core Team .2008. R: A language and environment for statistical computing. $R$ Foundation for Statistical Computing, Vienna, Austria. ISBN 3-900051-07-0, URL http://www.R-project.org.

Ramos-López M.A., González-Chávez M.M., Cárdenas-Ortega N.C., Zavala-Sánchez M.A.S. Pérez G. 2012. Activity of the main fatty acid components of the hexane leaf extract of Ricinus communis against Spodoptera frugiperda. African Journal of Biotechnology,11: 42744278.

Ratnadass A., Togola M., Cissé B., Vassal J.M. 2009. Potential of sorghum and physic nut (Jatropha curcas) for management of plant bugs (Hemiptera: Miridae) and cotton bollworm (Helicoverpa armigera) on cotton in an assisted trap-cropping strategy. Journal of semi-arid tropical research 7.

Ratnadass A., Wink M. 2012. The Phorbol Ester Fraction from Jatropha curcas Seed Oil: Potential and Limits for Crop Protection against insect pests. International Journal of Molecular sciences, $13: 16157-16171$.

Roach J. S., Devappa R., Makkar H., Becker K. 2012. Isolation, stability and bioactivity of Jatropha curcas phorbol esters. Fitoterapia, 83: 586-592. 
Shuhang W., Voorrips. R.E., Steenhuis-Broers G., Vosman. B., Van Loon J.J.A. 2016. Antibiosis resistance against larval cabbage root fly, Delia radicum, in wild Brassica-species. Euphytica, 211: 139-155.

Soroka J. J., Dosdall L.M. 2011. Coping with Root Maggots in Prairie Canola Crops. Insects and Diseases. Prairie Soils and Crops Journal, 4: 24-31.

Tripathi, A.K., Prajapati, V. and Kumar, S. 2003.Bioactivity of I-carvone, d-carvone and dihydrocarvone towards three stored product beetles. Journal of economic Entomology, 96: 1594-1601. 


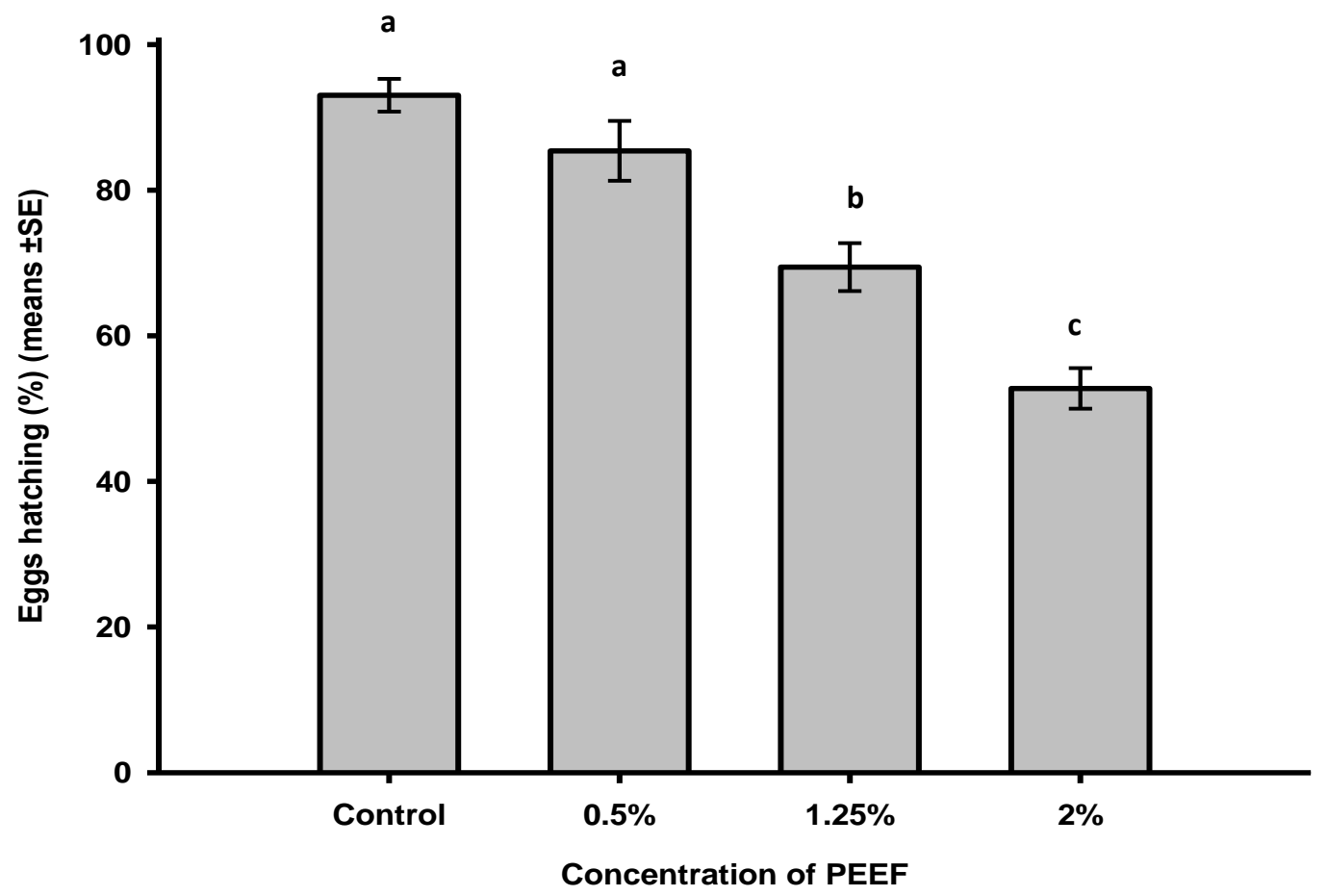

Figure 1a: Ovicidal effect of the Phorbol Esters Enriched Fraction (PEEF) on the eggs of $D$. radicum. Bars denoted with different letters are significantly different (All Pairwise Multiple Comparison Procedures Tukey's test, $p<0.05$ ).

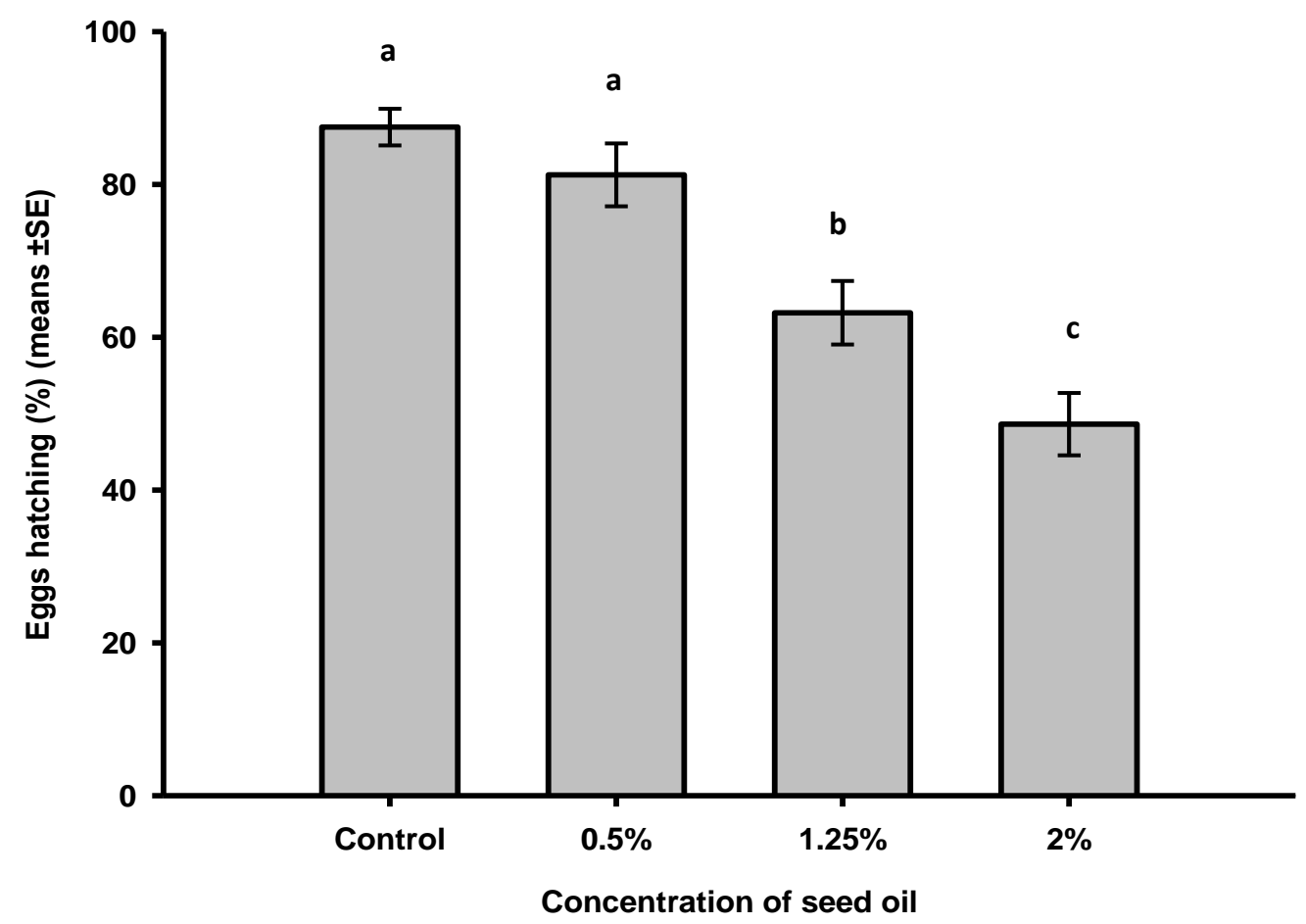

Figure 1b: Ovicidal effect of the seed oil of J. curcas on the eggs of D. radicum. Bars denoted with different letters are significantly different (All Pairwise Multiple Comparison Procedures Tukey's test, $p<0.05)$. 


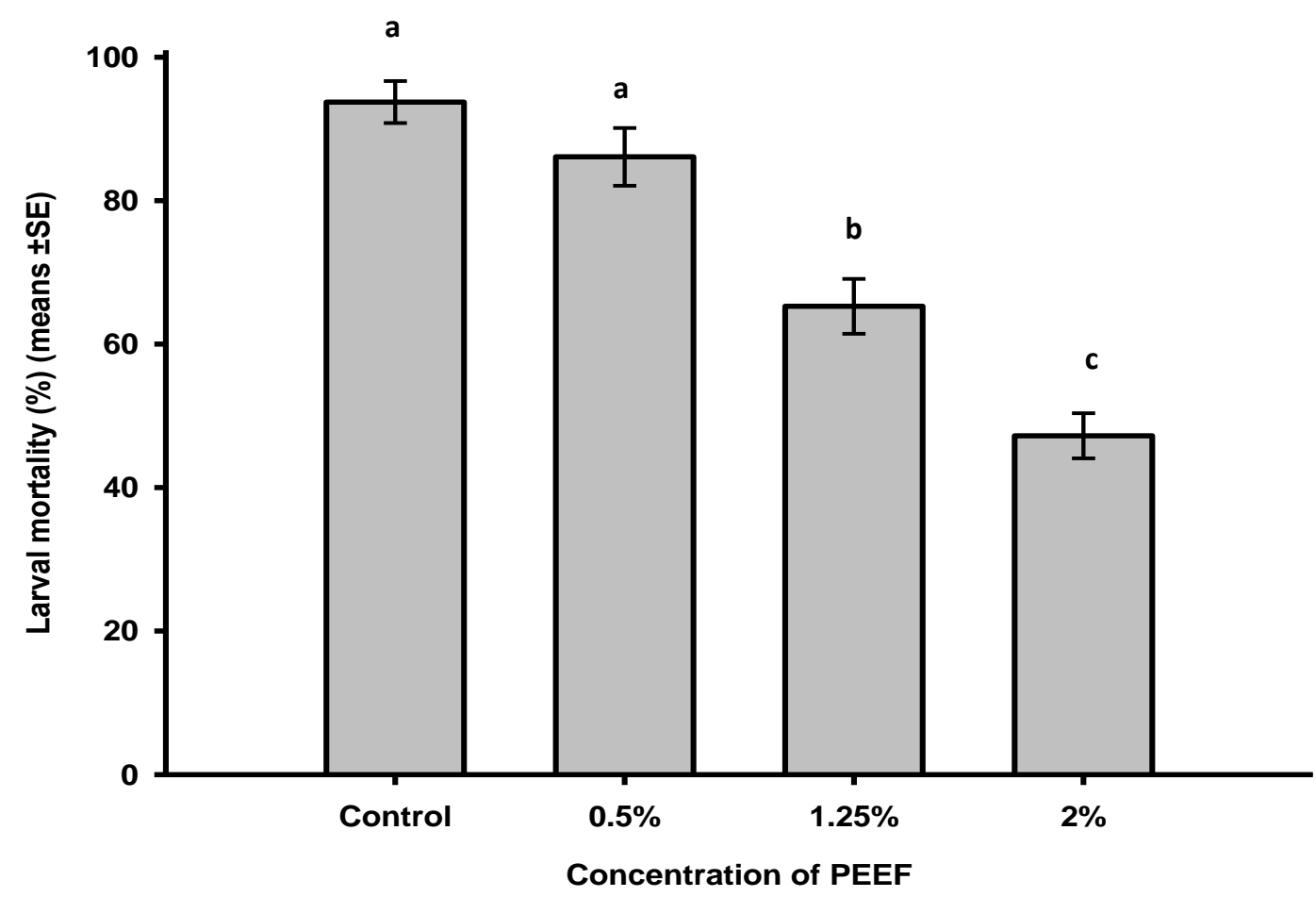

Figure 2a: Larvicidal effect of the Phorbol Esters Enriched Fraction (PEEF) on the larvae of $D$. radicum. Bars denoted with different letters are significantly different (All Pairwise Multiple Comparison Procedures Tukey's test, $p<0.05$ ).

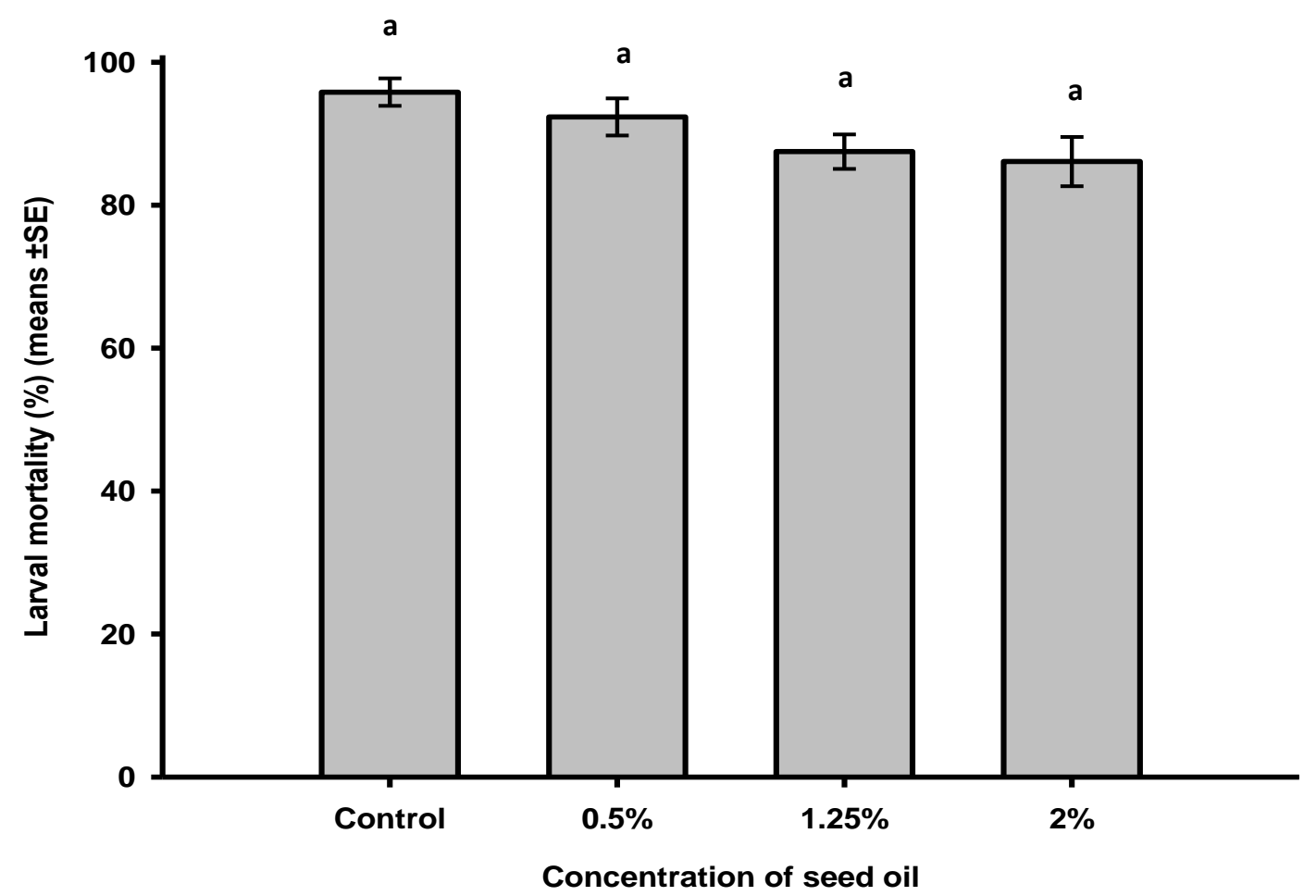

Figure 2b: Larvicidal effect of the seed oil of J. curcas on the larvae of $D$. radicum. Bars denoted with different letters are significantly different (All Pairwise Multiple Comparison Procedures Tukey's test, $p<0.05$ ) 


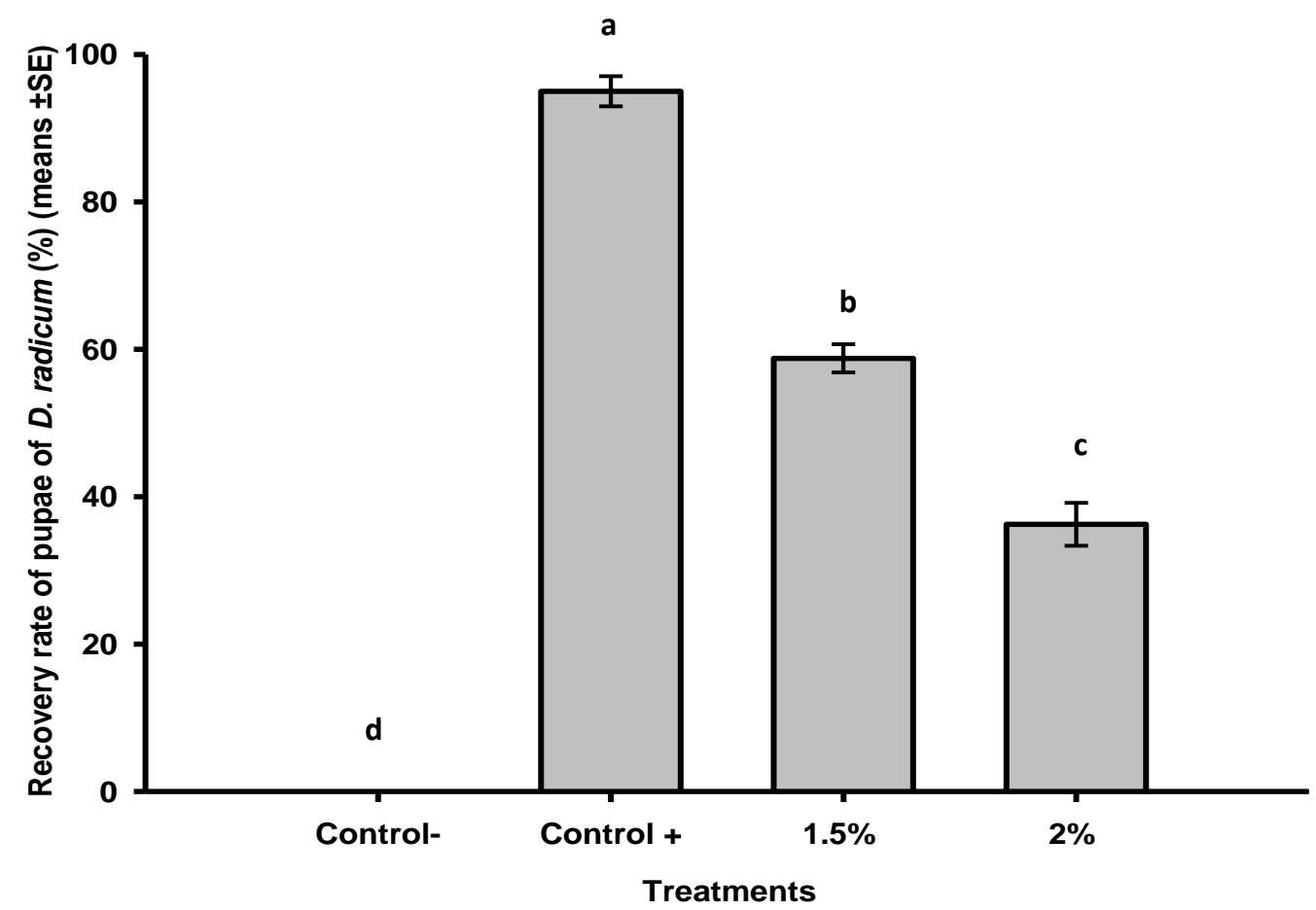

Figure 3a: Recovery rate of the pupae of $D$. radicum on cabbage plants after treatment with PEEF under greenhouse conditions. Bars denoted with different letters are significantly different (All Pairwise Multiple Comparison Procedures Tukey's test, $p<0.05$ ).

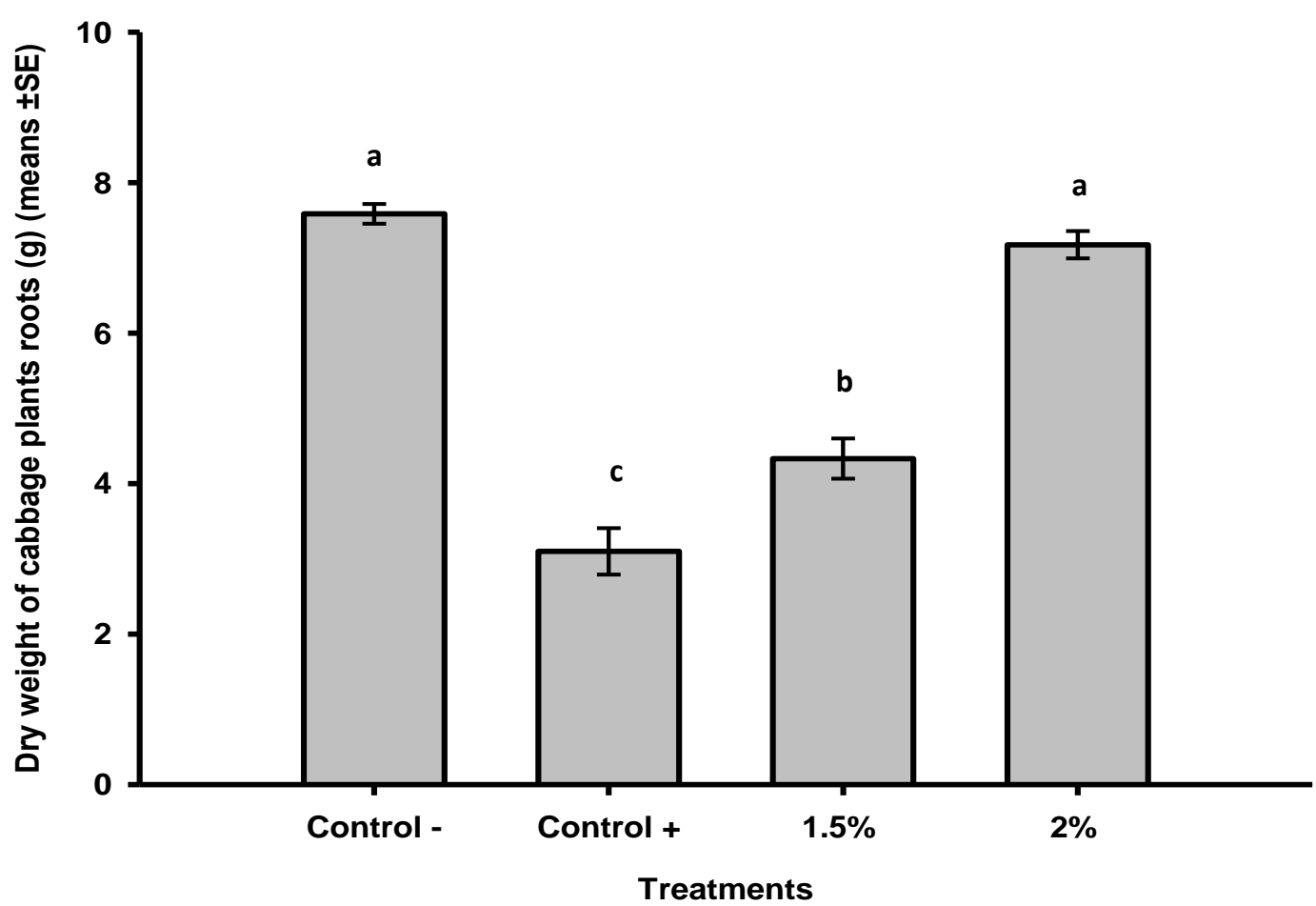

Figure 3b: Dry weight of the roots of cabbage plants after treatment with PEEF under greenhouse conditions. Bars denoted with different letters are significantly different (All Pairwise Multiple Comparison Procedures Tukey's test, $p<0.05$ ) 


\section{Chapter 5}

\section{Potential use of some biocompounds extracted from the physic nut tree Jatropha curcas in the control of the cotton bollworm Helicoverpa armigera (Lepidoptera: Noctuidae)}

\section{Summary}

The cotton bollworm Helicoverpa armigera (Hübner) (Lepidoptera: Noctuidae) is an economically important pest in field and greenhouse crops. Its major pest status derived from its polyphagy, high fecundity and mobility. Various botanical extracts have been reported to have a wide toxicity spectrum on $H$. armigera. However, only some botanical insecticides are used in crop protection, such as the physic nut tree Jatropha curcas well known for its toxicity but underutilized in pest management programs. The aim of the present study was to assess the insecticidal effect of this plant on $\mathrm{H}$. armigera and show the different pesticidal aspects of the Phorbol Esters Enriched Fraction (PEEF) and the seed oil (SOi).

The contact toxicity of PEEF was tested on the $2^{\text {nd }}$ and $4^{\text {th }}$ instar larvae of $H$. armigera. The larvae were topically treated with a $0.5 \mu$ l of PEEF applied on the anterior pronotum of the insect. There were 3 different groups: the untreated larvae, the larvae topically treated with $1 \%(\mathrm{~V} / \mathrm{V})$ of PEEF and larvae treated with $2 \%(\mathrm{~V} / \mathrm{V})$ of PEEF. The feeding toxicity of the PEEF was tested on the early $2^{\text {nd }}$ and the $4^{\text {th }}$ instar larvae of $H$. armigera. The ingestion toxicity was assessed by incorporating the PEEF into the artificial diet. After this, the medium presented to the larvae in small Petri dishes. There were 4 different treatments: the control larvae fed on non-treated discs, the starved larvae, larvae fed with 1\% PEEF (V/V) and larvae fed with 2\% PEEF (V/V).

The deterrent effect of the PEEF was tested on neonate larvae based on a dual choice test. It consisted of releasing 15 first instar larvae of $H$. armigera in the Petri dish at a distance of $6 \mathrm{~cm}$ from two diet discs. Larvae were left to make a choice and counted on each disc at $1 \mathrm{~h}, 8 \mathrm{~h}$ and $24 \mathrm{~h}$ after release. There were 2 different pairings: $\mathrm{C}$ vs. $1 \%$ and $\mathrm{C}$ vs. $2 \%$ with 15 Petri dishes for each choice test.

The pupation success was also assessed after feeding on PEEF treated diet. The pupicidal effect of two different concentrations of PEEF was tested on the $4^{\text {th }}$ and $5^{\text {th }}$ instar. Larvae were divided into 2 different independent groups with different dietary regimes: the 
first group was allowed to feed freely on the treated diet from the $4^{\text {th }}$ instar larvae until pupation while the second group was fed with the treated diet from the $5^{\text {th }}$ instar until pupation. At the end of the bioassay, pupae were collected, counted and left in controlled conditions for hatching.

The topical application of the PEEF on the cuticle of the $2^{\text {nd }}$ and $4^{\text {th }}$ instar larvae of $H$. armigera caused a non-significant mortality. The survivorship of the $2^{\text {nd }}$ instar larvae was not significantly different between treatments (Chi-square test, $\chi 2=10.97$, d.f. $=2, p>0.05$ ). About $80 \%$ of the larvae survived after application of $0.5 \mu \mathrm{l}$ of $2 \%$ PEEF on the anterior pronotum (Tukey's HSD; $p=0.08$ ). The topical application of the PEEF on the $4^{\text {th }}$ instar larvae showed non-significant effect (Chi-square test, $\chi 2=2.2$, d.f. $=2, p>0.05$ ). Only one $L_{4}$ larvae was dead after treatment with $2 \%$ of PEEF.

The choice feeding test showed a significant difference between treatments 1 hour after releasing the larvae $\left(F_{2,42}=165.2, \mathrm{p}<0.001\right)$. At this time of observation, $45.77 \%$ of the $1^{\text {st }}$ instar larvae were recorded on the control artificial medium while $26.66 \%$ were observed on the medium treated with $1 \%$ of PEEF. After $24 \mathrm{~h}$, more larvae moved from the treated to the untreated diet. An overall significant difference was observed $\left(F_{2,42}=165.2, p<0.001\right)$ between treatments. At $2 \%$ concentration of PEEF, a significant difference between treatments was observed after 1 hour $\left(F_{2,42}=111.3, \mathrm{p}<0.001\right)$. After 24 hours, the larval presence on the control artificial medium was significant and less larvae were recorded on the treated diet in comparison with the previous times of observation (Tukey's HSD; $p$ $<0.001)$.

After feeding on the artificial medium mixed with $2 \%$ of PEEF, the pupation rate of the $4^{\text {th }}$ instar decreased significantly to 66\% (Tukey's HSD; $p<0.05$ ). However, there was no significant difference in comparison with the control after feeding from the $4^{\text {th }}$ instar on a concentration of $1.25 \%$ of PEEF (Tukey's HSD; $p>0.05$ ). About $76 \%$ of the larvae reached the pupation stage and 2 pupae did not hatch. When the larvae of $H$. armigera were fed on PEEF from the $5^{\text {th }}$ instar larvae until pupation, a slight decrease of the pupation rate was observed. In this case, no significant effect was observed after administration of $1.25 \%$ (Tukey's HSD; p>0.05) and 2\% (Tukey's HSD; p>0.05) of PEEF compared to the control where all larvae pupated.

After feeding on PEEF and seed oil treated medium, the larval weight gain differed significantly between treatments $\left(F_{2,33}=34.86, \mathrm{p}<0.001\right)$. Compared to the control, larvae fed 
with $2 \%$ of PEEF showed a significantly lower weight gain (Tukey's HSD; $p<0.001$ ). A significant difference was also observed when larvae were fed on $3 \%$ of seed oil in comparison with the control (Tukey's HSD; $p<0.05$ ). Also, the ingestion of PEEF impacted significantly more the weight of larvae than the seed oil treatment (Tukey's HSD; $p<0.001$ ). The pupal weight of $H$. armigera was significantly affected $\left(F_{2,33}=4.32, p<0.05\right)$. Larvae fed with $2 \%$ of PEEF formed smaller pupae than the control treatment (Tukey's HSD; $p<0.05$ ). However, no significant difference of the pupal weight was observed in the seed oil treatment in comparison with the control (Tukey's HSD; $p>0.05$ ).

Although the limited killing effect of the extracts of J. curcas on $H$. armigera, the present study enlightened some insecticidal properties of these extracts that could be valorized to control this pest. The antifeedant effect of phorbol esters was the most important insecticidal aspect to be investigated and further applied in the management of $H$. armigera. This compound affected the assimilation of ingested food as well as the ability to convert ingested and digested food into growth. The pupicidal effect after feeding on PEEF treated diet would increase pupal mortality and decrease consequently the populations of $H$. armigera over generations. However, the application of J. curcas extracts as potential insecticidal compounds must be firstly subject to many toxicological studies before the concrete use as a standard bioinsecticide.

Keywords: Jatropha curcas, Helicoverpa armigera, Phorbol Esters Enriched Fraction, antifeedant, Lepidoptera, deterrent, food consumption. 


\section{Introduction}

The cotton bollworm Helicoverpa armigera (Hübner) (Lepidoptera: Noctuidae) is a polyphagous pest widely distributed in Africa, Asia, Europe and South Pacific regions (Satyan et al., 2009). It is considered as an economically important pest (Mensah et al., 2015) of a wide range of plants in field (Mironidis et al., 2008) and greenhouse crops (Sharma et al., 2005). The major pest status of this insect derived from its polyphagy, high fecundity, its mobility, and seasonal migration (Feng et al., 2005). These features reinforce the flexibility and plasticity of $H$. armigera to adapt to artificial and natural agro-ecosystems (CABI, 2016). H. armigera is listed as an A2 quarantine pest by EPPO (OEPP/EPPO, 2003). This quarantine status arises from the risk of introduction into glasshouse crops in northern Europe (CABI, 2016).

H. armigera is considered a polyphagous pest. It infests at least 60 cultivated and 67 wild host plants from many families including Asteraceae, Fabaceae, Malvaceae, Poaceae and Solanaceae (Pogue et al., 2004). Damages spans from the vegetative growth phase through the flowering phase to the fructification period. Early instars of $H$. armigera are voracious leaf feeders that shift later to the developing bods, fruits, or bolls, leading to serious reduction in yield (CABI, 2016). During development, larvae may feed on many fruits and form inside the infested fruits a messy, watery, internal cavity filled with cast skins and feces. H. armigera is a key pest in Africa, Asia, Europe and the former USSR, and Oceania. In India, where $H$. armigera commonly destroys over half the yield of pulse crops, pigeon pea and chickpea, losses were estimated at over \$US 300 million per annum (Reed et al., 1982). In the late 1980s, losses of both pulses and cotton were estimated to exceed \$US 500 million. In Australia, total losses were estimated Australian losses at \$A 23.5 million (Wilson, 1982).

The adults of $H$. armigera tend to lay eggs during flowering phase on the upper third of healthy plants. Eggs can be found on vigorously growing terminals, on flowering parts but rarely on fruits. At optimal temperature, the larvae can hatch after three days (Liu et al., 2004). The neonate larva eats through the eggs hell to emerge. In the beginning, larvae graze on tender young leaves, before moving to feed on buds, flowers, young pods, bolls or fruits (Kakimoto et al., 2003). The larval development includes six growth instars and takes two to three weeks in summer or four to six weeks in spring or autumn. At the end of their development, fully grown larvae crawl to the base of the host plant, tunnel up to $10 \mathrm{~cm}$ into 
the soil and form a chamber in which they pupate (Mironidis et al., 2008). The duration of pupation depends on temperature, taking around two weeks in summer and up to six weeks in spring and autumn (CABI, 2016). H. armigera overwinters as a pupa, under the soil surface. Larval food quality influences the over-wintering readiness of the cotton bollworm (Liu et al., 2007).

Because of the serious economic damages, chemicals have been heavily employed on H. armigera (Pogue et al., 2004). As a result, populations of the cotton bollworm have developed resistance to several groups of active ingredients (Kranthi et al. 2002) and insecticides become less effective against this pest. However, botanical pesticides, a good alternative to chemicals, tend to have broad-spectrum activity and are specific in their mode of action and relatively safe to living organisms and environment (Baskar et al., 2012). Some plants are rich with phytochemicals mobilized against pests and involved in plant defense (Richards et al., 2015). These phytochemicals do not always induce the instant death of insect but affects the metabolic pathways and physiological functions (Prakash et al., 1997, Prakash et al., 2008). Such effects are the antifeedant, hormonal disruption and antioviposition effect. Therefore, plant secondary metabolites can be an alternative control method to chemicals.

Various botanical extracts have been reported to have a wide spectrum of toxicity against pests and have been long used as effective as synthetic chemicals for pest management. These plant-based compounds affect arthropod pests, vectors and other pathogens, but only few of botanicals are used in agriculture (Koul et al., 2008) such as the physic nut tree Jatropha curcas well known for its toxicity. The genus Jatropha is native to tropical America and widely distributed in the tropical and subtropical areas of South America, Central America, Asia, Australia and Africa (Gübitz et al., 1999). It belongs to the tribe Jatropheae, orders Malpighiale in the Euphorbiaceae family and contains more than 170 known species (Wurdack, 2008). The most widespread specie around the world is Jatropha curcas (Ratnadass et al., 2012).

The aim of the present study was to assess the insecticidal properties of the physic nut tree J. curcas on the cotton bollworm $H$. armigera. We selected the Phorbol Esters Enriched Fraction (PEEF) and the seed oil (SOi) as extracts of $J$. curcas to evaluate their efficacy on $\mathrm{H}$. armigera. The bioassays have concerned the larval stages as well as the adults 
in laboratory and greenhouse conditions. The experiments were set-up with plants as well as with artificial diet. We addressed the following questions:

- Does the PEEF of J. curcas induce larval mortality by topical application?

- Does PEEF-treated diet affect the larval feeding behavior?

- Which larval stage is the most susceptible to the toxicity of PEEF?

- Does feeding on PEEF show any pupicidal effect on H. armigera?

\section{Material and methods}

\subsection{Insect culture}

The larvae of $H$. armigera used in this bioassay were collected from a laboratory culture. This rearing was originally established from eggs purchased from Bayer Crop Science AG (Monheim, Germany). Eggs were incubated for 4 days in a climatic chamber (WB 750 KFL; Mytron Bio-Und Solartechnik $\mathrm{GmbH}$, Germany) under controlled conditions $\left(20 \pm 1^{\circ} \mathrm{C}\right.$ temperature, $65 \%$ relative humidity and $16 \mathrm{~L}: 8 \mathrm{D}$ photoperiod). Neonate larvae were reared in groups of 150 larvae in Petri dishes (86.5 mm diameter x $14.5 \mathrm{~mm}$ height) (Sarstedt, Aktiengesellschaft \& CO Nuembrecht, Germany (Sarstedt, Aktiengesellschaft \& CO Nuembrecht, Germany) filled with $20 \mathrm{~g}$ of artificial medium. At the beginning of the $2^{\text {nd }}$ instar larvae, caterpillars were separated to be reared individually in small Petri dishes (35 $\mathrm{mm} \times 10 \mathrm{~mm}$ ) and kept in sterile boxes $(10 \mathrm{~cm} \times 10 \mathrm{~cm}$ ) (Sarstedt, Aktiengesellschaft \& CO Nuembrecht, Germany) in a climatic chamber (WB 750 KFL; Mytron Bio-Und Solartechnik $\mathrm{GmbH}$, Germany) under controlled conditions $\left(22 \pm 1^{\circ} \mathrm{C}\right.$ temperature, $65 \%$ relative humidity and 16L: 8D photoperiod). At the end of the life cycle, pupae were separated into females and males then placed at a ratio of $2: 2$ in sterile plastic boxes $(18 \mathrm{~cm}$ length $\times 13 \mathrm{~cm}$ width $\times 5.5 \mathrm{~cm}$ height) covered with a perforated lid. Adults were supplied with a honey solution $(1 \% \mathrm{~W} / \mathrm{V})$ mixed with $2 \mathrm{~g}$ of pollen as food resource.

\subsection{Host plant}

The greenhouse experiments were conducted on 3 weeks old tomato plants. Tomato plants (Solanum lycopersicum variety: Rio Grande; Reinsaat ${ }^{\circledR}$ KG, Sankt Leonhard am Hornerwald, Austria) were grown in plastic trays from seeds in a greenhouse chamber (22 $\pm 3^{\circ} \mathrm{C}$ temperature, $60 \%$ relative humidity and $16 \mathrm{~L}$ : 8D photoperiod). After 10 days, seedlings were transplanted into $11 \mathrm{~cm}$ diameter pots filled with non-sterile soil (Fruhstorfer Erde Typ 25, Hawita Gruppe GmbH, Vechta, Germany, peat fine structure with volcanic clay, pH: 5.7- 
6.3 , Fertilization of $200-300 \mathrm{mg} \mathrm{N}$ ) and sand mixture (3:1 volume). Plants were grown in the chamber, regularly irrigated and fertilized once a week since the 3 week after potting (fertilizer: Hakaphos 2g/L (15\% N, 11\% P2O5, 15\% K2O, 1\% Mg, 0.1\% Fe, 0.1\% Mn, 0.04\% Cu, $0.025 \% \mathrm{~B}$ and $0.005 \% \mathrm{Mo}))$.

\subsection{Artificial medium}

The laboratory bioassays such as the antifeedant effect of Jatropha were tested by mixing these extracts with the insect diet. Larvae were also reared on artificial diet for mass rearing. The artificial medium is mainly composed of bean powder and wheat germ mixed with yeast extract as a phagostimulant.

\subsection{Jatropha bioinsecticides}

In this study, two different extracts of $J$. curcas were screened for their insecticidal effect: the seed oil (SOi) provided by the company of JatroSolutions GmbH (Stuttgart, Germany) and the PEEF extracted in the laboratories of P.P.M e.V. (Pilot Pflanzenoeltechnologie Magdeburg, Germany). They have been extracted and purified following the method of Devappa et al. (2010).

\subsection{Experimental bioassays}

\subsubsection{Contact toxicity of PEEF}

The contact toxicity of PEEF was tested on the $2^{\text {nd }}$ and $4^{\text {th }}$ instar larvae of $H$. armigera. Larvae were collected from a stock colony maintained in a climatic chamber (WB 750 KFL; Mytron Bio-Und Solartechnik GmbH, Germany) under controlled conditions (22 $\pm 1{ }^{\circ} \mathrm{C}$ temperature, $65 \%$ relative humidity and $16 \mathrm{~L}$ : $8 \mathrm{D}$ photoperiod). The larvae were topically treated with $0.5 \mu$ l of PEEF applied with a micropipette on the anterior pronotum of the insect. There were 3 different groups in this bioassay for each larval instar: the untreated larvae, the larvae topically treated with $1 \%(\mathrm{~V} / \mathrm{V})$ of PEEF and larvae treated with $2 \%(\mathrm{~V} / \mathrm{V})$ of PEEF. After treatment, larvae were released in small Petri dishes (35 mm x $10 \mathrm{~mm}$ ) (Sarstedt, Aktiengesellschaft \& CO Nuembrecht, Germany) filled with $4.5 \mathrm{~g}$ of diet. The mortality was daily recorded until the $8^{\text {th }}$ day post treatment. Larvae were considered dead when no reaction to the stimulation was observed. There were 15 larvae per treatment and the bioassay was set-up once. Larvae were maintained in a climatic chamber in controlled conditions $\left(22 \pm 1^{\circ} \mathrm{C}\right.$ temperature, $65 \%$ relative humidity and $16 \mathrm{~L}$ : $8 \mathrm{D}$ photoperiod). 


\subsubsection{Deterrent effect of the PEEF}

This choice test was conducted in in vitro conditions on the $1^{\text {st }}$ instar larvae of $H$. armigera. After cooling down to room temperature, the artificial medium was cut into small discs of $1 \mathrm{~g}$ weight with a clean borer. The control diet discs were immersed in bidest water whereas the treated diet disc were dipped in a solution of $1 \%(\mathrm{~V} / \mathrm{V})$ and $2 \%(\mathrm{~V} / \mathrm{V})$ of PEEF contained in a $50 \mathrm{ml}$ falcon tube. The discs were left overnight dipped in the solutions in a cold room at $4 \stackrel{\circ}{ } \mathrm{C}$. In the day of the set-up of the bioassay, discs were taken out of the tubes and placed on sterile filter papers to dry. After drying, 2 different discs were placed in a 14 cm Petri dish lined with a sterile filter paper (125 mm diameter, Cat № 1001 125) (Schleicher and Schuell Bioscience $\mathrm{GmbH}$, Dasse, Germany). The control and treated discs were separated by a distance of $9 \mathrm{~cm}$. The dual choice test consisted of releasing 15 first instar larvae of $H$. armigera in the Petri dish at a distance of $6 \mathrm{~cm}$ from the diet discs. The larvae were left to make a choice and the Petri dishes were sealed with Parafilm to avoid the dryness of the food discs. Larvae were counted on each disc at $1 \mathrm{~h}, 8 \mathrm{~h}$ and $24 \mathrm{~h}$ after release. There were 2 different pairings: $C$ vs. $1 \%(\mathrm{~V} / \mathrm{V})$ and $\mathrm{C}$ vs. $2 \%(\mathrm{~V} / \mathrm{V})$ with 15 Petri dishes for each choice test. The Petri dishes were randomly distributed and kept in a climatic chamber under controlled conditions $(22 \pm 1 \circ \mathrm{C}, 16: 8 \mathrm{~h}(\mathrm{~L}: \mathrm{D})$ and $65 \% \mathrm{RH})$.

\subsubsection{Pupicidal effect of PEEF}

The pupation success of the larvae of $H$. armigera was assessed after feeding on PEEF treated diet. In this experiment, the pupicidal effect of two different concentrations of PEEF was tested on the $4^{\text {th }}$ and $5^{\text {th }}$ instar. Larvae were divided into 2 different independent groups with different dietary regimes: the first group was allowed to feed freely on the treated diet from the $4^{\text {th }}$ instar larvae until pupation, while the second group was fed with the treated diet from the $5^{\text {th }}$ instar until pupation. For that, larvae were firstly reared together after hatching, in groups of 40 in Petri dishes containing $20 \mathrm{~g}$ of untreated diet. In order to avoid cannibalism, larvae were separated at the end of the $2^{\text {nd }}$ instar and reared individually in small Petri dishes filled with $4.5 \mathrm{~g}$ of medium. In order to set up the bioassay with agesynchronized insects, only larvae that molted simultaneously at the $4^{\text {th }}$ instar for the first group and the $5^{\text {th }}$ instar for the second group were used.

To avoid the degradation of the phorbol esters, the medium was treated with the same immersion method as described in the previous experiments. There were 3 different treatments for each group: larvae fed on untreated diet, larvae fed on diet treated with 
$1.25 \%$ (V/V) of PEEF and larvae exposed to diet treated with $2 \%$ (V/V) of PEEF. Larvae were gently weighed and individually transferred with forceps to $90 \mathrm{~mm}$ Petri dishes lined with a sterile filter paper. The artificial medium was daily changed for every treatment until pupation. At the end of the bioassay, pupae were collected, counted, measured and left in controlled conditions for hatching. There were 12 Petri dishes per treatment randomly distributed in a climatic chamber $(22 \pm 1 \circ \mathrm{C}, 16: 8 \mathrm{~h}(\mathrm{~L}: \mathrm{D})$ and $65 \% \mathrm{RH})$.

\subsubsection{Effect of the PEEF on the food consumption}

The antifeedant effect of $J$. curcas compound was assessed on the $3^{\text {rd }}$ instar larvae of $H$. armigera under choice and non-choice conditions. The artificial medium was mixed with a concentration of $2 \%(\mathrm{~V} / \mathrm{V})$ of PEEF and presented to the larvae in form of food discs of $1.3 \mathrm{~g}$ weight cut with a sterile borer. The food was left to dry in laboratory conditions on a clean surface then placed with forceps separated by $5 \mathrm{~cm}$ in a $14 \mathrm{~cm}$ Petri dish on a moistened filter paper (125 mm diameter, Cat № 1001 125) (Schleicher and Schuell Bioscience GmbH, Dasse, Germany).

Larvae used in this bioassay were collected after hatching from a stock culture and reared on untreated artificial medium. They were separated at the end of the $2^{\text {nd }}$ instar until they reached the $3^{\text {rd }}$ instar larvae. The molting skin was used as an indicator of the insect development. We used larvae having freshly and simultaneously molted and with similar weights. In the choice test, one larva per Petri dish was exposed to 2 different food discs: the control and the $2 \%$ tread medium. Larvae were released at $5 \mathrm{~cm}$ distance from the food resource and left to make a choice before starting feeding on the chosen diet. There were 15 sealed Petri dishes each with only one larva individually feeding.

In the non-choice assay, only one food disc was presented to the larva, either the control food discs or the diet treated with $2 \%$ of PEEF. There were 15 larvae per treatment released separately in 15 Petri dishes. In both bioassays, larvae were left to feed freely during 3 days on the diet. At the end of the experiment, larvae were removed and the food discs were weighed to deduce the consumed amount of diet. The two bioassays were conducted in a climatic chamber under controlled conditions $(22 \pm 1 \circ \mathrm{C}, 16: 8 \mathrm{~h}(\mathrm{~L}$ : D) and $65 \%$ $\mathrm{RH})$. 


\subsubsection{Comparison of the antifeedant effect of PEEF and the seed oil}

The effect of the seed oil and the PEEF on the growth of $H$. armigera was assessed under laboratory conditions. The $4^{\text {th }}$ instar larvae were selected in this feeding test. They have a relative steadily feeding activity and release weighable pellets of feces. Larvae used in this bioassay were originating from eggs laid by the same female. They were reared in group of 40 larvae during the two first instars. At the $3^{\text {rd }}$ instar, when the cannibalism occurred, caterpillars were separated and reared individually in small Petri dishes (35 mm x $10 \mathrm{~mm}$ ) on untreated diet. At the end of the $3^{\text {rd }}$ instar, newly molted larvae to the $4^{\text {th }}$ instar were selected. They were weighed and placed individually in sterile Petri dishes $(86.5 \mathrm{~mm}$ diameter $\times 14.5 \mathrm{~mm}$ height) lined with a filter paper and sealed after releasing the larva. Insects were allowed to feed on artificial medium until the $6^{\text {th }}$ instar larvae. There were 3 different treatments: control, diet mixed with $2 \%(\mathrm{~V} / \mathrm{V})$ PEEF and diet treated with $3 \%(\mathrm{~V} / \mathrm{V})$ of seed oil. At the end of the bioassay, feces, larvae and pupae were weighed. There were 12 larvae per treatment feeding individually in Petri dishes. The bioassay was conducted in a climatic chamber under controlled conditions $(22 \pm 1 \circ \mathrm{C}, 16: 8 \mathrm{~h}(\mathrm{~L}: \mathrm{D})$ and $65 \% \mathrm{RH})$.

\subsection{Data analysis}

Statistical processing of results was carried out by standard methods using the statistical software R (v 3.0.2) (R Development Core Team, 2008). Prior to analysis, all data (mortality, weight and food consumption) were tested for homogeneity of variance and normality. To detect the difference between treatments, we performed One-way analysis of variance (ANOVA). If significant differences between groups were detected, means were compared by performing Tukey's test at $\alpha=0.05$.

The mortality of larvae was analyzed using generalized linear models (GLM) taking account of the binomial distribution of the data (alive or dead). To correct the anomalies in data variation (overdispersion/underdispersion), we proceeded to the quasi-binomial distribution error in data analysis. Thereafter, Tukey's test at $\alpha=0.05$ was employed to detect differences between means.

Giving that some larvae did not make a choice during the feeding choice test, the non-choice category was also considered during the data analysis which made counts distributed into 3 major groups (Control, treated and no-choice). This non-binary aspect of data deriving from choice bioassays (Control, Treated or No-choice) made it unsuitable to perform a binomial test for data analysis. In this case, we proceeded to generalized linear 
models (GLM) using Poisson distribution followed by quasi-poisson models analysis in case of dispersion anomalies. In case of significant differences between groups, data were subject to a Tukey's test at $\alpha=0.05$ to separate the means. The data of food consumption obtained from choice feeding test were analyzed based on Student's test to compare the amount of diet consumed between two groups.

\section{Results}

\subsection{Contact toxicity of PEEF}

The topical application of the PEEF on the cuticle of the $2^{\text {nd }}$ and $4^{\text {th }}$ instar larvae of $H$. armigera caused a non-significant larval mortality. The survivorship of the $2^{\text {nd }}$ instar larvae was not significantly different between treatments (Chi-square test, $\chi 2=10.97$, d.f. $=2$, p>0.05). About $80 \%$ of the larvae survived after application of $0.5 \mu \mathrm{l}$ of $2 \%$ PEEF on the anterior pronotum (Tukey's HSD; $p>0.05$ ). The application of $1 \%$ of PEEF did not cause a significant mortality in comparison with the control and a similar number of larvae survived compared to the control. PEEF induced a late toxic effect on the larvae of $H$. armigera. In fact, no mortality was recorded during the first seven days of the bioassay. The topical application of the PEEF on the $4^{\text {th }}$ instar larvae showed non-significant effect (Chi-square test, $\chi 2=2.2$, d.f. $=2, p=0.33$ ). Only one larva was dead after treatment with $2 \%$ of PEEF. The dead larvae showed symptoms of necrosis which spread from the application point to the whole cuticle of the insect. All the surviving larvae in all treatments continued their development to reach the pupal stage. All pupae hatched and gave healthy flying adults. We observed no larval mortality in the control groups.

\subsection{Deterrent effect of the PEEF}

This choice test showed a significant difference between treatments 1 hour after releasing the larvae $\left(F_{2,42}=165.2, \mathrm{p}<0.001\right.$; Figure $\left.1 \mathrm{a}\right)$. At this time of observation, $45.77 \%$ of the $1^{\text {st }}$ instar larvae were recorded on the control artificial medium while $26.66 \%$ were observed on the medium treated with $1 \%$ of PEEF. We recorded $27 \%$ of the larvae that did not make a choice. There was a significant difference between the control and the PEEF based treatment (Tukey's HSD; $p<0.001$ ). After 8 hours, a significant difference was observed between treatments $\left(F_{2,42}=188.4, p<0.001\right)$. The number of larvae that did not make choice was similar to the previous observation. However, the number of larvae present on the PEEF treated diet decreased to $19 \%$ but increased in the other hand on the control diet to $52.88 \%$ 
(Tukey's HSD; $p$ <0.001). After 24h, more larvae moved from the treated to the untreated diet. An overall significant difference was observed $\left(F_{2,42}=165.2, \quad \mathrm{p}<0.001\right)$ between treatments. About $73 \%$ of larvae were recorded on the control artificial medium however $13 \%$ of the larvae were observed on the diet mixed with PEEF (Tukey's HSD; $p<0.001$ ).

At $2 \%$ concentration of PEEF, a significant difference between treatments was observed after 1 hour $\left(F_{2,42}=111.3, p<0.001\right.$; Figure $\left.1 b\right)$. We recorded $50 \%$ of larvae on the control medium while $26.66 \%$ of larvae were observed on the diet treated with PEEF (Tukey's HSD; $p<0.001$ ). There were $22 \%$ of larvae did not make a clear choice during this time. After 8 hours from the set-up of the experiment, a significant difference was detected between treatments $\left(F_{2,42}=207.4, \mathrm{p}<0.001\right)$. The number of larvae that choose to feed on the control diet increased to $55 \%$ while the number of larvae on the PEEF treated diet dropped to $17.61 \%$ (Tukey's HSD; $p<0.001$ ). The number of larvae that did not make a choice remained constant. After 24 hours, the larval presence on the control artificial medium became more significant and less larvae were recorded on the treated diet in comparison with the previous time of observation (Tukey's HSD; $p<0.001$ ). We recoded $69.52 \%$ first instar larvae on the untreated diet whereas only $10 \%$ of the larvae were observed on the PEEF based medium.

\subsection{Pupicidal effect of PEEF}

The ingestion of PEEF by larvae from the $4^{\text {th }}$ instar showed a significant difference between treatments on the pupation success $\left(F_{2,33}=6.67, p<0.001\right)$. After feeding on the artificial medium mixed with $2 \%$ of PEEF, the pupation rate of the $4^{\text {th }}$ instar decreased significantly to $66 \%$ (Tukey's HSD; $p<0.05$ ). However, there was no significant difference in comparison with the control after feeding from the $4^{\text {th }}$ instar on a concentration of $1.25 \%$ of PEEF (Tukey's HSD; $p=0.06$ ). About $76 \%$ of the larvae reached the pupation stage and 2 pupae did not hatch.

When the larvae of $H$. armigera were fed on PEEF from the $5^{\text {th }}$ instar larvae until pupation, a slight decrease of the pupation rate was observed. In this case, no significant effect was observed after administration of $1.25 \%$ (Tukey's HSD; $p=0.83$ ) and 2\% (Tukey's HSD; $p=0.59$ ) of PEEF compared to the control where all larvae pupated. We recorded respectively after ingestion of $1.25 \%$ and $2 \%$ of PEEF $94.44 \%$ and $91.66 \%$ pupation success and we observed healthy adults. 
The pupal size of larvae treated from the $4^{\text {th }}$ instar was significantly different between treatments $\left(F_{2,85}=3.12, p<0.05\right)$. The pupae collected from larvae fed with $2 \%$ of PEEF were significantly smaller than the control (Tukey's HSD; $p<0.05$ ) while no effect on the pupal size was detected after feeding on $1.25 \%$ of PEEF (Tukey's HSD; $p=0.43$ ). The control pupa measured $19.44 \pm 0.69 \mathrm{~mm}$, the pupae obtained from larvae fed with $1.25 \%$ of PEEF measured $19.21 \pm 0.83 \mathrm{~mm}$ and the larvae exposed to $2 \%$ had a size of $18.95 \pm 0.69 \mathrm{~mm}$. There was no statistical difference on the length of pupae when larvae were exposed to the PEEF from the $5^{\text {th }}$ instar larvae $\left(F_{2,100}=1.22, \mathrm{p}=0.29\right)$. The pupal size was for the control, $1.25 \%$ and $2 \%$ treatment respectively $19.63 \pm 0.59 \mathrm{~mm}, 19.47 \pm 0.82 \mathrm{~mm}$ and $19.36 \pm 0.78$ $\mathrm{mm}$. Larvae that failed to pupate had a thin cuticle with mainly pupal distortions with subsequent wing malformations of the adults.

\subsection{Effect of the PEEF on the food consumption}

In non-choice conditions, the $2^{\text {nd }}$ instar of $H$. armigera consumed significantly high amounts of the untreated medium in comparison with larvae exposed to the PEEF treated medium (Student's t-test, d.f. $=60.89, p<0.001$ ). The final weight of the medium was 375.2 $\pm 07 \mathrm{mg}$ and $891.4 \pm 11 \mathrm{mg}$ respectively in the control and PEEF treated medium. The larvae consumed $879.2 \pm 6 \mathrm{mg}$ from the untreated diet and only $362.2 \pm 14 \mathrm{mg}$ from the medium treated with the J. curcas compound (Figure 2). In choice conditions, when the control and PEEF-treated food discs were presented together to larvae, the consumed amount from the treated diet decreased to $30.9 \pm 2 \mathrm{mg}$. Larvae preferred the untreated diet, fed more on the control artificial medium and avoided to feed on the treated food discs (Student's t-test, d.f. $=45.75, p<0.001)$.

\subsection{Comparative study of the insecticidal effect of the seed oil and the PEEF}

The weight gain differed significantly between treatments $\left(F_{2,33}=34.86, p<0.001\right.$; Figure 3 ). Compared to the control, larvae fed with $2 \%$ of PEEF from the $4^{\text {th }}$ to $6^{\text {th }}$ larval instar showed a significantly lower weight gain (Tukey's HSD; $p<0.001$ ). A significant difference was also observed when larvae were fed on $3 \%$ of seed oil in comparison with the control (Tukey's HSD; $p<0.05$ ). The results showed also that the ingestion of PEEF impacted significantly more the weight of larvae than the seed oil treatment (Tukey's HSD; $p<0.001$ ).

The pupal weight of $H$. armigera was significantly affected $\left(F_{2,33}=4.32, p<0.05\right)$. Larvae fed with $2 \%$ of PEEF formed smaller pupae than the control treatment (Tukey's HSD; 
$p<0.05)$. However, no significant difference of the pupal weight was observed in the seed oil treatment in comparison with the control (Tukey's HSD; $p=0.81$ ). In the control, seed oil and PEEF pupae weighed respectively $345.8 \pm 7 \mathrm{mg}, 337.3 \pm 6 \mathrm{mg}$ and $306.8 \pm 14 \mathrm{mg}$. There was no significant difference between the pupal weight of the larvae fed on seed oil and larvae fed on PEEF (Tukey's HSD; $p=0.08$ ).

The weight of feces produced by the larvae was significantly different between treatments $\left(F_{2,33}=24.91, \mathrm{p}<0.001\right)$. Larvae exposed to the food treated with $2 \%$ of PEEF produced more feces in comparison with the control (Tukey's HSD; $p<0.001$ ). Moreover, larvae fed on seed oil-admixed diet showed a significant difference in terms of feces production to the control (Tukey's HSD; $p<0.05$ ). There was a significant difference between the seed oil and PEEF treatment (Tukey's HSD; $p<0.05$ ).

\section{Discussion}

\subsection{Contact toxicity of PEEF}

The topical application of the PEEF caused low mortality on the $2^{\text {nd }}$ instar larvae and almost no visible effect on the $4^{\text {th }}$ instar. Our findings confirmed the results obtained by Ratnadass et al. (2009) and showed a lower toxicity of PEs by contact application than by ingestion. Although the skin irritant effect of phorbol has been early proved by Schmidt et al. (1980), our bioassay showed a weak evidence of this compound as an insecticide applied topically on $\mathrm{H}$. armigera. However, the few dead larvae showed signs of cuticle inflammation and epidermal hyperproliferation. These symptoms were reported by Goel et al. (2007) and resulted from hypersynthesis of DNA leading to the necrosis of the cuticle (Rios et al., 2006).

Many plants of the family of Euphorbiacea are known to contain oil, soap or latex possessing marked skin and mucous membrane irritant properties. The compounds involved in these effects have been shown to be esters of polyfunctional diterpene alcohols (Schmidt et al., 1980). De Vry et al. (2005) reported that the PEs fraction induced a dermatitis and cuticle irritation when topically applied on the epidermal tissues, resulting in cell damages and cuticle thickness. Declos et al. (1980) showed that phorbol esters were able to bind effectively to cuticle receptors, induce inflammation and tissue damage.

The necrosis and cell darkening, observed on the cuticle of the $2^{\text {nd }}$ instar larvae, were also reported by Najar-Rodríguez et al. (2007). After topical application, the lipophilic and oily nature of PEEF helps to penetrate the cell, accumulate inside the cytoplasm and affect 
their structural and functional properties. The seed oil of J. curcas was also reported as a cuticle irritating compound (Sabandar et al., 2013) and had been shown to cause cell disintegration and necrosis followed by a general burn effect of the insect cuticle (Devappa et al., 2011). Although there is evidence of PEs as a toxic compound, a weak contact toxicity was proven in this bioassay.

\subsection{Deterrent effect of the PEEF}

A feeding deterrent is a compound that prevents feeding without killing directly the insect which remains near the treated foliage or substrate and dies through starvation (Packiam et al., 2014). This feeding choice test assessed how effectively the PEEF inhibited insect feeding and proved the deterrent effect particularly on the $1^{\text {st }}$ instar larvae of $H$. armigera. At a concentration of $1 \%$ and $2 \%$ of PEEF, more larvae were recorded feeding on the control artificial medium, few were observed temporarily around the PEEF treated diet.

Most effective antifeedants on insects are sesquiterpene lactones, diterpinoids, triterpinoids, quinoline and indole alkaloids, which are presented in plants (Baskar et al., 2009). The photochemistry of the family Euphorbiaceae and the genus Jatropha was reviewed by Devappa et al. (2011) and revealed that the predominant ingredient is phorbol ester, providing a broad array of defenses against arthropod herbivores (Kumar et al., 2012). The deterrent effect of the PEEF used in our bioassay was mainly ascribed to the PEs, a diterpinoid fraction contained in the seed oil of J. curcas. The feeding inhibition effect of this compound was investigated by Devappa et al. (2012) on the fall armyworm Spodoptera frugiperda (Lepidoptera: Noctuidae). The results showed that the dietary intake by S. frugiperda was severely affected when fed on corn leaves treated with 0.0625 and 0.125 mg PEs $\mathrm{ml}^{-1}(\mathrm{w} / \mathrm{v})$ of PEEF.

A potential rejection of food may act via various mechanisms: olfactory repellency inducing the rejection of the substrate without coming in contact with the food; true gustatory deterrence after tasting the substrate and the larvae cause some small biting points on the substrate; physical obstacle via oral mechanoreceptors and/or toxicity via post-ingestive response, in this case, the larvae will consume relatively much food before they reject them (Li et al., 2014). In our bioassay, the gustatory deterrence could explain our results since most of the larvae came shortly in contact with the PEEF treated medium before moving few hours after to the untreated food. This observation has already been reported by Carpinella et al. (2003) after testing the deterrent effect of a limonoid from 
Melia azedarach (Meliaceae) on the larvae of the beetle Epilachna paenulata (Coleoptera: Coccinellidae).

Our findings suggested that the PEEF elicited an immediate rejection of the treated food on the $1^{\text {st }}$ instar larvae of $H$. armigera. It could be inducing a primary antifeedant effect, probably via the gustatory pathway regulated by sensory organs of the mouth parts (Wheeler et al., 2001, Isman et al., 2006). Many plant extracts have been reported to induce a feeding inhibition effect on the cotton bollworm H. armigera. Kathuria et al. (2005) showed that crude leaf extracts of Eucalyptus camaldulensis (Myrtaceae) and Tylophora indica (Asclepiadaceae) caused a significant feeding deterrence when exposed to the larvae of $H$. armigera on cabbage leaf discs. Baskar et al. (2012) reported that ononitol monohydrate isolated from the Sickle Senna plant Cassia tora (Fabaceae) showed at 1000 ppm more than 65\% antifeedant activity against $H$. armigera and Spodptera litura (Lepidoptera: Noctuidae) when larvae feed respectively on fresh treated cotton leaves and castor leaves.

\subsection{Pupicidal effect of PEEF}

The effect of botanical compounds on the pupal formation of $H$. armigera showed in our bioassay has been so far mentioned in many studies on Lepidoptera. Baskar et al. (2009) reported that the ingestion of crude hexane extract of Atalantia monophylla (Rutaceae) at a concentration of 100 ppm, 250 ppm, 500ppm and 1000 ppm induced different aspects of malformations (larval-pupal intermediate, pupal and adult intermediate) on $\mathrm{H}$. armigera. Baskar et al. (2012) showed also that feeding on leaves dipped in 125, 250, 500 and 1000 ppm of ononitol monohydrate extracted from the plant Cassia tora exhibited pupicidal activity against $H$. armigera and S. litura (Lepidoptera: Noctuidae). Moreover, Baskar et al. (2014) reported that triterpenoid friedelin isolated from hexane extract of Azima tetracantha leaves induced a high pupicidal effect at a concentration of 130.47 and 226.41 ppm on $H$. armigera and S. litura after feeding respectively on castor and fresh cotton leaves.

It was observed in our bioassay that the pupal size of larvae fed on $2 \%$ of PEEF from the $4^{\text {th }}$ larval stage until pupation differed significantly from the control. Pupae were smaller than those obtained from larvae fed on untreated diet. A similar observation was reported by Koul et al. (2004) on $\mathrm{H}$. armigera and showed that the aglaroxin A extracted from Aglaia elaeagnoidea (Meliaceae) caused a strong antifeedant effect and affected the larval growth. 
Subsequently, the pupal duration was prolonged and the pupae were smaller in size both in H. armigera and S. litura. In the same way, Abdelgaleil et al. (2005) reported that methyl 6hydorxyangolensate and 7-dideacetylkhivorin exhibited a significant reduction of adult emergence and hatching when mixed with diet of $S$. littoralis. In this study some adults emerged and were small in size with varied abnormalities.

The pupicidal effect of PEEF as a single active compound has not been reported in previous studies. However, Chauhan et al. (2015) showed that some extracts from Jatropha exhibited a pupicidal effect on the housefly, Musca domestica (Diptera). In this study, the variation in $\mathrm{LC}_{50}$ in hexane and ether extracts of J. curcas leaf was found to be $8.88-8.95$ $\mathrm{mg} / \mathrm{cm}^{2}$. The $\mathrm{LC}_{50}$ of the hexane and ether extracts of $J$. curcas bark varied between 9.72 $10.33 \mathrm{mg} / \mathrm{cm}^{2}$. Also, the pupicidal effect of the root extract of $J$. curcas exhibited a $\mathrm{LC}_{50}$ of $13.10 \mathrm{mg} / \mathrm{cm}^{2}$ in both hexane and ether solvent. Moreover, Bullangpoti et al. (2012) showed that feeding on diet mixed with ethanol extract from senescent leaves of J. gossypifolia caused larval mortality and pupal intermediates on S. frugiperda (Lepidoptera: Noctuidae). In our bioassay, pupal intermediates were frequently observed at a concentration of $2 \%$ of PEEF when larvae were fed from the $4^{\text {th }}$ larval stage. Larvae that reached the pupal stage formed pupae that became dark black with absence of movement few days after pupation.

\subsection{Effect of the PEEF on the food consumption}

The results obtained in this bioassay confirmed the deterrent/antifeedant properties of the PEEF of J. curcas. Antifeedants were earlier defined by Isman (1990) as "behaviormodifying substances that deter through a direct action on taste organs in insects". In our bioassay, the phorbol esters of $J$. curcas affected the food intake of the $2^{\text {nd }}$ instar of $H$. armigera by exerting strong direct antifeedancy and larvae did not feed on the diet treated with PEEF.

According to our bioassay, the food intake was reduced in the non-choice test or even suppressed in the choice test, depending on the concentration of PEEF. The reduction of food consumption after treatment with J. curcas extracts has been mentioned by Acda (2009) on the Philippine milk termite Coptotermes vastator (Isoptera: Rhinotermitidae). Termites consumed less paper when it was mixed with a concentration of $5 \%(\mathrm{~V} / \mathrm{V})$ of the seed oil of J. curcas. Khani et al. (2012) reported that the seed oil of J. curcas, rich with PEs, induced an antifeedant effect against the rice moth Corcyra cephalonica (Lepidoptera: Pyralidae) which increased with increasing plant extract concentrations. 
Moreover, Devappa et al. (2012) reported the antifeedant effect of the PEEF on the $3^{\text {rd }}$ instar larvae of the fall armyworm S. frugiperda (Lepidoptera: Noctuidae), induced at small PEEF concentrations.

\subsection{Comparative study of the insecticidal effect of the seed oil and the PEEF}

Insect growth is directly correlated with nutrient input (Hwang et al., 2008). In our study, the seed oil and the PEEF of J. curcas have been found to have clear antifeedant and toxic effects on the larvae of $H$. armigera. The experiment showed that the $4^{\text {th }}$ instar larvae of cotton bollworm came in contact with the food treated with $3 \%$ of seed oil and the other treated with $2 \%$ of PEEF. The reduced feeding activity on PEEF treated food after exposure could be the consequence either of rejection of food without substantial ingestion or of rejection following short periods of feeding. No relevant larval gain of $H$. armigera was observed, in particular after exposure to the PEEF of J. curcas.

Botanical and plant based extracts could affect in Lepidoptera the assimilation of ingested food as well as the ability to convert ingested and digested food into growth. Sadek (2003) reported that after feeding the $6^{\text {th }}$ instar larvae of the African cotton leafworm Spodoptera littoralis (Lepidoptera: Noctuidae) on the leaf extract of Adhatoda vasica (Acanthaceae), the larval growth was severely affected. Also, Martinez et al. (1999) showed that the ability to convert food into biomass was reduced when the $3^{\text {rd }}$ instar larvae of $S$. littoralis larvae were fed on diet treated with Azadirachtin for two days. Martinez et al. (2001) hypothesized that, in the absence of an adequate supply of amino acids, other nutrients then in excess for growth might be diverted into other metabolic survival pathways.

The reductions in food intake and the decrease of the ability to convert food into biomass would eventually affect the pupal weight. The antifeedant properties of the extracts of J. curcas has been shown by Devappa et al. (2012) and Ribeiro et al. (2012) on the fall armyworm S. frugiperda (Lepidoptera: Noctuidae). However, no previous studies reported the effect of PEEF as a compound derived from J. curcas on the pupal weight of H. armigera. Nevertheless, Ribeiro et al. (2012) reported no significant changes in pupal weight after feeding larvae S. frugiperda from their neonate stage on the methanol leaf extract of $J$. curcas. Also, Bullangpoti et al. (2012) showed that the leaf extract of J. gossypifolia delayed the pupation time of 7 days and caused some pupal deformations at higher doses. The bioassay showed also that the larvae fed on $2 \%$ of PEEF produced more feces then the 
control larvae. Chen et al. (2007) suggested that due to the poor efficiency of both ingested and digested food, mixed in our case with PEEF, much of the consumed food was not used and released as fecal matter.

\section{Conclusion}

Research so far published and focused on the genus Jatropha spp. and particularly the physic nut tree J. curcas, reported that extracts from this plant (leaves, seeds and oil) exhibited a variety of insecticidal properties. These effects on insects ranged from ingestion toxicity to anti oviposition deterrence to repellent effect and antifeedant activity. According to our study, the most relevant effect in terms of plant protection could be the antifeedant effect on early instar larvae. This feeding inhibition effect was mainly due to diterpene rich compounds, particularly phorbol esters. In spite of these insecticidal properties, the biocide characteristics of $J$. curcas are not yet valorized in terms of plant protection. The efficacy of the PEEF and the seed oil in reducing damage caused by the cotton bollworm would make these compounds a promising alternative for pest management. However, the lack of detailed toxicological studies and the absence of research investigating the potential side effects of phorbol esters limit their use as bioinsecticides in pest management programs. 


\section{References}

Abdelgaleil S.A.M., El-Aswad A.F. 2005. Antifeedant and growth inhibitory effects of tetranortriterpenoids isolated from three meliaceous species on the cotton leaf worm, Spodoptera littoralis (Boisd). Journal of Applied Sciences Research, 1: 234-241.

Acda M.N. 2009. Toxicity, tunneling and feeding behavior of the termite, Coptotermes vastator, in sand treated with oil of the physic nut, Jatropha curcas. Journal of Insect Science, 9: 1-8.

Baskar K., Duraipandiyan V., Ignacimuthua S. 2014. Bioefficacy of the triterpenoid friedelin against Helicoverpa armigera (Hub.) and Spodoptera litura (Fab.) (Lepidoptera: Noctuidae). Pest Management Science, 70: 1877-1883.

Baskar K., Ignacimuthu S. 2012. Antifeedant, larvicidal and growth inhibitory effects of ononitol monohydrate isolated from Cassia tora L. against Helicoverpa armigera (Hub.) and Spodoptera litura (Fab.) (Lepidoptera: Noctuidae). Chemosphere, 88: 384-388.

Baskar K., Kingsley S., Vendan S.E., Paulraj M.G., Duraipandiyan V., Ignacimuthu S. 2009. Antifeedant, larvicidal and pupicidal activities of Atalantia monophylla (L.) Correa against Helicoverpa armigera (Hübner) (Lepidoptera: Noctuidae). Chemosphere, 75: 355-359.

Bullangpoti V., Wajnberg E., Audant P., Feyereisen R. 2011. Antifeedant activity of Jatropha gossypifolia and Melia azedarach senescent leaf extracts on Spodoptera frugiperda (Lepidoptera: Noctuidae) and their potential use as synergists. Pest Management Science, 68: 1255-1264.

CABI. 2016. http://www.cabi.org/isc/datasheet/26757

Carpinella M.C., Defago M.T., Valladares G., Palacios S.M. 2003. Antifeedant and insecticide properties of a limonoid from Melia azedarach (Meliaceae) with potential use for pest management. Journal of Agricultural and Food Chemistry, 51, 369-374 369.

Chauhan N., Kumar. P., Mishra S., Verma S., Malik A., Sharma S. 2015. Insecticidal activity of Jatropha curcas extracts against housefly, Musca domestica. Environmental Science and Pollution Research, 22: 14793-14800.

Chen F., Wu G., Parajulee M.N., Ge F. 2007. Long-term impact of elevated carbon dioxide and transgenic $B t$ cotton on performance and feeding of three generations of cotton bollworm. Entomologia Experimentalis et Applicata, 124: 27-35.

De Vry C.G., Valdez M., Lazarov M., Muhr E., Buelow R., Fong T., Lyer S. 2005. Topical application of a novel immunomodulatory peptide, RDP58, reduces skin inflammation in the phorbol ester-Induced dermatitis model. Journal of Investigative Dermatology, 125: 473 481.

Delclos K.B., Nagle D. S., Blumberg P.M. 1980. Specific binding of phorbol ester tumor promoters to mouse skin. Cell, 19: 1025-1032. 
Devappa R.K., Angulo-Escalante Miguel A., Makkar H.P.S., Becker K. 2012. Potential of using phorbol esters as an insecticide against Spodoptera frugiperda. Industrial Crops and Products, 38: $50-53$.

Devappa R.K., Maes J., Makkar H.P.S., De Greyt W., Becker K. 2010. Quality of biodiesel prepared from phorbol ester extracted Jatropha curcas. Journal of American Oil Chemist's Society, 87:697-704.

Devappa R.K, Makkar H.P.S., Becker K. 2011. Jatropha Diterpenes: a Review. Journal of the American Oil Chemists' Society, 88: 301-322.

Feng H.Q., Wu K.M., Ni Y.X., Cheng D.F., Guo Y.Y. 2005. High-Altitude Windborne Transport of Helicoverpa armigera (Lepidoptera: Noctuidae) in Mid-Summer in Northern China. Journal of Insect Behavior, 18: 335-349.

Goel G., Makkar H., Francis G., Becker K. 2007. Phorbol esters: structure, biological activity, and toxicity in animals. International Journal of Toxicology, 26279-88.

Gübitz G.M., Mittelbach M., Trabi M. 1999. Exploitation of the tropical oil seed plant Jatropha curcas L. Bioresource Technology, 67:73-82.

Hwang S.Y., Liu C., Shen T.C. 2008. Effects of plant nutrient availability and host plant species on the performance of two Pieris butterflies (Lepidoptera: Pieridae). Biochemical Systematics and Ecology, 36: 505-513.

Isman M. 2006. Botanical insecticides, deterrents and repellents in modern agriculture and increasingly regulated world. Annual review of Entomology, 51:45-66.

Isman M.B, Koul O, Luczynski A, Kaminski J. 1990. Insecticidal and antifeedant bioactivities of neem oils and their relationship to azadirachtin content. Journal of Agricultural and Food Chemistry, 38: 1406-1411.

Kakimoto T., Fujisaki K., Miyatake T. 2003. Egg Laying Preference, Larval Dispersion, and Cannibalism in Helicoverpa armigera (Lepidoptera: Noctuidae). Annals of the Entomological Society of America, 96: 793-798.

Kathuria V., Kaushik N. 2005. Feeding inhibition of Helicoverpa armigera (Hübner) by Eucalyptus camaldulensis and Tylophora indica extracts. Insect Science, 12: 249-254.

Khani M., Awang R.M., Omar D., Rahmani M. 2012. Bioactivity Effect of Piper nigrum L. and Jatropha curcas L. Extracts against Corcyra cephalonica (Stainton). Agrotechnology, 2: 105.

Koul O., Kaur H., Goomber S., Wahab S. 2004. Bioefficacy and mode of action of rocaglamide from Aglaia elaeagnoidea (syn. A. roxburghiana) against gram pod borer, Helicoverpa armigera (Hübner). Journal of Applied Entomology, 128: 177- 181.

Koul O., Walia S. 2008. Comparing impacts of plant extracts and pure allelochemicals and implications for pest control,49: 1-30. 
Kranthi K. R., Jadhav D.R., Kranthi S., Wanjari R.R., Ali S.S., Russel D.A. 2002. Insecticide resistance in the major insect pests of cotton in India. Crop Protection, 21: 449-460.

Kumar G.R.K., Bapat V.A., Johnson T. S. 2012. Jatropha, Challenges for a new energy crop: phorbol esters and other toxic constituents. Farming, Economics and Biofuel of Jatropha curcas L., 24: 441-458.

Li W., Hu J., Yang J., Yuan G., Guo X., Luo M. 2014. Feeding Deterrence of Common Spices against Helicoverpa armigera larvae. Advances in Bioscience and Biotechnology, 5: 10251031.

Liu Z., Gong P., Wu K., Wei W., Sun J., Li D. 2007. Effects of larval host plants on overwintering preparedness and survival of the cotton bollworm, Helicoverpa armigera (Hübner) (Lepidoptera: Noctuidae). Journal of Insect Physiology, 53: 1016-1026.

Liu Z., Li D., Gong P., Wu K. 2004. Life table studies of the cotton bollworm, Helicoverpa armigera (Hübner) (Lepidoptera: Noctuidae), on different host plants. Environmental Entomology, 33: $1570-1576$.

Martinez S.S., Van Emden H.F. 1999. Sublethal concentrations of azadirachtin affect food intake, conversion efficiency and feeding behaviour of Spodoptera littoralis (Lepidoptera: Noctuidae). Bulletin of Entomological Research, 89: 65-71.

Martinez S.S., Van Emden H.F. 2001. Growth disruption, abnormalities and mortality of Spodoptera littoralis (Boisduval) (Lepidoptera: Noctuidae) caused by azadirachtin. Neotropical Entomology, 30: 113-125.

Mensah R., Leach D., Young A., Watts N., Glennie P. 2015. Development of Clitoria ternatea as a biopesticide for cotton pest management: assessment of product effect on Helicoverpa spp. and their natural enemies. Entomologia Experimentalis et Applicata, 154: 131-145.

Mironidis G. K., Savopoulou-Soultani M. 2008. Development, survivorship, and reproduction of Helicoverpa armigera (Lepidoptera: Noctuidae) under constant and alternating temperatures. Environmental Entomology, 37: 16-28.

Najar-Rodríguez A.J., Walter G.H., Mensah, R.K. 2007. The efficacy of a petroleum spray oil against Aphis gossypii Glover on cotton. Part 1: Mortality rates and sources of variation. Pest Management Science, 63: 586-595.

OEPP/EPPO. 2003. Bulletin OEPP/EPPO Bulletin 33, 245-247

Packiam S. M., Baskar K., Ignacimuthu S. 2014. Feeding deterrent and growth inhibitory activities of PONNEEM, a newly developed phytopesticidal formulation against Helicoverpa armigera (Hübner). Asian Pacific Journal of Tropical Biomedecine, 4: 323-328. 
Pogue M.G. 2004. A New synonym of Helicoverpa zea (Boddie) and differentiation of adult males of $H$. zea and $H$. armigera (Hübner) (Lepidoptera: Noctuidae: Heliothinae) Annals of the Entomological Society of America, 97: 1222-1226.

Prakash A., Rao J. 1997. Botanical pesticides in agriculture, vol. 461.14 pp.

Prakash A., Rao J., Nandagopal V. 2008. Future of Botanical Pesticides in rice, wheat, pulses and vegetables pest management. Journal of Biopesticides, 1:154-169

R Development Core Team .2008. R: A language and environment for statistical computing. $R$ Foundation for Statistical Computing, Vienna, Austria. ISBN 3-900051-07-0, URL http://www.R-project.org

Ratnadass A., Togola M., Cissé B., Vassal J.M. 2009. Potential of sorghum and physic nut (Jatropha curcas) for management of plant bugs (Hemiptera: Miridae) and cotton bollworm (Helicoverpa armigera) on cotton in an assisted trap-cropping strategy. Journal of semi-arid tropical research.7pp

Ratnadass A., Wink M. 2012. The Phorbol Ester Fraction from Jatropha curcas seed oil: Potential and Limits for Crop Protection against insect pests. International Journal of Molecular sciences, 13: 16157-16171.

Reed W., Pawar C.S. 1982. Heliothis: a global problem. In: Reed W, Kumble V, ed. Proceedings of the International Workshop on Heliothis Management. ICRISAT Center, Patancheru, India, 15-20 November 1981 International Crops Research Institute for the Semi-Arid Tropics Patancheru, Andhra Pradesh India, 1: 9-14.

Ribeiro S. S., Da Silva T. B., De Souza Moraes V. R., De Lima Nogueira P. C., Costa E. V. 2012. Chemical constituents of methanolic extracts of Jatropha curcas and effects on Spodoptera frugiperda (J.E.Smith). Química Nova, 35: 2218-2221.

Richards L.A., Dyer L. A., Forister M. L., Smilanich A. M., Dodson C. D., Leonard M. D., Jeffrey C. S. 2015. Phytochemical diversity drives plant-insect community diversity. Proceedings of the National Academy of Sciences PNAS, 112: 10975 -10978.

Rios M. Y., Aguilar-Guadarrama A.B. 2006. Nitrogen-containing phorbol esters from Croton ciliatoglandulifer and their effects on cyclooxygenases-1 and -2. Journal of Natural Products, 69:887-890.

Sabandar C., Norizan A., Faridahanim M.J, Sahidin I. 2013. Medicinal property, phytochemistry and pharmacology of several Jatropha species (Euphorbiaceae): A review. Phytochemistry, 85: 7-29.

Sadek M. M. 2003. Antifeedant and toxic activity of Adhatoda vasica leaf extract against Spodoptera littoralis (Lep., Noctuidae). Journal of Applied Entomology, 127: 396-404. 
Satyan R. S., Malarvannan S., Eganathan P., Rajalakshmi S., Parida A. 2009. Growth inhibitory activity of fatty acid methyl esters in the whole seed oil of Madagascar Periwinkle (Apocyanaceae) against Helicoverpa armigera (Lepidoptera: Noctuidae). Journal of Economic Entomology, 102: 1197-1202

Schmidt R.J., Evans F.J. 1980. Skin irritant effects of esters of phorbol and related polyols. Archives of Toxicology, 44: 279-289

Sharma H. C., Pampapathy G., Kumar R. 2005. Standardization of cage techniques to screen chickpeas for resistance to Helicoverpa armigera (Lepidoptera: Noctuidae) in greenhouse and field conditions. Journal of Economic Entomology, 98: 210-216.

Wheeler D.A., Isman M.B. 2001. Antifeedant and toxic activity of Trichilia americana extract against the larvae of Spodoptera litura. Entomologia Experimentalis et Applicata, 98: 9-16.

Wilson A.G.L. 1982. Past and future Heliothis management in Australia. In: Reed W, Kumble $\mathrm{V}$, ed. Proceedings of the International Workshop on Heliothis Management. ICRISAT Center, Patancheru, India, 15-20 November 1981 International Crops Research Institute for the Semi-Arid Tropics Patancheru, Andhra Pradesh India, 343-354

Wurdack K.J. 2008. Molecular evolution and phylogenetics of Euphorbiaceae: Beyond the model organisms. Plant and Animal Genomes XVI Conference San Diego, CA. http://www.intl-pag.org/16/abstracts/PAG16_W21_155.html. 


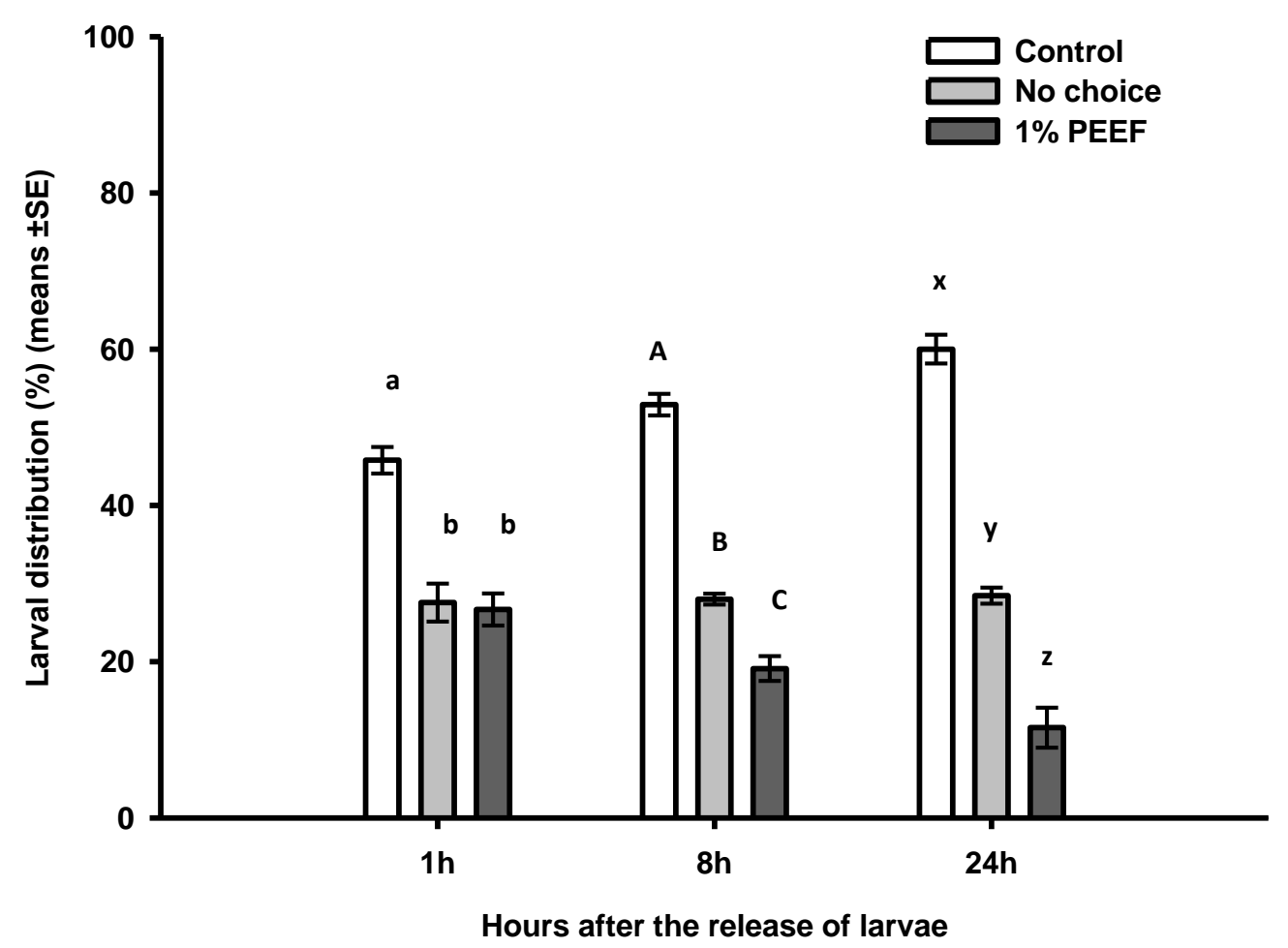

Figure 1a: Deterrent effect of PEEF on neonate larvae of $\mathrm{H}$. armigera. Control (untreated diet) vs. $1 \%$ PEEF-treated diet. Bars denoted within the same group with different letters are significantly different (All Pairwise Multiple Comparison Procedures Tukey's test, $p<0.05$ ).

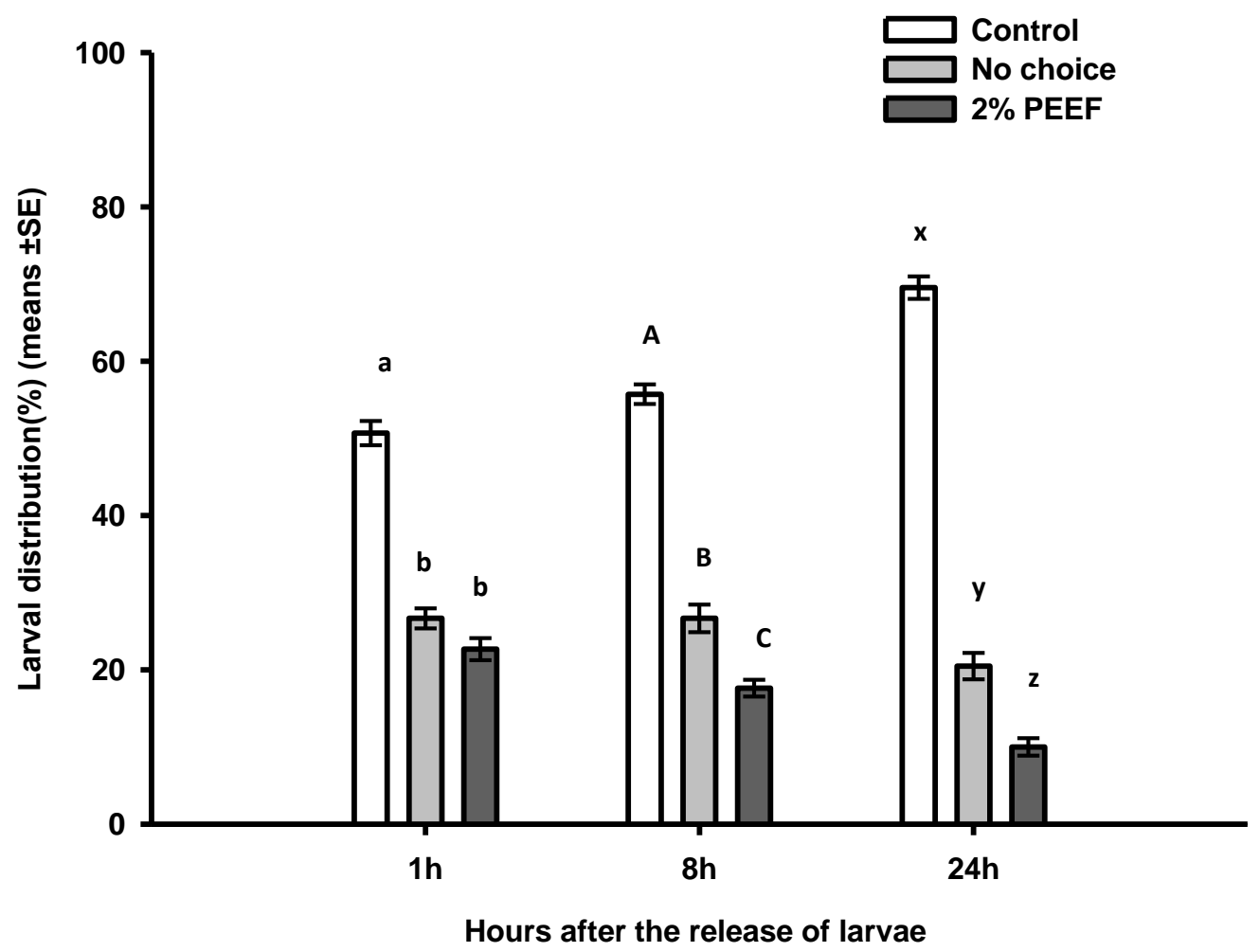

Figure 1b: Deterrent effect of PEEF on neonate larvae of $\mathrm{H}$. armigera. Control (untreated diet) vs. $2 \%$ PEEF-treated diet. Bars denoted within the same group with different letters are significantly different (All Pairwise Multiple Comparison Procedures Tukey's test, $p<0.05$ ). 


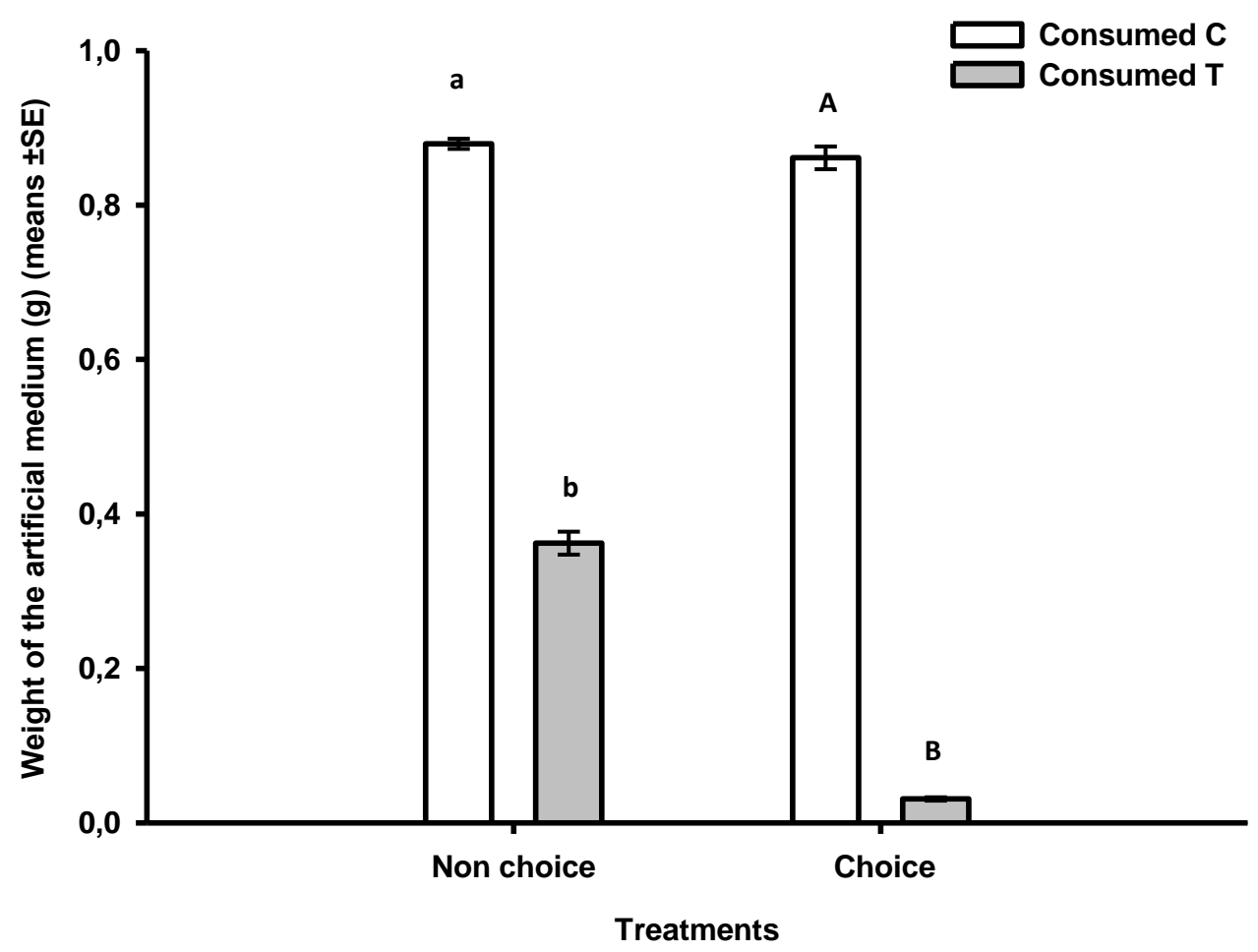

Figure 2: Effect of 2\% PEEF on food consumption of $3^{\text {rd }}$ instar larvae in choice and non-choice conditions. Consumed C: control diet. Consumed T: PEEF-treated diet. Bars denoted within the same group with different letters are significantly different (Student's t-test, $p<0.05$ ).

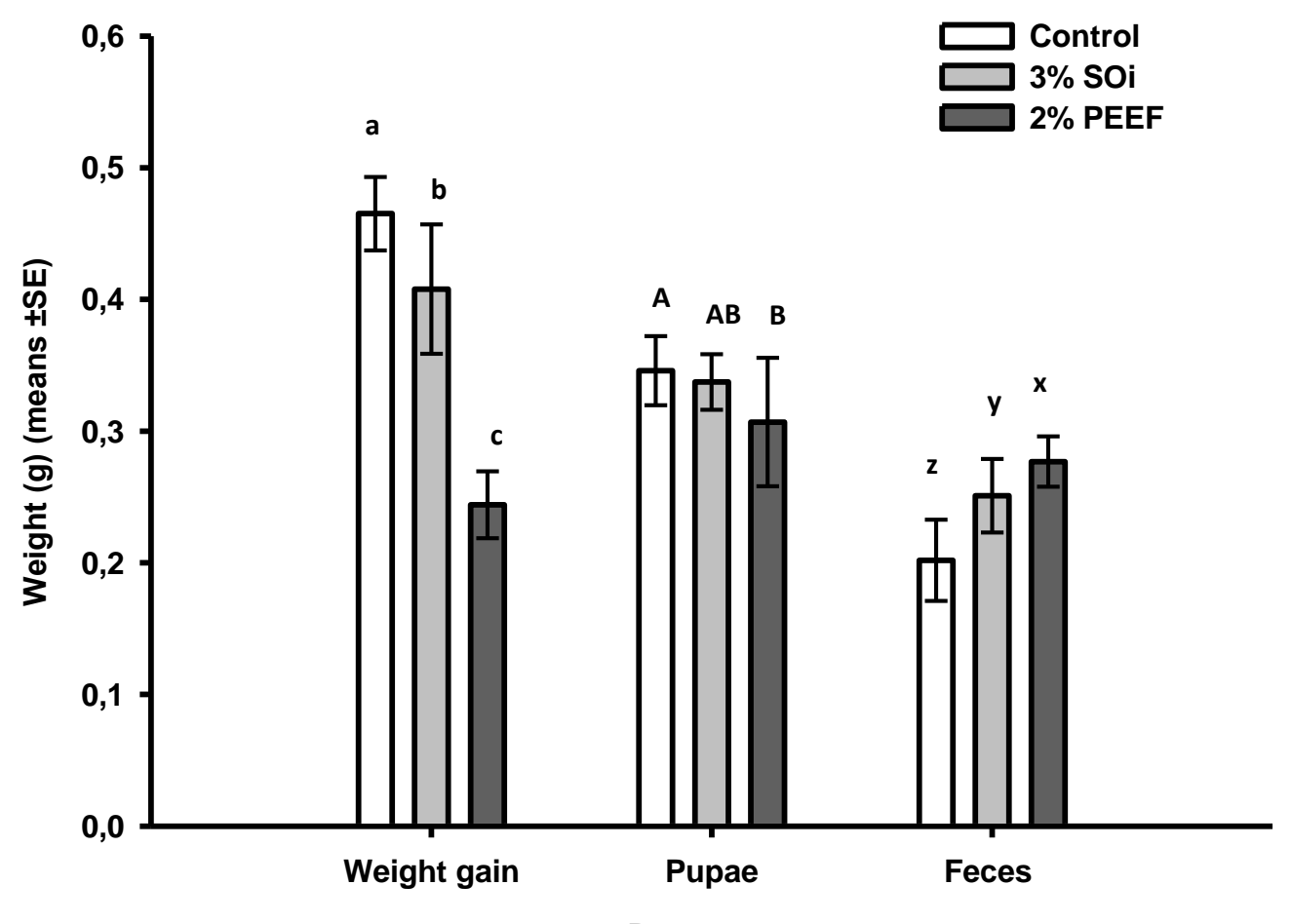

Parameters

Figure 3: Effect of $3 \%$ of seed oil (SOi) and $2 \%$ of PEEF on the weight gain, pupal weight and feces production by larvae. Bars denoted within the same group with different letters are significantly different (All Pairwise Multiple Comparison Procedures Tukey's test, $p<0.05$ ). 


\section{Chapter 6}

\section{General discussion and conclusion}

The physic nut tree J. curcas is a rich source of phytochemicals (Devappa et al., 2011). The assessment of the efficacy of the seed oil and the Phorbol esters fraction showed a high efficacy on aphids. Oils appeared to induce mortality due to asphyxia by obstruction of tracheae and tracheoles (Stadler et al., 2009). However, the effectiveness of these compounds was widely depending on their mode of application. When sprayed or topically applied on the aphids, the oil covered the insect cuticle, blocked the spiracle and caused the suffocation of the aphid (Taverner et al., 2001).

The spray of these extracts directly on insects was highly effective than spraying the host itself before infestation. The high efficacy of the contact application compared to the ingestion effect would limit the use of these compounds as preventive bioinsecticides. The mode of action of the PEs and the seed oil made them highly effective on the insect's cuticle. Consequently, plants should be already infested with aphids to induce mortality by spray application. Otherwise, ingesting compounds already sprayed on the plant as preventive approach would induce a low killing effect.

The root extract of $J$. curcas caused in in vitro conditions a high repellent effect on aphids. The extract from secondary roots was reported to be rich with gallic, ellaguic and coumaric acids (El Diwani et al., 2009). However, a slight decrease of its efficacy was observed overtime on plants. In spite of this time-limited effect, the root extract of J. curcas could be considered, as a basic-extracted product (only aqueous extract), a bioinsecticide that prevented plants from aphid infestation. Nevertheless, further phytochemical analysis of the root extract would help to study its composition and understand which components induced repellency.

The seed oil of $J$. curcas caused an inhibition of reproduction on the adults of $A$. fabae. The reproduction inhibitory effect of the seed oil, shown by our study, was already reported by Ratnadass et al. (2012). As a response to nutrient stress, during the starvation of aphids, the fat reserves content of the soma, necessary to provide lipids to the ovaries, decreased by nearly $50 \%$ and was mobilized in profit of the insect survive (Grüber et al., 1988 ; Arrese et al., 2010). This insecticidal property represented an efficient barrier to the populations of aphids to reproduce and colonize plants. Although the lack of perfect 
adherence of the seed oil with the leaf surface, which would permit adults to survive, these aphids would not be able to establish viable growing colonies: the limited non-treated leaf areas would not help to establish viable colonies for long time. The competition for nutrients would affect the colony growth and cause its decline.

The extracts of $J$. curcas could be an alternative for the control of Lepidopteran species. The killing effect of the PEEF differed from specie to another. It was low on the diamondback moth but high on the cotton bollworm. Inspite of the weak contact toxicity of the PEEF on $\mathrm{H}$. armigera, the ingestion of PEEF induced a high toxic impact on the $2^{\text {nd }}$ instar larvae. The PEs are analogues of diacylglycerol, an activator of protein kinase C (PKC). PKCs act as regulators of many metabolic processes. As diacylglycerol has a short biological halflife in the cell, the activation of PKC is temporary. However, the activation of PKCs by PEs, is much extended, which subsequently disrupts a number of cell process and leads to the cell exhaustion (Goel et al., 2007).

A major interest should also be given to investigate further the antifeedant properties of the physic nut tree on Lepidopteran species. The deterrent property of PEEF on the early instars larvae of $P$. xylostella and $H$. armigera could be another approach in terms of plant protection. The disruption of the larval feeding behavior induced by the presence of PEEF on the feeding substrate inhibited larval growth. The antifeedant effect on the larvae of P. xylostella could also be caused by the ingestion of aqueous leaf extract applied on the host plant. All these antifeedant extracts affected the insect's fitness and the reproduction performance of the subsequent adults.

The physic nut tree J. curcas could be an interesting source of insecticidal compounds against root-feeding insects. The seed oil and the PEEF exhibited ovicidal and larvicidal effect on the cabbage root fly $D$. radicum under laboratory conditions. Essential oils create a thin layer on the surface of eggs and stop the gas exchanges. They might also cause hardness in eggs which make it difficult for larvae to hatch (Buteler et al., 2011). Although PEEF decreased the pupation rate of larvae under greenhouse conditions, many pupae were collected from the soil-treated cabbage plants. The efficacy of PEEF in semi-real conditions on $D$. radicum could be enhanced by increasing the number of times of soil treatments, for instance 4 times instead of only twice during this study. The degradability of PEs-based extracts by biotic and abiotic factors would limit their longevity in soil and reduce subsequently their efficacy on root-feeding insects. 


\section{References}

Arrese E. L., Soulages J. L. 2010. Insect fat body: energy, metabolism and regulation. Annual Review of Entomology, 55: 207-225.

Devappa R.K., Makkar H.P.S, Becker K. 2011. Jatropha Diterpenes: a Review. Journal of the American Oil Chemists' Society, 88: 301-322.

El Diwani G., El Rafie S., Hawash S. 2009. Antioxidant activity of extracts obtained from residues of nodes leaves stem and root of Egyptian Jatropha curcas. African Journal of Pharmacy and Pharmacology, 3: 521-530.

Goel G., Makkar H., Francis G., Becker K. 2007. Phorbol Esters: structure, biological activity, and toxicity in animals. International Journal of Toxicology, 26:279-88.

Grüber K., Dixon A.F.G. 1988. The effect of nutrient stress on development and reproduction in an aphid. Entomologia Experimentalis et Applicata, 47: 23-30.

Ratnadass A., Wink M. 2012. The Phorbol Ester Fraction from Jatropha curcas seed oil: Potential and limits for crop protection against insect pests. International Journal of Molecular sciences, 13: 16157-16171.

Stadler, T., and Buteler, M. 2009. Modes of entry of petroleum distilled spray-oils into insects: a review. Bulletin of Insectology ,62: 169-177.

Taverner, P.D., Gunning, R.V., Kolesik, P., Bailey, P.T., Inceoglu, A.B.; Hammock, B., Roush, R.T. 2001. Evidence for direct neural toxicity of a "light" oil on the peripheral nerves of lightbrown apple moth. Pesticide Biochemistry and Physiology, 69: 153-165. 


\section{DECLARATIONS}

1. I, hereby, declare that this Ph.D. dissertation has not been presented to any other examining body either in its present or a similar form. Furthermore, I also affirm that I have not applied for a Ph.D. at any other higher school of education.

Göttingen.

Signature

Name.

2. I, hereby, solemnly declare that this dissertation was undertaken independently and without any unauthorised aid.

Göttingen,

Signature

Name. 
